\title{
Attentional narrowing as a model for partial amnesia
}

Citation for published version (APA):

Wessel, J. P. (1997). Attentional narrowing as a model for partial amnesia. [Doctoral Thesis, Maastricht University]. Universiteit Maastricht. https://doi.org/10.26481/dis.19970613jw

Document status and date:

Published: 01/01/1997

DOI:

10.26481/dis.19970613jw

Document Version:

Publisher's PDF, also known as Version of record

\section{Please check the document version of this publication:}

- A submitted manuscript is the version of the article upon submission and before peer-review. There can be important differences between the submitted version and the official published version of record.

People interested in the research are advised to contact the author for the final version of the publication, or visit the DOI to the publisher's website.

- The final author version and the galley proof are versions of the publication after peer review.

- The final published version features the final layout of the paper including the volume, issue and page numbers.

Link to publication

\footnotetext{
General rights rights.

- You may freely distribute the URL identifying the publication in the public portal. please follow below link for the End User Agreement:

www.umlib.nl/taverne-license

Take down policy

If you believe that this document breaches copyright please contact us at:

repository@maastrichtuniversity.nl

providing details and we will investigate your claim.
}

Copyright and moral rights for the publications made accessible in the public portal are retained by the authors and/or other copyright owners and it is a condition of accessing publications that users recognise and abide by the legal requirements associated with these

- Users may download and print one copy of any publication from the public portal for the purpose of private study or research.

- You may not further distribute the material or use it for any profit-making activity or commercial gain

If the publication is distributed under the terms of Article $25 \mathrm{fa}$ of the Dutch Copyright Act, indicated by the "Taverne" license above, 


\title{
Attentional Narrowing
}

\author{
as a Model for Partial Amnesia
}


Remember, my friend.

that knowledge is stronger than memory, and we should not trust the weaker.

Professor van Helsing (1897)

Afbeelding omslag:

Nicole Rodriguez - Axo III

Druk:

Datawyse Maastricht / Krips Repro Meppel

ISBN 90-9010540-9 


\section{Attentional Narrowing}

\section{as a Model for Partial Amnesia}

PROEFSCHRIFT

ter verkrijging van de graad van doctor aan de Universiteit Maastricht, op gezag van de Rector Magnificus, Prof. Mr. M.J. Cohen, volgens het besluit van het College van Decanen, in het openbaar te verdedigen op vrijdag 13 juni 1997 om 14.00 uur

door

Jeannine Petra Wessel 
Promotores:

Prof, dr. H.L.G.J. Merckelbach

Prof, dr. M.A. van den Hout

\section{Beoordelingscommissie:}

Prof. dr. H.G. Schmidt (voorzitter)

Dr. A. Arntz

Prof. dr. R. van Dyck (Vrije Universiteit)

Prof. dr. W.Th.A.M. Everaerd (Universiteit van Amsterdam)

Dr. A.T.M. Jansen 


\section{Contents}

1. Psychological Trauma and Amnesia 7

1.1. The memories of ms. G. 7

1.2. The phenomenon of psychogenic amnesia 8

1.2.1. What is psychogenic amnesia? 8

1.2.2. The evolution of the PTSD diagnostic criteria 10

1.2.3. On the prevalence of partial amnesia and how it is measured 12

1.3. Functional explanations of Psychogenic Amnesia 16

$\begin{array}{lll}\text { 1.3.1. Repression } & 16\end{array}$

1.3.2. Dissociation 18

$\begin{array}{ll}\text { 1.3.3. Critical notes on repression and dissociation } & 19\end{array}$

2. Emotion and Memory 23

2.1. Emotion enhances memory 23

2.1.1. Field studies: flashbulb memories 23

2.1.2. Memory for emotional stimuli in the laboratory 25

2.2. Emotion impairs memory 26

2.2.1. Weapon focus 26

2.2.2. Laboratory induced amnesia 27

2.3. Does emotion enhance or impair memory?

Theoretical accounts 28

2.3.1. The Yerkes-Dodson law 28

2.3.2. Attentional narrowing 30

2.4. Studies on attentional narrowing 32

2.4.1. Detail memory for real-life events and some critical notes 32

2.4.2. Detail memory in the laboratory and some complications 33

3. Integration and Aim of the present Dissertation 37

3.1. Recapitulation 37

3.2. Specific issues in testing the attentional

3.2.1. Physiological arousal, visual attention and memory 38 
3.2.2 Differences in stimulus characteristics 38

3.2.3. What is central, what is peripheral? 39

3.2.4. Ecological validity 39

4. Empirical Studies $\quad 41$

4.1. Arousal, visual attention and detail memory 43

4.2. Circumstantial evidence for attentional narrowing 55

4.3. "Spider Focus" and detail memory $\quad 65$

$\begin{array}{lll}\text { 4.4. Memory for phobic cues } & 73\end{array}$

4.5. Characteristics of traumatic memories in normall subjects

5. Main results and theil implications for $\begin{array}{ll}\text { testing the attentional narrowing hypothesis } & 91\end{array}$

5.1. Overview of the main findings 91

5.1.1. Physiological arousal, visual attention and memory 91

5.1.2. Differences in stimulus characteristics 94

5.1.3. What is central, what is peripheral?

5.1.4. Ecological validity 96

5.2. Implications for testing the attentional

$\begin{array}{llr}\text { 5.2.1. } & \text { Arousal } & 97\end{array}$

5.2.2. Attention, elaborative encoding, and memory 98

5.3. Spider phobic memory: Attentional narrowing $\begin{array}{ll}\text { or cognitive bias? } & 100\end{array}$

5.3.1. Fear networks and information processing in phobics 101

5.3.2. What if cognitive avoidance is lleft out of consideration? 102

$\begin{array}{ll}\text { 5.4. Concluding remarks } & 104\end{array}$

6. Towards a model of partial amnesia $\quad 105$

6.1. Attentlonal narrowing 105

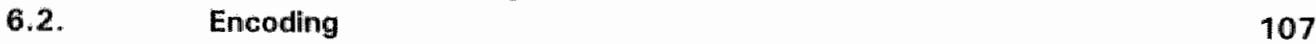

$\begin{array}{ll}\text { 6.3. Encoding and retrieval interactions } & 108\end{array}$

$\begin{array}{ll}\text { 6.4. Trying to forget } & 109\end{array}$

6.5. Why search for a model for partial amnesia? 11

$\begin{array}{ll}\text { References: } & 113\end{array}$

$\begin{array}{lr}\text { Samenvatting } & 123\end{array}$

$\begin{array}{lr}\text { Dankwoord } & 127\end{array}$

$\begin{array}{lr}\text { Publications } & 129\end{array}$

$\begin{array}{lr}\text { Curriliculum Vitae } & 131\end{array}$ 


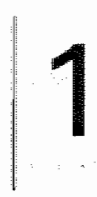

\section{Psychological Trauma and Amnesia}

1.1. The memories of Ms. G.

An individual who experiences an extremely distressing or life-threatening event, either as a witness or a victim, may subsequently develop Post-traumatic Stress Disorder (PTSD). PTSD is a memory-related disorder. Hallmark of the disorder is a frequent and unbidden emergence of traumatic memories, thoughts, nightmares, or images. According to the fourth edition of the Diagnostic and Statistical Manual of Mental Disorders (DSM-IV, APA, 19941, at least one of these reexperiencing symptoms is necessary in order to justify a diagnosis of PTSD. Thus, by definition people with PTSD suffer from an excess of memory. In contrast, an other PTSD symptom listed in DSM-IV is "the inability to recall an important aspect of the trauma" (APA, 1994, p.428). Such lack of memory is not absolutely required for the diagnosis of PTSD according to DSM-IV criteria. Yet, its presence in the diagnostic criteria suggests that at least some traumatized individuals suffer from both an abundance and a lack of memory. Consider the following case example (Wessel, van Rijsoort, Merckelbach \& Arntz, 19951.

Ms. G. was 13 years old when she witnessed a distresing event involving her parents. At age 32 , ms. G. was diagnosed with PTSD and was offered behaviour therapy. This therapy consisted of imaginary axposure Isee Foa, Steketee, \& Olasov Rothbaum, 1989\%, aimed at the extinction of the anxiety accompanying hor tratimatic memories. For this purpose, ms $G$. was to recount the traumatic event in minute dotail, as if it were happening presently. During the first therapy session, ms. G. told her therapist that at the night of the ovent, she was lying in bed listening to her parents fighting in the adjucent bedroom. When all was ciliet, the soared child got out of bed and enterad the piarental bedroom to seg what had happened. She saw her mother lwing an the floor in an awkward position, her face covered with blood, apparently dead. Upon questioning of the therapist, $m s$. $G$. siaid that her mother wore a torn dress. The most horrifying mormory for ms. $G$. Was that when she went back to the parental bedroom some time later that evening, she discovered that lher mother had vanished. Ms. G. repeated this account several times during the first therapy session. At the beginning of the next session, ms. G. said she was bothered by the fact that despite her efforts, she could not remember what exactly her mother was wearing. Again, ms. G. recounted her story several times. However, during the third time, she suddenly fell sillent. Shocked, she told her therapist that she now knew that her mother had been naked when she found her. She concluded that her father must have raped her mother. 
Thus, initially ms. G. had given the impression that her traumatic memory was complete. The recovery of a new memory later in therapy suggests that this initial impression was not correct: in retrospect, she seemed to fit the PTSD criterium of not being ablle to remember an important aspect of her trauma. Why did $\mathrm{ms} G$. initially fail to remember her mother's nudity? On the one hand, this may be the natural consequence of the passing of some twenty years. Many memories fade with the passage of time. It has often been stressed that forgetting is an utterly common phenomenon, whereas remembering is an exception (e.9. Loftus, Garry \& Feldman, 1994). On the other hand, it may be that ms. G.'s forgetting did not reflect a normal memory process, but some sort of pathology. In clinical literature, it is generally assumed that traumatic memories are rather different from normal memories and that forgletting is a common consequence of trauma (e.g., van der Kolk \& Fisler, 1995; Harvey \& Herman, 1994; Whitfield, 1995). Accordingly "DSM-IV's predecessor (DSM-III-R, APA, 1987) labelled the PTSD symptom of an inability to recall psychogenic amnesia. In DSM-IV, this label was omitted, but the description of the symptom is identical to that in DSM-III-R. Thus, a closer look at the concept of psychogenic amnesia is in order.

\subsection{The Phenomenon of Psychogenic Amnesia}

\subsubsection{What is Psychogenic Amnesia?}

At first sight, the concept of psychogenic amnesia is relatively straightforward. The term amnesia implies some type of pathological forgetting (Garry, Loftus \& Brown, 1994; Loftus et al., 1994). According to DSM-IV, such forgetting should be "too extensive to be explained by ordinary forgetfulness" (APA, 1994, p. 478). In addition, the label psychogenic literally means 'caused by the mind', leaving aside whatever it is in the mind that causes such forgetting. However, inspection of the DSM classification paints a somewhat more complicated picture. For example, psychogenic amnesia is a specific diagnostic entity in the category of the Dissociative Disorders, which describes individuals who have no memory whatsoever for certain time periods (localized amnesia), or even their entire life Igemeralized amnesia). In Dissociative Identity Disorder (DID formerly Multiple Personality Disorder), amnesia refers to gaps in time as well as to the observation that some personalities have no knowledge of other personalities. In PTSD, as described above, aminesia seems to pertain to aspects of an event. To further complicate matters, in DSM-IV the term psychogenic amnesia was replaced by dissociative amnesia. This development is rather unfortunate. The label dissociative explicitly points to the defense mechanism of dissociation as a causal factor in the disturbance (Kihlstrom, Tataryn \& Hoyt, 1993). However, as will be argued later in this chapter, it is doubtful whether dissociation can provide a plausible explanation for amnesia. The term psychogenic amnesia is merely referting to the psychological nature of the memory disorder, as opposed to a neurologicalIV based memory dysfunction. Therefore, throughout the current text, the label psychogenic amnesia will be used to denote any forgetting of (traumatic) autobiographical material without an organic basis. For sake of clarity, forgetting of only certain aspects of an event will be referred to as partial amnesia. In this sense, partial amnesia is viewed as a specific form of psychogenic amnesia. 
Surprisingly little has been written about partial amnesia. Most studies in this domain have focussed on localized and generalized amnesta. In order to trace specific properties of psychogenic amnesia literature on its localized and generalized form will be briefly reviewed. This literature seems to consist mainly of case descriptions. In some early reports on the disorder, general characteristics of groups of amnesic patients are described le.g., Kanzer, 1939; Sargent \& Slater, 19411, whereas the more recent literature pertains to -often spectacular- single case studies (0.9., Domb \& Beaman, 1991; Christianson \& Nilsson, 1989; Kopelman, Christensen, Puffett \& Stanhope, 1994\%. For example, Christianson and Nilsson (1989) describe the case of a woman who woke up in a park, not knowing who she was or what had happened to her. Eleven weeks later she remembereid that she had been raped.

In descriptive studies as well as literature reviews (e.g. Kihlstrom et al., 1993; Kopelman, 1987; Nemiah, 1989; Spiegel, 1994) of generalized psychogenic amnesia, three characteristics of the disorder are emphasized. First, psychogenic amnesia refers to a disturbance in memory that is not related to organic dysfunctions. Thus, the disorder is distinguishable from organically based conditions producing amnesia such as brain injury. temporal lobe epilepsy, alcohol intoxication, transient global amnesia and so forth (see for an extensive discussion of these issues; Kopelman, 1987; Sivec \& Lynn, 1995). Second, the memory dysfunction in psychogenic amnesia is predominantly in the realm of episodic or autobiographical memory, whereas other memory domains le.g., semantic memory, procedural knowledge) appear to be relatively unaffected (Christianson \& Nilsson, 1989; Kihlstrom et al., 1993; Kopelman, 1987; Kopelman et al., 1994; Spiegel, 1994). A third connotation sticking to the concept of psychagenic amnesia is that the lost information is registered and stored, but is temporarily unavailable to consciousness (Kihlstrom et al., 1993; Nemiah, 1989; Spiegel, 1994). Yet, it is often assumed (e.g. Kihlstrom et al,, 1993; Spiegel, 1994) that such unavailable memories influence behaviour outside of the patient's awareness (i:e:, implicit memory).

Apart from psychogenic amnesia for entire periods of time, yet another form of psychogenic amnesia should be briefly mentioned. This form pertains to the total forgetting of specific types of events, typically instances of child sexual abuse. DSM-IV would label such forgetting selective or systemized amnesia ${ }^{\prime}$. In recent years, there has been a strong rise in reports on such form of forgetting (see Loftus, 1993; Lindsav \& Read, 1994). Retraspective reporting of selective amnesia varies from 19 to 59 percent: in samples of individuals who claim to be sexually abused as a child (Albach, 1993; Briere \& Conte, 1993; Elliot \& Briere, 1995; Herman \& Schatzow, 1987; Loftus, Polonsky \& Fullilove, 1994: Feldman-Summers \& Pope, 1994). However, the premise that such forgetting is pathological and exceeds ordinary forgetting has been heavily criticized le.g." Loftus et al., 1994; Pope \& Hudson, 1995) ${ }^{2}$.

\footnotetext{
${ }^{1}$ Selective amnesia is reported by persons who beliew that they were abused as a child, yet chaim that they were not able to recall such abuse for many years (Lindsay \& Read, 1994; Loftus, 19931. This phenomenon is commonly referred to as 'recowered memories".

2 Selective amnesia has become a highly controversial topic. A number of authors le.g., Lindsay Read, 1994: Loftus, 1993 seriously doubt whether such cases are genuirie instances of psychogenic amnesila. These authors point out that the recovery of traumatic memories may be false memories, caused by highly suggestive therapeutic techniques (e:g., hypnosis, guided imagery, jourmalling, etc.).
} 
In sum, then, relatively many (case) studies have been published of psychogenic amnesia in tits localized, generalized and, more recently, selective forms. The assumption that some form of amnesia is a common response to trauma has become prominent in clinical literature. It is, therefore, surprising that relatively little has been written about the PTSD symptom of piartial amnesia. The scarce literature on partiall amnesia will be consiclered next. Prior to discussing prevalence rates of the symptom, its evolution in psychiatric nosology will be described.

\subsubsection{The evolution of the PTSD diagnostic criteria}

Until the $1970 \mathrm{~s}$, interest in post-traumatic reactions seemed to coincide with the world wars (A.chibald \& Tuddenham, 1965). During wartime, symptoms in soldiers were extensively studied le.g., Grinker \& Spiegel, 1945; Myers, 1919; Sargent \& Slater, 1940; 1941). Research on the so-called war neuroses inspired the occasional clinician to study victims of civilian disasters, such as the 1942 Cocoanut Grove fire, in which a crowded night club burned down (Adler, 1945). Accordingly, the first edition of the DSM included a diagnostic category named Gross Stress Reaction, in which the transient nature of posttraumatic symptoms was emphasized (Andreasen, 1985; Wilson, 1995). Yet, during the $1950^{\prime}$ 's and $1960^{\prime} s$, studies of World War II veterans and concentration camp survivors led to the recoginition that these symptoms could obtain a chronic character (see for a review, Archiball \& Tuddenham, 1965). Despite these findings, the second edition of the DSM, published in 1968, devoted even less attention to post-traumatic symptomatology than DSM 1 . This was presumably due to the fact that World War II had ended more than two decades before publication of this second edition (Andreasen, 1985). In DSM-II, the category of Gross Stress Reaction was omitted. Instead, fear associated with combat was briefly mentioned under the category Adjustment Reaction of Adult Life (Wilson, 1995) ${ }^{3}$. Neither DSM-I nor DSM-II mentioned partial amnesia as a post-traumatic reaction.

The return of soldiers from the Vietnam War in the 1970 's fuelled a renewed interest in post-traumatic symptomatology, resulting in the inclusion of PTSD as a specific diagnostic antity in the DSM-1I, published in 1980 (Andreasen, 1985; Herman, 1992). In this diagnostic category, partial amnesia was not explicitly mentioned. However, one of the symptoms incorporated was "memory impairment or trouble concentrating" (p. 238). This description seems to refer to difficulties in general memory functioning, rather than specific forgetting of aspects of a trauma. Accordingly, some researchers asked disaster victims whether they had become unusually forgetful (Solomon \& Canino, 1990) or experlenced difficulties with everyday memory (Cardeña \& Spiegel, 1993). Others merely reported memory impairment in disaster victims and, like DSM-III, offered no clues as to how this description should be interpreted (e.g.. Madikasira \& O'Brien, 1987; Wilkinson, 1983). In light of this, it is highly surprising that such studies are sometimes cited as evidence for the occurrence of psychogenic amnesia le.g., Briere \& Conte, 1993; Koopman, Classen, Cardeña, \& Spiegel, 1995; Spiegel \& Cardeña, 1991; Van der Kolk \&

\$ Other atuthors (9.9. Brett, Spitzer \& Williams, 1988; Green, Lindy \& Grace, 1985$)$ point out that according to DSM-1H, persons suffering from post-traumatic symptoms could be diagnosed with Transient Situational Disturbance. 
Fisller, 1995).

Compared to DSM-11, the revised edition of the manual (DSM-111-R, APA, 1987), placed greater emphasis on avoidance symptoms (Brett al., 1988), It was in this symptom cluster, that partial amnesia was included. What led to the sudden emergence of this symptom? According to Keane 11993), PTSD symptoms in DSM-III-R were structured in line with a framework outlined by Brett and Ostroff 11985/. Brett and Ostroff's framework relied on a number of clinical accounts of PTSD symptomatology that were predominantly derived from psychoanalytic theory: Psychogenic amnesia takes an important place in such accounts and is viewed as the result of (unconsciously) defending against intirusive phenamena.

It is rather odd that the PTSD diagnostic criteria in DSM-III-R were derived from theoretical framework. Beginning with the publication of its third edition 11980$)$, the DSM system specifically aimed at providing a classification that was descriptive and neutral with respect to theoretical formulations ${ }^{4}$. Thus, the critical question to be asked is what empirical evidence favours including partial amnesia as a PTSD symptom. Consider two sources of evidence cited in the Brett and Ostroff (1985) paper. The first source of evidence is work that was carried out in the World War II era. However, Brett and Ostroff themselves note that these are merely anecdotical accounts, and warn against "generalizing from selected clinical examples" (p. 420). Indeed, whereas amnesia was emplhasized by authors such as Kardiner (Brett \& Ostroff, 1985), the term is not even found in the index of Grinker and Spiegel's (1945) classic book on post-traumatic symptoms in Air Force personnel: The latter authors do, however, report one case (out of 65) of partial amnesia in which a gunner remembered only few details of a traumatic event ${ }^{5}$. A more systematic study of psychogenic amnesia was carried out by Sargent and Slater (1941). They found that some thirteen percent of a thousand consecutively referred soldiers showed either fugue-like states or retrospective amnesia for certain periods of time. However, in this study partial amnesia was not mentioned. Taken together, evidence for partial amnesia in writings originating in the 1940 's is scarce and anecdotical.

A second source of evidence cited by Brett and Ostroff (1985) is the work of Horowitz and colleagues (Horowitz, 1979; 1986; Horowitz, Wilner \& Alvarez, 1979; Horowitz, Wilner, Kaltreider \& Alvarez, 1980). Inspired by Freud's writings, Horowitz conceptualized the trauma response as alternating states of intrusion and denial, depending on what control operations would be in effect. In his view, intrusive phenomena reflect a completion tendency, serving the purpose of integrating the reality of the traumatic event into existing cognitive schemata. However, such completion tendency may somehow be too excessive, leading to emotional flooding. Consequently, a state of denial is introduced, of which amnesia is one possible outcome. Horowitz tested his theory in a clinical sample Horowitz, 1979; Horowitz et al., 1980). Memory failure was found in $34 \%$ of his sample. However, several methodological considerations cast doubts on the interpretation of this

\footnotetext{
4n DSN-II and DSM-1I, disorders were classified along the lines of psychodynamic theory.

${ }^{5}$ In addition, Grinker and Spiegel described the case of a ground combat soldien, displaying al stuporous state and generalized amnesia. The authors included this case "for the sake of comparison" (p. 95) in arguing that such cases are rarely seen in flying personnel. Therefore, citing Grinker and Spiegel"s book as providing evidence for the frequent occurrence of psychogenic amnesia in World War II soldiers 10.6. , van der Kolk 2 Fisler, $1995 \rrbracket$ is unjustified.
} 
percentage as adequately reflecting partial amnesia. To start with, amnesia was broadly operationalized as the "finability to recall expectable detalls or sequences of events. amnestic areas, (or) inability to remember in (a) usually expectable manner" (Horowitz; 1979. p. 2391. This operationalization does not specifically address partial amnesia. Furthermore, the method of measurement may be questioned. Clinicians judged symptom severity on a 6 -point rating scale (ranging from $0=$ not at all to $5=$ severe) after they had seen the subjects for an evaluation interview. It is not clear if and how amnesia was assessed in the evaluation interwiew, and the question rises on what basis the post-interview judgennents were made. More importantly, all positive responses Iranging from $1=$ slight to $5=$ severe) apparently were collapsed in order to obtain the percentage. Such procedure creates a bias towards positive responses for two reasons. First, endorsement of the item is based on more response categories 15 categories/ than rejection of the item (1 category). In other words, the probability of a positive answer is greater than the probability of a negative answer. Second, it may well be that clinicians were inclined not to score the extremes of the scale which, as noted, consisted of multiple anchor points. Such a response tendency may have caused an underrepresentation of negative answers. Taken together, the results of this study do not provide convincing evidence for the occurrence of partial amnesia as a PTSD symptom ${ }^{6}$.

In sum, then, inclusion of partial amnesia in the DSM-III-R diagnostic category of PTSD was inspired by cilinical-theoretical formulations of the trauma response rather than empirical evidence (Davidson \& Foa; 1991; Keane, 1993; Brett et al., 1988). In DSM-IV (1994), partial amnesia is still listed as a PTSD symptom. In addition, the symptom is included in the new diagnostic categary of Acute Stress Disorder (ASD).

\subsubsection{On the prevalence of partial ammesia and how it is measured}

Given the absence of partial amnesia in DSM-III (APA, 1980), it is not surprising that there is a lack of empirical studies on the prevalence of that symptom during the years prior to publication of the manuall's revised edition in 1987. After publication of DSM-III-R, however, one would have expected a flow of studies on partial amnesia in PTSD. Yet, there was no such flow. Untill now; no studies specifically addressing the prevalence of partial amnesia have been published. However, a number of studies examined PTSD symptom profiles in clinical samples that had been exposed to various kinds of traumatic events (e.g., disasters, physical or sexual assault, etc. J. Several of these studies provide percentages of subjects endorsing question(s) measuring partial amnesia. Table 1.1 (page 14-15) gives an overview of the prevalence of partial amnesia in these studies. This table is not intended to be exhaustive, but merely illustrates the various ways in which the issue of partial amnesila has been investigated.

The percentages in table 1.1 vary from as low as $3.2 \%$ (Kuch \& Cox, 1992) to as high as

\footnotetext{
6 Noverthatess, it seems that Horowitz took the results of this single study as sufficient and unequivocal evittence for his theory. Ho wrote several papers and book chapters unfolding his ideas, repeatedlly reporting the results of this single study (Horowitz, 1979; 1986; Horowitz, Wilner, Kaltreider \& Alvarez, 1980; Horowitz a Reidbord, 19921.
} 
90\% (Bernstein Carlson \& Rosser-Hogan. 199.4\%). There are two types of explanations for the extreme variability of these percentages. The first type pertains to methodological differences between the 14 studies under consideration. To begin with, sample characteristics are quite diverse. For example, subjects were Cambodian, Japanese, Korean, Turkish, Jewish of North-American. Cultural background may well be an issue. Consider the Cambodian sample studied by Bernstein Carlson and Rosseir-Hogan (1994), in which $90 \%$ of the subjects endorsed the partial amnesia item. Chueng (1994), studying a similar sample, reports that the partial amnesia item had to be omitted, because subjects in a pilot study did not understand it correctly. Thus, the accuracy of the percentage reported by Bernstein Carlson and Rosser-Hogan is questionable: the high percentage may reflect an overestimation due to cultural differences in interpreting the item.

Another methodological issue concerns the diversity of traumatic experiences in the samples in table 1.1. These traumas consisted of one-time events le.g., rape, massshooting, motor vehicle accidents) or prolonged stressful situations (e.g. marital abuse, torture, Holocaust, war). It has been hypothesized (e.g., Herman, 1992; Terr, 1991; 1994) that single traumatic events (Type I) give rise to detailed memories, whereas amnesia may be a common consequence of prolonged or repeated trauma (Type II). However, in the studies under consideration there appears to be no systematic elevation of percentages in samples that suffered from repeated trauma.

Apart from sample and trauma characteristics, the methods used for measuring partial amnesia were diverse. Some studies employed clinician-administered diagnostic interviews, others relied on questionnaires. Kuch and Cox (1992) reviewed psychiatric assessments that took place sometime between 0 and 17 years earlier. Although the authors scored DSM-III-R criteria, a substantial number of assessments may have been conducted prior to inclusion of the partial amnesia criterion in DSM-III-R in 1987. Thus, the percentage reported by Kuch and Cox (1992) may reflect an underestimation.

A final methodological consideration is that in some studies (Foa, Riggs \& Gershuny, 1995; Kim-Goh et al., 1995) response categories were collapsed in order to obtain percentages for the presence of partial amnesia. It was argued earlier (see \$1.2.2) that such procedure may cause an overestimation of the percentage of the sample endorsing the symptom.

A second type of explanation for the diverse percentages in table 1.1 stresses a more fundamental issue: partial amnesia is a particularly problematic symptom to measure. Consider the following example. Foa and co-workers (1995) used a PTSD SVmptom Scale in which the exact wording of the partial amnesia question was: "(During the past two weeks) are there any important aspects of the assault that you still cannot remember?". Thus, subjects are asked to evaluate the importance of something that they have no knowledge of. Strictly speaking, an affirmative answer to this question could be regarded indicative of the presence of a memory land thus the absence of amnesial. Of course, it could be that there is some characteristic of the situation that can be inferred without actually remembering (e.g., the face of an assailant). Another possibility is that others told the subjects that there were certain aspects for which the subjects themselves have no

\footnotetext{
7 Note that a similar version of this 1994 siudy was published earlier (Bernstein Carison B Rosser-Hogam, 1993). Both papers describe the same data and research questions. However, the 1993 paper is not men. tioned in the referencie list of the 1994 paper.
} 


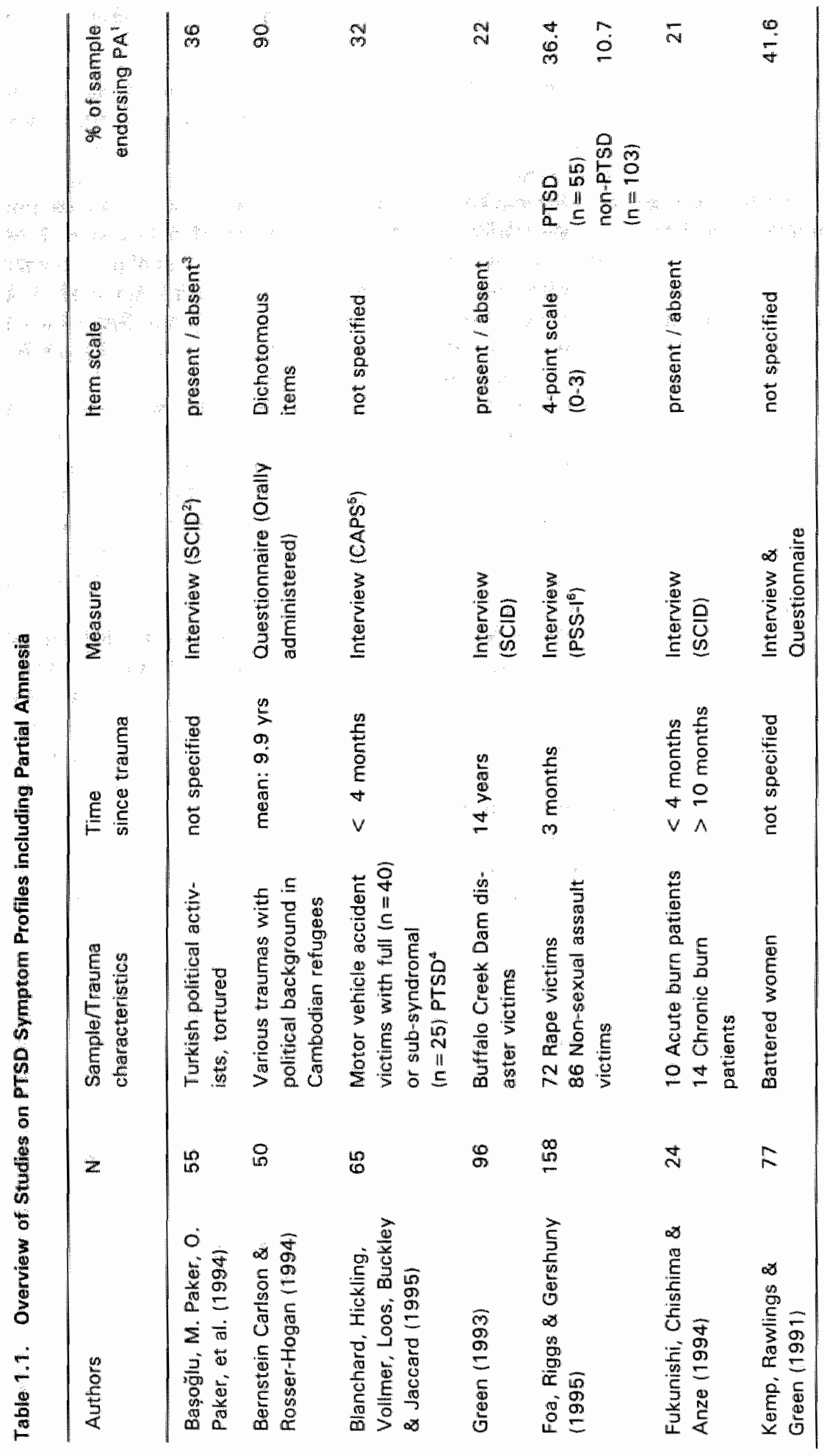




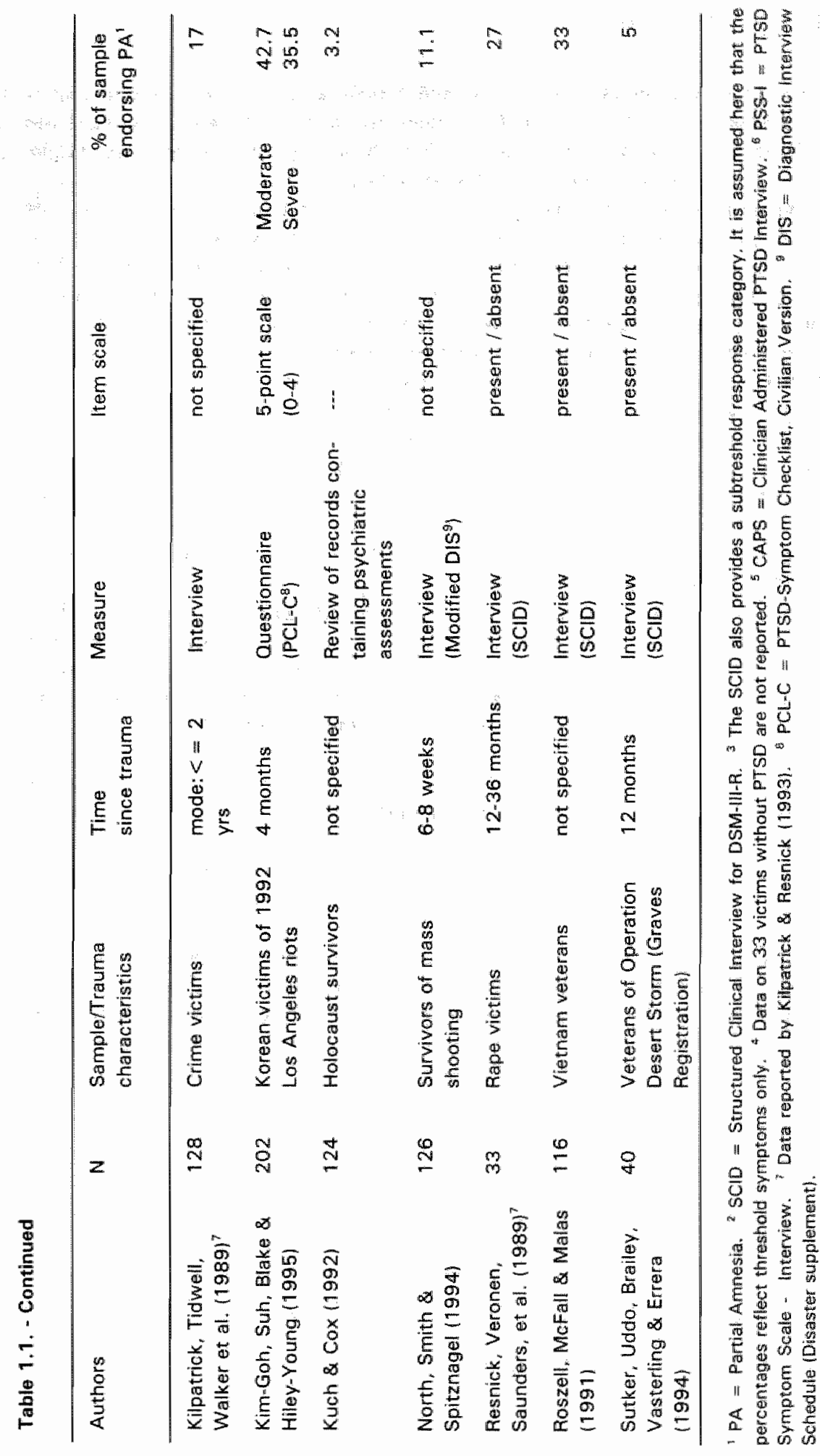


memory. In these cases, positive responses would indeed reflect a lack of memory of such aspects. The question, then, is whether the inability to recall qualifies as a partial form of psychogenic amnesia. As noted before (see \$1.2.1), a number of requirements should be met before this question can be answered affirmatively.

The first reguirement is that organic caluses (e.g., head injury, alcohol intoxication) should be excluded. This requirement is relatively easy to meet, yet unfortunately, in only one of the studies under consideration these exclusion criteria are reported (Kuch \& Cox, 1992). The second requirement is that it must be established that the lack of memory is too extensive to be explained by ordinary forgetfulness. Presumably, this feature of psychogenic amnesia is captured by the word important in the description of its partial form in DSM-III-R and symptom scales derived from this manual (e.g., Foa et al., 1995). The underlying message is that forgetting something important is somehow pathological. Apart from the question whether such an assumption is justified, the problem with the notion of importance is that it is subjective and context-dependent. For example, ms. G.'s (see $\$ 1.1)$ initial inability to recall what her mother was wearing seemed insignificant. However, eventually it became a crucial issue for $\mathrm{ms} \mathrm{G.,} \mathrm{as} \mathrm{it} \mathrm{dramatically} \mathrm{changed} \mathrm{her}$ interpretation of what happened. On the whole, it is doubtful whether partial amnesia can be measured with a single question.

In sum, studies of PTSD symptom profiles report widely varying percentages for the occurrence of partial amnesia. This diversity may be due to methodological differences or result from the fact that partial amnesia is a problematic symptom to measure. Thus $s_{r}$ it is not at all clear whether partial amnesia is a common response to trauma. Such a claim should be substantiated by systematic study of partial amnesia in PTSD.

\subsection{Functional Explanations of Psychogenic Amnesia}

Despite the paucity of systematic, empirical studies about its prevalence, much has been theorized about the origins of psychogenic amnesia. As was noted earlier (51.2.11), psychogenic amnesia refers to an inability to recall that exceeds ordinary forgetfulness. This definition implies that amnesia is caused by a special, pathological mechanism rather than normall memory processes involved in forgetting. Repression and dissociation are two special mechanisms that are often mentioned in this context. These concepts will be outlined below.

\section{3. \%. Repression}

In the past few vears, the concept of repression has received a great deall of attention. One of the reasons for a renewed interest in the concept is the diebate on selective amnesia or so called recovered memories (see \$1.2.1.). It is widely believed that the defense mechanism of repression is responsible for lack of conscious awareness of traumatic events (Goodman, Quas, Batterman-Faunce, Riddlesberger \& Kuhn, 1994). Although the debate about recovered memories is fairly recent, the history of the repression construct goes back to the end of the 19th century. In that time, the Viennese psychiatrist 
Sigmund Freud ${ }^{\&}$ treated patients suffering from hysterical symptoms. lnitially, Freud believed that his patients' symptoms were, without exception. caused by sexual trauma (Freud, 1896/1952). He hypothesized that the defense mechanism of repression served to remove traumatic memories from consciousness. Around the turn of the century. Freud abandoned this so-called seduction theory ${ }^{9}$. Instead; he hypothesized that hysterical symptoms were caused by fantasies, originating in oedipal conflict (vain der Kollk \& Kadish, 1987). In this context, repression reflects warding off unconscious conflicts, wishes, and impulses, rather than actual traumatic memories. Nowadays, repression is central to psychodynamic theory (Bower, 1990), and the uncovering of repressed material is the primary aim of psychoanalysis (Bornstein

What is the exact definition of repression? In a thorough analysis of Freud's writings on the concept. Erdelyi (1990) concluded that all that Freud meant by the term was the intentional non-thinking of some material. Nevertheless, in the course of the past century the concept of repression seems to have evolved, and now encompasses more than mere "not thinking of something". Consider, for example, the following portrait of repression.

Repression is a perwerse process. It appears to efface the offending materiat, but this is an illusion - the contents of the unconscious are indestructible. Repressed material, like radioactive waste; lies there in leaky canisters, never losing potency, eternally dangerous. What is worse, it actiwely presses for expression. constantly threatering to erupt into consciousness. No one can control these forces; the best we can do is try to deflect them (Hornstein, 1992, p. 260).

In reviewing 60 years of research on repression, Holmes (1990) identified three elements that appear to be present in most definitions of the concept. Hornstein's description seems to harbour these three elements: The first element mentioned by Holmes (1990) is that repression involves selective forgetting of materials that cause the individual pain. $A$ second characteristic is that repression is not under voluntary control. A third element is the notion that repressed material is not lost, but is stored in the unconscious and potentially can return to consciousness.

In addition. Holmes (1990) alluded to two different types of repression. Primary repression refers to moving threatening material into the unconscious before it is consciously recognized as stressful. In repression after expulsion, the individual recognizes something as stressful "and banishes the material to the unconscious in order to avoid anxiety. Whereas the former type may refer to impulses and wishes generated by the unconscious itself, the latter type may pertain to traumatic memories.

\footnotetext{
8 Some authors le.g., Crombag \& Merckelbach, 1996) point out that the concept of repression is found in early 19 th century writings. Thus, strictly speraking, the common idea that the concept of repression was introduced by Freud is incorrect. Newertheless, repression takes a central place in Freud"s influmtial theory and his name is clasely tied to the repression concept.

9 There are several accounts of Freud's unotiwes for abandoning the: seduction theory. For example, feminist oriented authors (e.g., Albach, 1993; Herman, 1992) maintain that Freud realized that if hysterical symptoms were, indeedi, caused by repressed traumatic memories, this would imply that child sexuall abuse was much

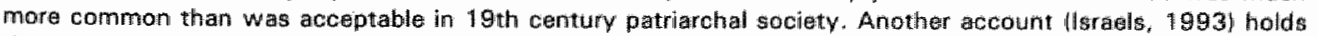
that Freud changed his theory because the treatment derived from it was not successful.
} 


\subsubsection{Dissociation}

Simillar to repression, the concept of dissociation emerged in the 19 th century. Pierre Janet is invariably referred to as the founding father of the concept ${ }^{10}$ and his dissertation, Written in 1889, is considered to be the first systematic situdy of dissociative symptoms 16.9. van der Hart \& Horst, 1989, Kihlstrom al., 1993; van der Kolk \& van der Hart. 1989; van der Kolk, Brown \& van der Hart, 1989; Putnam, 1989; Spiegel, 19941. According to secondary accounts, Janet regarded dissociation as a reaction to events that were subjectively stressful to psychologically weak individuals: In such persons, certain elementary structures of the mind (psychological automatisms) would split off from conscious awareness, forming new and isolated nuclei of consciousness, capable of exerting influence over behaviour.

Following Janet, madern formulations of dissociation share the notion of an alteration in consciousness or continuity of experience le.g. Allen, 1993; Braun, 1988; Kihlstrom, Glisky \& Angulo, 1994; Putnam, 1989). In addition, two aspects of dissociation currently receive strong emphasis. To begin with. whereas Janet mainly thought of dissociation as a pathological phenomenon (Erdelyi; 1990; Kihlstrom et al., 1994; Putnam, 1989; but see van der Hart \& Horst, 1989), dissociative experiences are now conceptualized as a continuum ranging from everyday experience (e.g., being absorbed by a movie) to serious dissociative disorders such as Dissociative Identity Disorder (Bernstein \& Putnam, 1986; Braun, 19881.

Consequently, an important question for many researchers is what distinguishes normal and pathological dissociation (e.g. Kihlstrom et al. 1994; Putnam, 1989). The answer to this question is far from clear. Roughly, two positions are taken in the literature. One position is represented by Kihlstrom and co-warkers (1994), who argue that the continuum hypothesis clearly implies that the difference between normal and pathological dissociation should lie in the frequency, intensity or extent of such experiences. In line with this conceptualisation, self-report measures of dissociation (e.g., Dissociative Experiences Scale, DES; Bernstein \& Putnam, 1986) have been employed in order to determine what thresholld or cut-off score should be regarded indicative of pathology (e.g., Bernstein Carlson at al., 1993).

Another position regarding the nature of dissociative experiences is taken by authors who acknowledge the axistence of a dissociative continuum, yet attempt to define pathologicall dissociation in terms of specific characteristics. For example, some authors (Braun, 1988; van der Kolk \& van der Hart, 1989; Putnam, 1989/ propose that pathological dissociation is characterized by the symptoms of an altered sense of identity and psychogenic amnesia. Still others (e.g. Spiegel \& Cardeña, 1991) emphasize that truly dissociative experiences are recognized by an inability to integrate certain events within consciousness, even when the person attempts to do so. Thus, in these accounts, one and of the hypothesized dissociative continuum (i.e., instances of normal dissociation) is left out of consideration. All in all it appears difficult for these authors to reconcile the

\footnotetext{
10 Kinlstrom and cawworkers (1993) point out that Janet spoke of desagregation. They feet that the English trarisiation of this term into dissociation is unfortunate. According to these authors, this creates the impression that there is a link with "the doctrine of the association of ideas" (p. 205\%. They argue that disaggregation would have provided a more correct translation, because this term refers to the breaking up of mental life intio component parts.
} 
notions of "normal" and pathological dissociation.

A second point worth noting is that in recient formulations, psychological trauma has becomie inseparable from the concept of dissociation. Janet is credited for being the first to describe the link between trauma and dissociation (van der Hart \& Horst, 1989; van der Kolk \& van der Hart; 1989; Putnam, 1989\%. However, compared to Janet, current accounts seem to place much stronger emphasis on trauma. Janet appears to have stressed the subjective nature of the traumatic events in his patients fwan der Hart \& Horst, 1989). For example, one of Janet's patients was not prepared for her first menstruation, and experienced this (and subsequent events) as extremely traumatic. Such an event hardly fits the current definition of trauma, as this definition refers to events which involve "(...) actual or threatened death or serious injury, or a threat to the physical integrity of self or others" (APA, 1994, p. 427). Nowadays; severe and repeated trauma (0.g." child sexual abuse) is frequently reported being closely related to dissociative pathology (e.g., Boon \& Draijer, 1993; Splegel, 1994). Furthermore, Janet is said to have identified a traumatic event precipitating psychopathology in barely half of his case load 1257 of 591 cases; wan der Kolk et al., 1989, p. 368\%. He explicitly stated that he saw dissociative symptams not exclusively as a consequence of trauma (Janet, 1930 , cited by van der Kolk et al., 1989). Current authors, however, emphasize the traumatic origins of patho: logical dissociation le.g., Boon \& Draijer, 1993; Braun, 1993; Classen, Koopman \& Spiegel, 1993; van der Kolk \& van der Hart, 1989; Putnam, 1989; Spiegel, 1994l. Some authors (e.g., Kihlstrom et al.; 1994; Spiegel \& Cardeña, 1991) refrain from absolute statements, pointing out that claims about causality are based on retrospective research, and that the precise nature of the relation between trauma and dissociation is yet to be established. Nevertheless, dissociation is now commonly viewed as a defense or coping mechanism acting in response to overwhelming events from which no escape is possible fe.g. Allen, 1993; Braun, 1988; Putnam, 1989; Spiegel, 1994; Spiegel \& Cardeña, 19911. The purpose of this mechanism is detachment from the emotional impact of the traumatic event (Classen et al., 1993; van der Kolk \& van der Hart, 1989).

\subsubsection{Critical notes on repression and dissociation}

In essence, both the concept of repression and dissociation refer to defense mechanisms. In response to trauma, the mind resorts to defenses in order to ward off the affect associated with such experience. In dissociation literature, authors emphasize differences between repression and dissociation (e.g." van der Hart, 1994; Spiegel, 1994). For example, dissociation theorists hypothesize that mental structures are organized in a parallel fashion, with amnesia reflecting the boundaries between these structures. Alternatively, the repression hypothesis would reflect an archeological view of mental structures, in which the unconscious would ly in the depths beneath the conscious. Interestingly, in these comparisons repression is referred to as the warding off of wishes and impulses, whereas dissociation would pertain to actual traumatic events. Thus, dissociation theorists seem to ignore literature in which repression is claimed to cause lack of memory for actual trauma le.g., Albach, 1993; Herman \& Schatzow, 19871. When this literature is taken into account, the repression and dissociation hypotheses appear to be rather similar. In short, both hypotheses assume that traumatic memories are stored somewhere in the 
mind in some inaccessible form, but are nevertheless capable of exerting influence over behaviour. There are several major problems associated with these functional explanations:

The first problem is that both the concepts of repression and dissociation suffer from a lack of clarity and carry different meanings (see Frankel, 1990; Hacking, 1995; Garry et al., 1994; Kihlstrom et al, 1994). As for repression, such different meanings pertain to what exactly is banished from consciousness (wishes and impulses versus actual memories) and to the (unjconscious nature of the defense (e.g., Erdelyi, 1990). As for dissociation, it has been argued (Frankel, 1990; Hacking, 1995) that the definition of the concept as a continum is overly wide (see 31.3 .2 ), and that this overinclusive definition should be abandoned altogether.

A second problem is brought about by the functional nature of both hypotheses: special mechanisms are invoked in order to ward off painful affect. However, this does not explain why certain individuals would repress or dissociate their traumatic memories whereas other people do not (Loftus \& Kaufman, 1992). Furthermore, in case of partial amnesia, the question rises why repression or dissociation would only act on aspects of a traumatic event, rather than on the entire traumatic memory (Christianson, 1992). A related problem is that the functional connotation creates the pitfall of circular reasoning. Consider an example provided by Terr $(1994)$.

In the first week of september, a new graduate student at Berkeley forgets to attend his library orientation. "I fust forgot", he says. But little later his story sournds more complex. He recalls a time when three of his classmates in clementary school shot spitballs in the school library and he, wronglv, was thrown out. He has repressed, not forgotten, his appointment in the graduate-school library. The emotional meaning of his earlier himiliation has inferfered with his ability to keep the appointment in mind ( $p .7$, italics added).

Terr's line of reasoning is the following: repression causes the forgetting of painful material, thus any forgetting of painful material is caused by repression. Clearly, this author confuses the mechanism with its outcome. Another example of such confusion is using the terms amnesila and repression / dissociation interchangeably le.g., Herman \& Schatzow, 1987; van der Hart, 1994; Pope \& Hudson, 1995; see for a discussion of this issue, Loftus et al., 1994). Perhaps this confusion is due to the fact that repression and dissociation are mechanisms that cannot be measured directly, but can only be inferred from their outcome (i.e., amnesia).

This brings about a third problematic issue: repression and dissociation are difficult concepts to study. As Williams (1994a) puts it: "because any examination of memories of traumatic events can only rely on observed behavior, there may never be conclusive proof that a specific mechanism is responsible for the observed forgetting" (p. 1182). For this reason, Bower (1990) argues that a lack of memory can only be attributed to specific functional mechanisms if other, perfectly ordinary reasons for forgetting are controlled for. However, field studies on lack of memory for traumatic events have been unsuccessful in demonstrating that such memory failure is beyond explanation in terms of ordinary forgetting (Pope \& Hudson, 1995). Likewise, experimental research on predictions flowing from the repression hypothesis has failed to rulle out such alternative explanations (Holmes, 19901 .

The latter problem has led Holmes (1990) to conclude that the repression concept should be abandoned and that research into emotion and memory should focus on other 
processes underlying selectivity in perception and recall. Yet; Erdelyi (1990) emphatically argued against abandoning the repression concept. This author maintains that for research purposes the concept should be operationalized as the mere not-thinking of something. Thus, the connotations of functionality and unconscious acting should be omitted from such an operationalization. In a similar argument concerning dissociation, Ensink (1992) points out that there is no evidence for the existence of different streams of consciousness. She operationalizes dissociation as disturbances of perception rather than memory. Dissociation would reflect a failure in correctly employing the attentional strategies that lie between perceiving and noticing (i.e. , becoming aware of perceptions). Taken together. these authors propose that the repression and dissociation hypotheses can be studied. provided that they are operationalized in ordinary information processing terms. Such efforts to save the concepts of repression and dissociation are admirable, but they sadly miss their target. These concepts exist by virtue of the assumption that phenomena like psychogenic amnesia cannot be explained in terms of ordinary memory processes. If translation into conventional information processing terms provides the only way to study the concepts of repression and dissociation, then the very existence of these concepts becomes irrelevant.

Taken together, repression and dissociation are ill-defined concepts, that lack explanatory power and are impossible to measure directly. Moreover, redefining the concepts results in their redundancy. In fine, it would be surprising, if not suspect, to find the repression and dissociation hypotheses surviving another decade. 


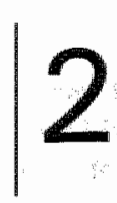

\section{Emotion and Memory}

In the previous chapter, clinical literature on memory for traumatic events was reviewed. What does non-clinical literature on emotion and memory say about how emotional events are remembered? This literature provides a complicated picture. On the one hand it appears that emotional experiences are well remembered. On the other hand, it seems that memory for emotional events is impaired. In the following, these contradictory findings will be discussed in more detail.

\subsection{Emotion enhances Memory}

\subsubsection{Field studies: flashbulb memories}

When people are asked in which circumstances they learned of a shocking (publicl event, they generally give elaborate accounts of those circumstances. Consider, for example, James Kullik's account of what happened on november 22, 1963 , the day that president J.F. Kennedy was shot.

I was seated in a sixthugrade music class, and over the intercom I was told thet the prosidant had been shot. At first, everyone just looked at each ather. The class started yelling, and the music teacher tried to calm everyone down. About ten minutes later I heard over the intercom that Kennedy had died anid that everyone should return to their homeroom. I remember that when 1 got to my homeroom my teacher was crying and everyone was standing in a state of shock. They told us to go home (Browr \& Kulik, $1977,0.74)$.

Brown and Kulik (1977) introduced the term flashbulb memories for this phenomenon. These authors studied flashbulb memories for a number of shocking events (public as well as personal) and observed that certain types of information frequently occurred. More specifically, they identified six canonical categories, concerning the place, the ongoing event that was interrupted by the news, the informant, the affect observed in others, own affect, and the immediate aftermath. Indeed, Kulik's own flashbulb account seems to encompass all but one (own affect) of these categories. 
How did Brown and Kulik explain the flashbulb memory phenomenon? In their view, surprise and consequentiality are the two principle determinants that cause the flashbulb to tire. The authors use the flashbulb as a metaphor for a special neurobiological now print/ mechanism. That is, whenever an organism encounters an unexpected and biologically significant event, the brain "takes a picture" -albeit incomplete- of cues that predict such event. Such mechanism would have evolved because of its survival value.

Brown and Kulik's (1977) paper inspired researchers to study flashbulb memories for various shocking and surprising events, such as the assassination attempt on president Reagan (Pillemer, 1984), the murder of Swedish prime minister Olof Palme (Christianson, 1989), the space shuttle Challenger explosion (Biohannon, 1988; McCloskey, Cohen \& Wible, 1988; Neisser \& Harsch, 1992), the Hillsborough disaster (Wright, 1993) or the resignation of Britain's prime minister Margaret Thatcher (Conway et al., 1993). Such reports have focused on roughly two issues. One issue concerns the determinants of flashbulb memories. Contrary to Brown and Kulik's claim that surprise is a "sine qua non" (p. 84) for flashbulb memories, research indicates that flashbulbs occur for expected (i.e.. non-surprising) events, such as the landing of the first man on the moon (Winograd \& Killinger, 1983). Although Brown and Kulik viewed consequentiality as a flashbulb memory determinant, emphasis seems to have shifted towards influence of emotion on flashbulb formation. The results of several studies (Bohannon, 1988; Conway et al., 1993; Pillemer, 1984) suggest an association between intensity of affect and flashbulb memories. Yet, in other studies (Christianson, 1989; Neisser \& Harsh, 1992) this association was not found. Thus, evidence for the role of emotion in flashbulb formation is mixed.

A second issue in the flashbulb memory literature is what mechanism is responsible for the phenomenon. A debate le.g., McCloskey, Cohen \& Wible, 1988; Schmidt \& Bohannon, 1988; Cohen, McCloskev \& Wible, 1988) evolved on the question whether the flashbulb phenomenon should be explained in terms of ordinary memory mechanisms or in terms of a special mechanism'. Central to this discussion is the issue of accuracy. Although they never stated it directly. Brown and Kulik's (1977) original formulation implied that flashbulb memories are veridical representations of the flashbulb event ${ }^{2}$. However, the results of several studies indicate that at least a number of flashbulb memories are inaccurate at repeated testing (Christianson, 1989; McCloskey et al., 1988; Neisser \& Harsh, 1992; Weaver, 1993; but see Conway et al., 1993) or show systematic biases (Wright, 1993). Furthermore, flashbulb memories do not appear to differ from other vivid autobiographical memories (Rubin \& Kozin, 1984) or memories for insignificant personal events, provided that subjects are given the instruction to remember these events (Weaver, 1993). Taken together, these findings contradict the notion that flashbulb memories are unusually accurate and form a special class of autobiographical mem-

\footnotetext{
"Note that this discussion is reminiscent of the debate about the need for a special mechanism le.g", repression or dissociationl for explaining psychogenic amnesia.

2 In the words af Brown and Kulik: "It is our assumption then that the FB memory is always there, unchanging as the slumbering Rhinegold, and serving by means of rehearsal to generate some variety of accounts ${ }^{\Xi}$ (p. 86 ). This statement reflacts the authors" view that a flashbulb memory is a memory trace rather than a verbal account. The narrative is constructed from the memory trace and becomes more elaborated li.e. contain more canonical categories) with rehearsal. That such narrative constructions may be false does not appear to ba a possibility that Browin and Kulik considered (see Brewer, 1992).
} 
ory. Thus, a special mechanism for explaining the flashbulb phenomenon does not seem to be necessary. Accordingly. Brown and Kulik's now print! hypothesis has been largely abandoned and alternative explanations in terms of ordinary memory mechanisms have been put forward (McCloskey, 1992). One of these explanations points to the social function of flashbulb events and the rehearsal that they invite (Loftus \& Kaufman, 1992; Wright, 1993). Another account emphasizes the role of affect or emotion in encoding and rehearsal (Conway et al., 1993).

\subsubsection{Memory for emotional stimuli in the laboratory}

The label emotion denotes a variety of discrete affective states. For example, one may feel either happy or sad, or one may be either paralysed with fear or madly in love. Despite their variety, it is recognized (e.g., Bradley, 1994; Bradlley, Greenwald, Petry \& Lang, 1992; Lang, Greenwald, Bradley \& Hamm, 1993) that emotional states are organized along two independent dimensions: valence (pleasant - unpleasant) and arousal (excited calm). Bradley and co-workers (1992) examined memory for a large number of slides that varied on these dimensions. They found that physiological arousal, rather than physiological correlates of valence, best predicted performance on immediate and delayed lafter a 1-year periodly memory tasks. Cahill and coworkers (Cahill, Prins, Weber \& McCaugh, 1994) further investigated the relation between arousal and memory. Subjects were given either a placebo or a $\beta$-adrenergic antagonist (propanolol) prior to presentation of emotional or neutral stimuli. Although ratings of the emotional properties of the slide-story did not differ, only placebo subjects showed an increase in physiological arousal at the presentation of emotional stimuli. The placebo subjects displayed an enhanced memory for the emotional story, whereas the propanolol group failed to show a memory advantage. Taken together, the results of these experiments provide evidence that an increase in physiological arousal is associated with enhanced memory performance.

What is the mechanism underlying this relation? One explanation le.g., Cahill et al., 1994; McGaugh, 1992) emphasizes the role of the amygdala in the formation of emotional memory. The amygdala is a small region in the limbic system of the brain that assigns emotional significance to certain stimuli (LeDoux, 1992). It is hypothesized that emotion-induced activation of the sympathic nervous system causes the release of sevaral neurotransmitters in the amygdala, which in turn, strengthen emotional memory storage. Another explanation is more psychological in nature. Bradley 11994 ; see also Bradley et al., 1992) interprets the positive association between arousal and memory in terms of the network theory of emotional memory. According to this account, emotions are repre. sented as an associative memory network, in which information about stimuli, responses (behavioural as well as physiological), and evaluative meaning are strongly connected (e.g., Lang, 1988). Bradley proposes that arousal responses may cause an extensively elaborated memory representation. In other words, because an emotional stimulus evokes many different responses (e.g., skin conductance responses, increased cardiovascular activity, heightened interest; see Lang et al., 1993), more response information would be stored in memory, leading to a retrieval advantage. 


\subsection{Ernotion impails Memory}

Field studies on flashbub memories as well as laboratory studies suggest that emotion enhances memory. Yet, there is some evidence that recall of emotional experiences may be impatired. For example, Williams $(1994 \mathrm{~b})$ found that $38 \%$ of her sample failed to report an instance of sexual abuse that was documented 17 years earlier ${ }^{3}$. Still, apart from clinical literature (see chapter 1 ), there are relatively few field studies that clearly demonstrate a lack of recall for emotional experiences. In the following, two laboratory phenomena suggesting that emotion impairs memory will be discussed: weapon focus and laboratory induced amnesia.

\subsubsection{Weapon focus}

Weapon focus refers to a witness' attention being directed to a weapon during the commission of a crime (Egeth, 1994: Steblay, 1992). Consider a bankteller that is held at gunpoint during a robbery. The teller would direct his or her attention to the gun, at the expense of attention for other information, such as the facial features or clothes of the guin-pointing culprit. As a consequence, such information would be poorly encoded and the teller would have difficulty describing or recognizing the perpetrator upon questioning by the police.

The empirical evidence is relatively scarce, but nevertheless supports the notion that confrontation with a weapan results in an impaired memory for the perpetrator.. Steblay (1992) subjected all the available cexperimentall literature on the phenomenon (twelve studies to a meta-analysis. She found that the presence of a weapon had a moderate effect on the accuracy of perpetrator descriptions, yet a small effect on line-up identification. What variables mediate such effect? The weapon focus account emphasizes the threat associated with the weapon. This threat could have two consequences: heightened arousal and attention allocation to the source of threat (Steblay, 1992). As for the importance of heightened arousal in creating the weapon focus effect, the evidence is mixed. For example, Maas and Kohnken (1989) employed a design in which a confederate confronted subjects with either a large syringe or a pen. Compared to subjects who saw a pen, subjects in the syringe condition reported increased tension during confrontation with the syringe and poorly recognized the confederate. Thus, these results suggest that arousal is associated with memory impairment. In contrast, Kramer and co-workers (Kramer, Buckhout \& Eugenio, 1990) found poor memory for a weapon-carrying person in the absence of heightened arousal. Thus, these data indicate that an increase in arousal is not critical for obtaining a weapon focus effect.

As for attentional focusing, in a study measuring visual attention (eye-movements), it was found that subjects look more often and for longer durations at a gun than at a check

\footnotetext{
The Williams (1994b) study is frequently cited (e.g. van der Hart, 1994) as providing evidence for the occurretice of selective psychogenic amnesia and repression or dissociation. However, Willams data do nor exclude alternative explanations in terms of infantile amnesia li.e., the absence of autobiographical memories for the first wo vears of life, see Howe, Courage \& Peterson, 1994l, a relluctance to disiclose the abusive event, and so forth (see boftus at al., 1994, for an extensive discussion of these issues).
} 
(Loftus, G.R. Loftus \& Messo, 1987). Although this finding is in line with the weapon focus account, the authors express doubts concerning the specificity of the effect. For example, there is some evidence that people tend to fixate longer and more often on any object that is not to be expected given the context (G.R. Loftus \& Mackworth, 1978). Bearing such findings in mind, Loftus and colleagues hypothesize that any unusual object. (e.g., a banana) might have produced a weapon focus effect.

\subsubsection{Laboratory induced amnesia}

A number of researchers sought to induce amnesia for emotional events in the laboratory, in order to study the processes underlying memory loss le.g., Christianson \& Nilsson,

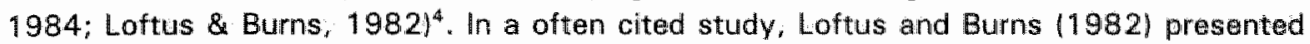
subjects with either a violent or non-violent version of a film depicting a bank robbery. The violent film ended with a scene in which a child was shot in the face. The results sug gested that subjects who saw the violent ending displayed a retrograde amnesia. That is, they showed poorer memory for a detail of the child's clothing that had been clearly visible prior to the shooting. Christianson and Nilsson (1984) took a different approach. They presented a series of slides of human faces, accompanied by slides with four verball descriptors (e.g.. occupation, hobby). Subjects were instructed to memorize one of the four descriptors and memory for that descriptor was later tested. For subjects in an emotional condition, the middle portion of the slide series showed horribly disfigured faces, whereas subjects in a control condition were presented with neutral faces only. The results indicated that the traumatic group had a poor memory for descriptors associated with the gruesome faces. In addition, an anterograde amnesia li.e., poor memory for information following the emotional slides), but no retrograde amnesia was obtained. Another study provided some tentative evidence to suggest that positive stimuli ferotic pictures) may have a similar detrimental effect on memory for verbal descriptors (Christianson, 1986). Overall, the results of these studies suggest that emotion is associated with impaired recall.

How can this impaired recall be explained? Loftus and Burns (1982) interpret the retro. grade amnesia effect in terms of memory consolidation: witnessing a shocking event would disrupt the lingering processing necessary for full memory storage. This explanation is rather unspecific: what exactly about a shocking event (or its witness) would bring about such disruption of consolidation? One possible candidate is the physiological arousal accompanying an emotional state. Christianson and colleagues (Christianson \& Mjorndal, 1985; Christiansan, Nilsson, Mjörndal, Perris, \&jellden, 1986) further investigated the

\footnotetext{
4 This line of research was initiated in the late 1960s. In 1969. Tulwing reported that including hinh-pirionty words (i.e., names of famous persons that were to be memorized by the subjectsi) in otherwise homogenousi word lists, resulted in impaired recall for words immediately preceding the high-priority words. Deatterman le.g., Detterman, $1975 ; 1976$; Detterman \& Ellis, 1972) further explored the psychological processas underiying laboratory induced amnesia. Yet, extensive discussion of these experments is bevond the scope of the present dissertation, because these researchers aimed at providing a laboratory madel for organic aninesia le.g., resulting from electroconvulsive shock, concussion, anoxia, etc. and employed non-emotional stimuli.
} 
role of arousal in memory impairment. They found that memory for verbal descriptors was impaired when arousal was brought about by gruesome slides. This memory impairment was unrelated to a state of heightened arousal per se (i.e., induced by adrenaline injections: and unvelated to slides). Christianson and co-workers (1986) hypothesize that the verbal descriptors are poorly elaborated during encoding, because cognitive resources are drawn to the content of the gruesome slides.

\subsection{Does Emotion enhance or impair Memory? Theoretical Accounts}

The literature reviewed above renders a puzzling picture. Studies of flashbulb memories suggest that emotional events are exceptionally well recalled. Yet, experiments on weapon focus show that memory for an assailant may be poor. The physiological component of emotion, autonomic arousal, is frequently mentioned as a likely carididate for influencing memory "Yet, there is evidence that arousal enhances as well as impairs emotional memory. There are two theoretical accounts that incorporate both effects. These accounts will be discussed next.

\subsection{The Yerkes-Dodson law}

In reviewing research on eyewitness memory, Deffenbacher (1983) stumbled on a similar puzzling picture: sometimes memory for emotional events is good, sometimes it is poor. He proposed that these mixed findings reflect a curvilinear relation between arousal and memory performance, commonly referred to as the Yerkes-Dodson law or inverted $U$ curve 10.g., Neiss, 1988; Teigen, 1994). The Yerkes-Dodson law is frequently cited in the eyewitness literature (Egeth, 1994). In short, the assumption is that with increasing arousal, memory becomes more accurate, until an optimum is reached. Beyond this optimum, a further increase in arousal results in memory impairment. Thus, according to Deffenbacher, results indicating enhanced eyewitness accuracy would fit the left hand (rising slopej of the curve, whereas results suggesting impaired eyewitness accuracy would reflect the right hand (descendling slope) of the curve.

Although Deffenbacher's (1983) argumentation may seem intuitively plausible, it is a clear-cut example of circullar reasoning isee also Christianson, 1992; Egeth, 1994). Deffenbacher assumes that varying levels of arousal cause either enhanced or impaired memory accuracy, and he then treats the observed memory effects as an index of arousal levels. For example, he discusses a study suggesting that subjects in an emotional condition display enhanced memory relative to a control condition. However, on one particular test females in the emotional condition performed more poorly than controls. Deffenbacher interprets this findings as follows: "Perhaps females (...) passed beyond the optimal arousal level as soon as the male target person ermerged upon the scene" (p. 241). The problem is that this optimal arousal level is an unknown variable and that it may vary with task complexity (Neiss, 1988). Accordingly, any result suggesting a disconfirmation of the inverted $U$ hypothesis can be explained away by assuming that subjects were either under- or overaroused. This, in combination with ethical constraints precluding any rigorous experimental test invalving extremely high arousal levels, has led Neiss (1988) to 
conclude that the inverted $U$ hypothesis is "effectively immunized against falsification" $(\mathrm{p}$. 355). Yet, this has not been the only point of concern for critics of the Yarkes Dodson law (e.g., Christianson, 1992; Egeth, 1994; Neiss, 1988; 1990; Teigen, 1994):

In a historical review; Teigen (1994) discusses the original experiments carried out by Yerkes and Dodson in 1908 . These researchers studied the relation between stimulus strength (i.e., intensity of electrical shock), discrimination difficulty (i.e., intensity of light) and habit-formation (i.e., learning to discriminate between a black and a white box) in mice. The results of two out of three experiments indicated that learning was nost efficient at intermediate shock levels and these findings resulted in farmulation of the Yerkes. Dodson law. However, Teigen (1994) points out that the original experiments were carried out in an unsystematic fashion (e.g., different shock levels over experiments) and relied on a very small number of animals (sometimes four, sometimes two mice per condition) ${ }^{5}$. Thus, formulation of a general principle on basis of such findings is questionable. Nevertheless, the Yerkes-Dodson law has become increasingly popular and is cited in many psychology handbooks. Over the years, the variables in the inverted $U$ function have been reformulated with any paradigm shift in psychology (Teigen, 1994 ). For example, the $x$ axis has reflected punishment, motivation, drive level, or arousal, whereas the $y$-axis has referred to learning, performance, coping, or memory. Currently, the law is most frequentIy described in terms of arousal and some kind of performance le.g., motor performance, Neiss, 1988; cognitive performance, Anderson, 1990; memory performance Christianson, 1992).

This liberal formulation of the inverted $U$ function brings about yet another point of concern. As Christianson (1992) puts it: "What kind of arousal is referred to in this function?" (p. 295). Arousal has long been viewed as a unitary concept (see Neiss "1988, for a review). This position is taken by Anderson (1990), who states: " $(\ldots)$ arousal is best conceived of as a unitary conceptual dimension (...) arousal is a hypothetical construct representing the sum (in a principal-component sense) of a variety of processes that mediate activation, alertness, and wakefulness" (p. 98) ${ }^{*}$. Others (e.g., Christianson, 1992; Neiss, $1988 ; 1990$ ) have argued against such view. They point out that there are various activation systems (e.g., the reticular activation system involved in alertness; the limbic system involved in anxiety) and that indicators of arousal are not highly correlated. Fur. thermore, Neiss $(1988 ; 1990)$ argues that arousal cannot be induced in its pure form, that is, separate from an emotional context. Thus, arousal should be regarded as a physiological component of emotion, varying across emotional states (e.g., sexual arousal, anxiety-related arousal, etc.), rather than as a general construct. For this reason, (general) arousal cannot be regarded as a causative factor in enhancing or detoriating performance (Neiss, 1988).

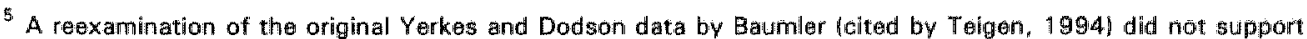
the original conclusions. Instead of the original series criterium li.e. three errorless series of 10 trials on the consecutive daysl. Baumler used an errors criterium li.e., the number of errors before the first mouse reached the series criterium). In the sitrong shock condition, the difficult discrimination task rendered less errors.

6 Such unitary view of arousal is also implicit in Deffenibacher"s 11983 ) rewiew on eyewitregs accuracy. He includes a variety of methods that presumably bring about or reflect essentially the same arousal state. Far example, Deffenbacher seems to equal the state created by witnessing a staged theft land reflected by ratings of theft seriousness! to the state reflected in measures of trait anxiety.
} 
In conclusion, the Yerkes-Dodson law does, at first sight, reconcile mixed findings in eyewitness research. However, it turns out that the ease with which these mixed findings are fitted into the hypothetical inverted $U$ curve is due to its conceptual vagueness.

\subsubsection{Attentional narrowing}

Until now, this review has largely ignored the question of what exactly constitutes memory performance. Memory has been referred to as either enhanced or impaired, and has inchuded number of emotional slides recalled or recognized (52.1.2), recall of a number of verbal descriptors accompanving gruestome slides $(\$ 2.2 .2)$, identification or recognition of a person ( $\$ 2.2 .1)$ or the recall of personal circumstances upon learning of an emotional event $(52.1 .1$. As became apparent in the latter case, autobiographical memory is not necessarily complete in the sense that it encompasses every detail of an emotional event. Thus, people may remember certain aspects well, whereas other aspects are poorly retained. Christianson and colleagues (Christianson, Goodman \& Loftus, 1992) explain contradictory results in studies on emotional memory in terms of what aspects a particular researcher focuses on. A comparison of two frequently cited field studies may illustrate their point. Yuille and Cutshal (1986) studied the memory of witnesses to a shooting incident in which a person was killed. Subjects were interviewed four to five months after giving an initial statement to the police. The witnesses were highly accurate in recalling the event. Yet, errors were noted le.g, confusion over or forgetting of actions, descriptions, etc.l. Wagenaar and Groeneweg (1990) reassessed the memory of World War II concentration camp survivors 40 years after their original testimonies. Almost all witnesses remembered their experiences in detail. But again, errors occurred (e.g., forgetting of names, dates, and even instances of malltreatment or murderl. Despite the fact that the results of both studies are similar in that they show that aspects may be either well or poorly remembered, the authors differ dramatically in their interpretations. Yuille and Cutshal (1986) emphasize the accuracy of their witnesses and maintain that their data contradict the claim that high levels of stress impair eyewitness memory: In contrast, Wagenal and Groeneweg (1990) stress the errors in their witnesses' accounts and argue that their data contradict the claim that high levels of stress result in accurate eyewitness reports. Perhaps, then, one way of reconciling conflicting results of studies on emotional memory is taking into account that particular aspects of emotional events may be remembered differently.

What is the underlying mechanism for differential recall of aspects of emotional events? A common starting point for theorizing is Easterbrook's (1959) cue-utilization hypothesis. Easterbrook (1959) proposed that an increase in drive would restrict the range of cues utilized by an organism. The use of task-relevant (central) cues would be maintained, whereas the number of task-irrelewant (peripheral) cues used would decrease. This would result in constant or enhanced task llearning, whereas the amount of incidental learning would be reduced". Presumably because his aim was to provide a general principle to

7 Easterbrook 19959 ) further hypothesized that progressive restriction of the range of cues would first enhance by exclusion of peripheral cues) but later limpair (by exclusion of central cues) proficiency. He noted 
account for differential effects of emation on behaviour organization. Easterbrook formu. lated his hypothesis in broad terms. For example, he used the terms drive and emotion interchangeably to denote "a dimension of emotional arousal or general covert excite* ment" (p. 184). In his view, this dimension referred to the internal state of hungry mice as well as neurotic humans. As became apparent earlier 152.3 .11 , such general arousal concept is problematic in that it does not specify what kind of emotion or arousal is referred to. Furthermore, although he is often credited for explaining impaired performance in terms of attentional narrowing (e:g.; Christianson, 1992; Reisberg \& Heuer, 1992), Easterbrook did not restrict his concept of cue utilization range to any specific attentional process. Although in discussing the concept he occasionally referred to "breadth of perceptiwe field" (p. 185) or "narrowing of attention" (p. 1911), he made it very clear that being a response-oriented theorist, such processes were not all that important to him.

The writer believes it incorrect to speak of perception and response as if they were distinct processesi when it is evident that perception is an actiwe event and when the very concept of response implies preceding perception. The correct unit according to this view is the use of a cue. $1 \ldots 1$ The subject's behaviour reflects the number of distinctions made; the more discriminative is the behaviour "the greater is the number of cues that has been used. Except by introspection, neither discriminative perception nor discriminative response can be alleged to have occurred in the absence of evidence of both (p. 188-189, italics added).

Contemporary researchers (e.g., Christianson, 1992; Heuer \& Reisberg, 1992; Yuille \& Tollestrup, 1992) have applied the cue-utilization hypothesis to memory for emotional events. Instead of cue-utilization, attentional narrowing takes a central position in these accounts. Christianson (1992) offers the most detailed description of such attentional narrowing hypothesis. This author defines emotion as high levels of stress or anxiety, with corresponding increases in autonomous arousal. This emotional arousal would bring about an attentionall focus on the gist of the event (central details), at the expense of attention for peripheral (irrelevant) information. Accordingly, memory for central information would be enhanced, whereas peripheral information would be poorly retained. Christianson (1992) further suggests that attentional narrowing is associated with increased elaborative processing of the information attended to. Yuille and Tollestrup (1992) extend the attentional narrowing hypothesis to account for instances in which victims or witnesses have poor memory for both central and peripheral details. These authors propose that attention may not only be directed to the environment, but also inwardly, for example to the victim's emotional responses. In these cases, few external details would be stored.

In sum, memory for emotional events appears not to be an all-or-nothing phenomenon. Some (centrall details of an emotional event may be well retained, whereas memory for otheir (peripheral) details may be poor. This differential recall would be the result of attentional narrowing due to emotional arousal. The attentional narrowing hypothesis may account for the mixed findings that were discussed earlier. For example, in case of a weapon focus, the face of the perpetrator may be peripheral and the weapon may be

\footnotetext{
T....continued?

in passing that the Yerkes-Dodson llaw may be explained in such way. This explanation has so often been cited le.g. Christianson, 1992; Deffenbacher, 1983; Egeth, 1994) that the impression is created that Easterbrook explicitly formulated his cue-utilization hypothesis to account for the Yerkag Dodson law. However. Easterbrook casually explained yet three other psychological principles popular in the $1950^{\circ}$ s in terms of his hypathesis (p. 196-197).
} 
central. Likewise, verbal descriptors accompanving gruesome slides may be considered peripheral and thas be poorly remembered. Of course, such an interpretation is post-hoc. Studies specifically destgned for testing the attentionall narrowing hypothesis will be reviewed next.

\subsection{Studies on Attentional Narrowing}

\subsubsection{Detall memory for real-life events and some critical notes}

Only a few studies specifically examined memory for central and peripheral details of reallife emotional events. Christianson and Loftus (1990) asked normal college students about their memory for the most traumatic event they ever experienced. The subjects reported that they remembered more central than peripheral details. In addition, the amount of central details remembered was positively associated with emotionality ratings. Yet, it is important to note that the central / peripheral classification in this study was based on what the subjects thought they remembered. Put differently, it is unclear for what reason subjects classified detalls as either central or peripheral. For example, it is possible that vividly remembered details led subjects to rate those details as central.

Christianson and Hübinette (1993) interviewed victims of bank robberies. The details of these incidents had been documented in police reports. Thus, this approach allowed for determining memory accuracy. The results indicated that overall, memory for some details (e.g., time and date of the robbery; colour of the robber's hair, etc.) was less accurate than memory for other details (e.g., actions, weapon, etc.). However, victims who reported relatively low emotionality during the robbery displayed poor memory for circumstantial details compared to victims who reported relatively high emotionality during the robbery. Christianson and Hübinette refrained from classiffying details as either central or peripheral. Nevertheless, it is tempting to assume that circumstential detail is peripheral. In that case, the finding that such peripheral detail is remembered more poorly in a low emotionality group is the exact opposite of what the attentional narrowing hypothesis would predict. However, two problems preclude interpretation of this result as contradicting the attentionall narrowing claim. First, retrospective emotionality ratings may be a poor index of original emotion (see Neisser \& Harsch, 1992). Put differently, judgements of an emotional state during an event that happened several months earlier may be an unreliable basis for assigning subjects to either a high or low emotionality group. A second problem pertains to the post-hoc classifucation of detail. It could be argued that the finding that the high emotionality group showed a better memory for circumstantial details indicates that these details are not irrelevant and that classifying them as peripheral is unjustified. Note that in this fashion, any detail memory result can be explained by claiming that a certain item did not really fit either a central or a peripheral category ${ }^{8}$.

\footnotetext{
Fote that this pitfall is also apparent in Christianson's (1992) statement that "central and peripheral details are distinguisheid as differentially remembered detail information within an emotional scienario" tp. 291, italics addedy. The attentional narrowing hwpothesis predicts that central and peripheral details are differentially remembered as a consequence of particular attentional processes. Thus, classifying details as either central or peripheral should take place irrespective of how those details are remembered.
} 
The considerations above uncover a fundamental problem in field studies on attentional narrowing. That is, real-life and highly emotional events are typically uncontrollable and unpredictable. For example, it is impossible (if not highly unethical) to obtain emotionality ratings from subjects being held at gunpoint during a robbery. Likewise, it is hardly a realistic option to manipulate detail information in a bank, hoping for a robbery to occur at some paint in time. Yet, these problems could be circumvented by selecting naturally occurring situations that are controllable, but that are nevertheless highly stressful for those involved. Two studies /Goodman. Hirschman, Hepps \& Rudy, 1991; Howe, Courage \& Peterson, 19941 followed such an approach. These authors studied memory in children for a medical situation (inoculation or venipuncture, Goodman at al, 1991; treatment in a hospital emergency room, Howe et al., 1994/. The designs of these studies were similar in that the children's emotional reactions were rated by their parent land an independent rater, Goodman et al., 1991), and that independent judges classified details as either central or peripheral. The results of both studies indicate that central details were better remembered than peripheral details. Yet, neither study found a relation between stress ratings and detail memory. Thus, although memory patterns were consistent with the attentional narrowing claim, the absence of an association with stress ratings contradict this claim.

Taken together, studies on detail memory for real-life emotional events suggest that central details are better retained than peripheral details. Yet, the findings regarding an association between emotion and detail memory are mixed. Such findings may have been brought about by problems inherent in a field approach. Clearly, more studies relying on real-life stressful situations that are controllable to a certain extent le.g.. Goodman et al., 1991 ) are urgently needed.

\subsubsection{Detail memory in the laboratory and some complications}

Problems inherent in field studies can be circumvented in laboratory experiments " That is, emotionality can be measured during exposure to emotional stimuli and detail information can be manipulated and a priori classified. Table 2.1. (p. 34-35) summarizes a number of experimental studies testing the attentional narrowing hypothesis ${ }^{9}$. The designs of these studies are quite similar. Typically, normal college students are shown a series of slides depicting a story. The middle portion of these slide series is critical, and varies across conditions le.g., emotional versus neutral?. After viewing the slides, subjects are englaged in some filler activity. Subsequently, they are given an unexpected memory test for the details of the slide series.

A first glance at the table suggests that the specific predictions of the attentional narrowing hypothesis are largely confirmed. The overall picture suggests that compared to controls, subjects who saw emotional stimuli: a) displayed higher emotional arousal as

\footnotetext{
The table only includes studies that were explicitly designed to test the attentional narrowing hypothesili. Some of these studies had rather complex designs le.gi., Burke et al, 1991. Christianson \& Loftus, 1987, axp 1 in that they also manipulated testing interwals. For sake of simplicity, the table contains only the variables that are directly pertinent to the attentional narrowing hypothesis li,e., emotional arougal, attention, and detail memoryl.
} 


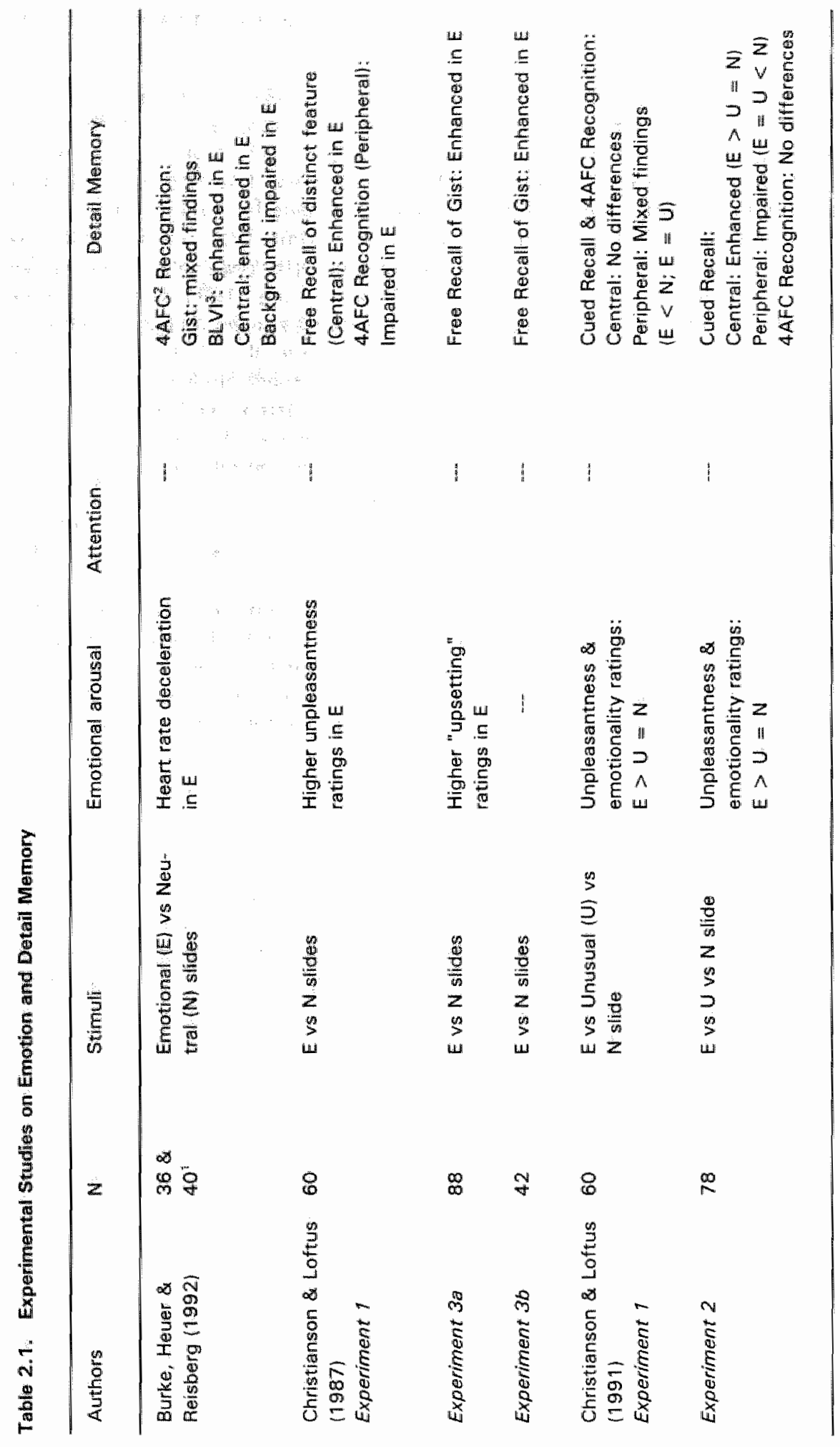

त 


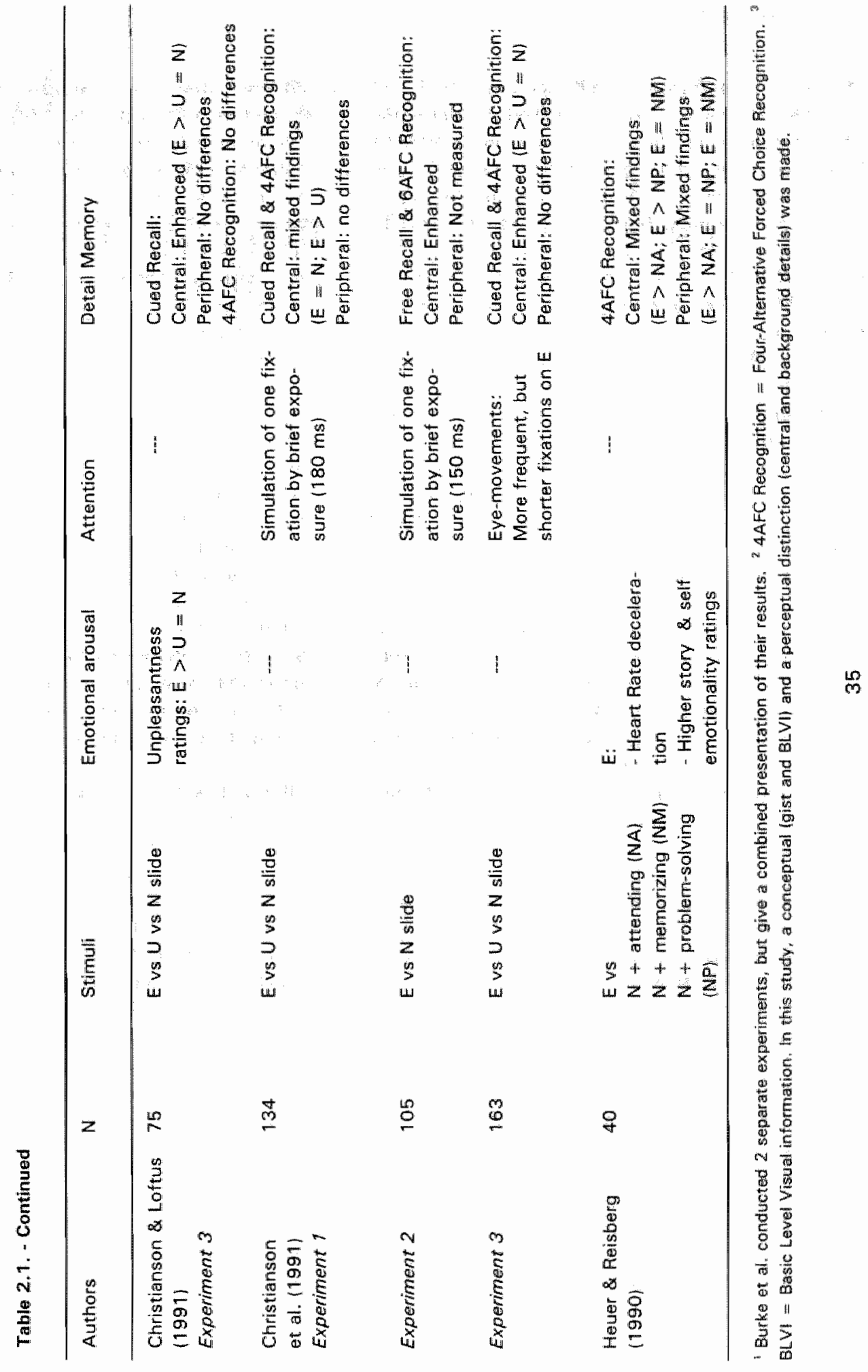


indicated by heartrate or selli-report measures; b) focused their attention as shown by their eyemovements; and c) recalled central details better, and peripheral details poorer.

Yet, a number of observations should be added to this overall picture. To begin with, it should be noted that none of the studies measured emotional arousal, attention, and memory concurrently. Thus, athough the global picture is in accordance with the attentional narrowing hypothesis, the precise relations between arousal, attention, and detail memory are yet to be established. Furthermore closer scrutiny of the column summarizing detail memory results revealls an inconisistent pattern. Perhaps methodological differences are responsible for these inconsistent results. For example, some studies measured memory for only one central and one peripheral detail le.g. Christianson \& Loftus, 1991; Christianson et al., 19911, whereas athers tested memory for a range of details (Burke et al "1992; Heuer \& Reisberg, 1990). The latter method allows for analyses of variance and thus provides a more sensitive test.

More importantly, however, there are a number of fundamental problems inherent in the laboratory approach. The first problem is that in emotion and memory experiments relying on normal subjects, it is inevitable that emotional and neutral stimuli are quite different. Consider, for example, Heuer and Reisberg"s (1990) slide stories, in which a son wisits his father at work, Father is either a mechanic repairing a car (neutral storyl or a surgeon performing surgery on an accident victim lemotional story. It may not seem unusual for a son to visit his father in a garage. However, it is rather surprising -if not unlikely- that a surgeon would allow his child entrance to an operation theatre. Thus, in this type of study, the observed memory effects may be attributable to stimulus characteristics other than emotionality, such as salience. Christianson and Loftus (1991) attempted to unravel salience and emotionality and included an unusual condition in their experiments. Unfortunately, this unusual slide was rated as less attention-catching than the emotional slide. Thus, the issue of salience remains unresolved.

A second problematic issue is that the definition of central and peripheral detail is not entirely clear. Christianson (1992) considers central information to be "information that is connected with the source of the emotional arousal (i.e., the gist of the event and its central details)" and peripheral information as "information that is irrelevant or spatially peripheral to the source of emotional arowsal" (p. 291). Thus, a detail may be classified as central on either conceptual (ite., essential for evoking emotion) or perceptual (i.e., in the centre of the visual field grounds. There is some evidence to suggest that differential recall occurs for details classified according to a perceptual rather than a conceptual distinction (Burke et al. "1992). Thus, an empirical basis for including a conceptual distinc" tion in the definition of central and peripheral detail is lacking. A related problem pertains to setting the boundary between central and peripheral detail. According to Christianson 11992), central and peripheral detail should be viewed as constituting a continuum rather than absolute, dichotomous categories. Yet, it is unclear how to determine, for example, the exact relevance of a particular detail.

In summary, the attentional narrowing hypothesis is supported in that on the whole, results of field studies as well as laboratory experiments on memory for emotional material suggest that central details are well, and peripheral details are poorly remembered. Vet, the evidence is not conclusive. In addition, there are a number of problems with both the fleld and the laboratory approach that need clarification. 


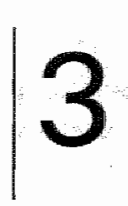

\section{Integration and Aim of the present Dissertation}

\subsection{Recapitulation}

In the first chapter, the claim in clinical literature that trauma frequently results in (partial) amnesia was discussed. It tumed out that the empirical evidence to support this claim is inconclusive. In addition, special mechanism hypotheses for explaining amnesia line., repression and dissociation) suffer from major problems; such as conceptual vagueness, lack of explanatory power, and the impossibility for direct measurement. Still, the assumption that emotion leaves its marks on memory is widespread. Therefore, the second chapter reviewed non-clinical literature on emotion and memory. At first sight; this litera* ture renders mixed findlings: the evidence suggests that emotion in general and autonomic arousal in particular may either enhance or impair memory. Unlike the so-called YerkesDodson law, the attentional narrowing hypothesis appears to provide a suitable explana* tion for such mixed findings. According to this attentional narrowing hypothesis, physiological arousal leads to attentional focusing on central detail information, at the expense of attention for peripheral information. Indeed, results of field studies as well as laboratory experiments on memory for emotional material indicate that central details are well, and peripheral details are poorly remembered. But again, the evidence is not conclusive.

In spite of this, the attentional narrowing hypotheses may provide a more parsimonious and testable account of the effects of trauma on memory than the special mechanism hypotheses of repression and dissociation. In chapter one, it was noted in passing that two seemingly contradictory memory phenomena may be observed in individuals suffering from PTSD: intrusions and partial amnesia. Put differently, PTSD patients may display both an excess and a lack of memory. Bearing the attentional narrowing hypothesis in mind, one might speculate that intrusions reflect the central, threatening information of the traumatic event, whereas partial amnesia pertains to peripheral information of that situation (see Merckelbach \& van den Hout, 1993).

Thus, further exploration of the attentional narrowing hypothesis may be a worthwhile enterprise. There are several problems with the existing research on attentional narrowing. 
Some of these problems were identified in chapter two. The section below provides a short overview of how these and other problems are addressed in the empirical studies that follow in the next chapter.

\subsection{Specific Issues in testing the Attentional Narrowing Hypothesis}

\subsubsection{Physiological arousal, visual attention and memory}

According to the attentional narrowing hypothesis, three variables are important in the formation of emotional memory: physiological arousal, attention, and central and peripheral detail memory. An overview of the existing experimental research testing this hypothesils (table 2.1 ) leads to the conclusion that these three variables were never concurrently measured. The experiment described in section 4.1 addresses this issue and investigates the association between physiological arousal, visual attention (eye-movements), and centrall and peripheral detail memory for emotional slides.

\subsubsection{Differences in stimulus characteristics}

Most experiments on attentional narrowing rely on normal, healthy subjects; who are presented with either emotional or neutral stimuli. Inherent in such approach is that these stimulus materials differ on more dimensions than emotionality alone. Thus, it may be that characteristics other than emotionality are responsible for subsequent memory effects. One possible candidate is the uniqueness of an event, which may enhance memory independent of the emotionality associated with such event. As Brewer (1992) notes, a single visit to a particular shoestore may be better recalled than yet another argument in a long and stormy interpersonal relationship. In addition, experimental studies on the socalled isolation effect show that stimuli that differ from a homogenous context are relatively well recalled (e.g., Fabiani \& Donchin, 1995; Hunt, 1995; Wallace, 1965)".

There are two ways to control for the possible side-effects of using different stimuli. A first approach is to contral for the possible influence of uniqueness by including a control condition in which normal subjects are presented with an unusual stimulus (Christianson \& Loftus, 1991). This approach was followed in the experiments described in sections 4.1 , 4.2 and 4.4. A second approach is presenting the same stimuli to groups of subjects who differ in the way in which they evaluate these stimuli. More specifically, presenting a

\footnotetext{
1 The isoliation foffect is better known as the Von Restorff effect. For many years, the Von Restorff effect was interpreted as the result of perceptual salience: because a critical item violates its prevailing context, it receiver more attentional processing, resulting in enhanced recall. Yet, in a thorough analysis of Von Restorf's (1933) original experimants, Hunt 119951 points out that Von Restorf obtained an isolation effect for critical items that were presented prior to establishment of a context. Thus, perceptual salience is not a necessary requirement, and disimilarity between the critical item and its homogenous context is sufficient for obtaining an isclation effect. Therefore. Hunt argues, it is unjustified to equate the Von Restorff effect with the effects of silience on memory. This is not to say that perceptual salience is unimportant. It should be noted that in experiments pertinent to the current discussion (a.9., Christianson \& Loftus, 1991), a context was established prior to presentation of the critical item. Thus ${ }_{n}$ perceptual salience may still play a role in obtaining onhanced memory for that item.
} 
group of phobics with their feared object would result in anxiety, whereas that object would give rise to little emotion in a non-phobic sample. This approach was followed in the studies reported in sections 4.3 and 4.4 .

\subsubsection{What is central, what is peripheral?}

As was noted in section $2,4.2$, detail information of an emotional event may be cllassified on both conceptual and perceptual grounds. At present, the evidence favours a perceptual classification of detail information. That is, one experiment found impaired recall of peripheral background detail, but not conceptually peripheral information (Burke et al., 1992). It should be noted that in experimental studies employing slides, conceptually irrelevant information is usually also in the background (i.e., spatially peripherall. Thus, the question still remains whether it is conceptual or perceptual relevance that is responsible for the differential recall of central and peripheral information in these experiments. This issue is addressed in section 4.4. This section describes an experiment in which spatial position of conceptually relevant and irrelevant information was manipulated.

\subsubsection{Ecological validity}

To what extent may results from emotion and memory experiments be generalized to reallife traumatic situations? Yuille and Tollestrup (1992) argue that laboratory and real-life events are not comparable, because laboratory subjects are typically uninvolved bystanders in events of low impact (i.e., evoking relatively mild emotion). This position implies that the question of how emotion affects memory may only be addressed by field studies. Yet, the experimental method has the advantage over field studies that it allows for testing the specific predictions flowing from the attentional narrowing hypothesis under controlled conditions. Therefore, Christianson (11992) points out that to become fully informed, researchers should rely on multiple methods ii.e., both field studies and experimental simulations).

In light of this discussion, the studies presented in the next chapter attempted to approach real-life events to a greater extent than is usually the case in emotion and memory experiments. Yuille and Tollestrup (1992) suggest that the differences between laboratory and real-life situations lie in involvement and emotionality of the subjects. Thus, several strategies were employed. First, in order to increase involvement, normal college students were given extensive self-relevant instructions prior to viewing slides. Two experiments using this manipulation are described in sections 4.1 and 4.2 . The second strategy consisted of obtaining higher levels of emotionality than in experiments relying on normal subjects. For this purpose, phobic subjects were confronted with their feared object. These experiments are described in sections 4.3 and 4.4 . Finally, section 4.5 describes a field study in which college students were asked about the characteristics of their most traumatic memory. 
4

Empirical Studies 


\title{
4.1
}

\section{Arousal, Visual Attention and Detail Memory}

\begin{abstract}
Summary
The present study examined the attentional narrowing hypothesis of emotional memory. This hypothesis states that physiologicall arousal leads to attentional focussing. thus enhancing momory for central information, but impairing memory for peripheral information. $\| n$ a preliminary study, newly developed stimulus material was tested: An emotional target slide differed from unusual and neutral shides with respect to emotionality, but was rated equally outstanding as the unusual slide. In the main experiment, subjects siaw this stimulus material while physiological arousal, eye-movements, and detail memory were measured. Although the emotional condition displayed longer fixation durations on the central item, and shorter fixations on the peripheral item of the target slide than the neutral condition, fixation patterns did not differ when the emotional condition was comparad to the unusual condition. In addition, no differential effects on memary were obtained. Taken together, the findings are inconsistent with the attentional narrowing account of emotional memory.
\end{abstract}

\section{Introduction}

The question of how the details of emotional events are remembered has received considerable attention in recent years (see for reviews, Christianson, 1992; Egeth, 1994). Following Easterbrook's (1959) cue-utilization hypothesis, Christianson (1992) argues that detail information of emotional events are differentially recalled due to attentional narrowing. That is, in emotionally arousing situations, attention would be directed to information associated with the gist of emotional scenes (central details) rather than irrelevant information (peripheral details). This, in turn, would result in better recall of central information and poorer memory for peripheral information. Accordingly, two variables are

The four studies reported in section 4.1 and 4.2 are described in a single paper: Wested, 1 , van der Kooy, $P$, \& Merckelbach, H. Arousal, attention and memory: Circurnstantial evidence for the attentional narrowing hypothesis. Submitted for publication. 
important for emotional memory formation: physiological arousal and attention.

As for the first variable, detail memory studies consistently show that emotional scenes produce higher self-report ratings of emotionality (Christianson \& Loftus, 1987; 1991; Hever \& Reisberg, 1990) or larger physiological responses (Burke et al. 1992; Heuer \& Reisberg, 19901 than do neutral scenes. Consistent with the attentional narrowing hypothesis, in these studies central details were relatively well recalled, whereas memory for peripheral details was relatively poor (Burke, Heuer \& Reisberg, 1992; Christianson \& Loftus, 1987; 1991; but see Heuer \& Reisberg, 1990 ).

The second variable involves visual attention. It is generally assumed that eye fixation patterns reflect visual attention (Christianson, Loftus, Hoffman \& G.R. Loftus, 1991; G.R. Loftus, 1972; Loftus, G.R. Loftus \& Messo, 1987٪. Studies measuring eye-movements suggest that compared to neutral scenes, emotional scenes elicit longer fixation durations (Loftus et al., 1987) or a higher frequency of fixations (Christianson et al., 1991; Loftus et al., 1987) on central features. These studies found, again, that central details of emotional material were better (Christianson et ai., 1991), and peripheral details were poorer recalled (Loftus et al., 1987) than those of neutral material.

Taken together, the attentional narrowing hypothesis is supported by studies measuring memory for arousing stimuli and by studies examining visual attention and memory. However, as yet, no study on detail memory has concurrently measured arousal, visual attention, and detail memory. For this reason, the present study aimed at testing the attentional narrowing hypothesis by employing measures of these three variables in one sample.

Two additional issues were addressed. The first issue concerns the question whether attentional narrowing is restricted to emotional events. It could be argued that emotional events are not only emotional, but also quite unusual in the course of daily life. There are reasons to believe that unusual stimuli are differently remembered or attended to than neutral stimuli. First, studies of the so-called isolation effect show enhanced memory for outstanding stimuli in a homogenous context isee Hunt, 1995). Second, eye-movement data indicate that people fixate longer and more often on unusual objects compared to objects that are to be expected given the context (G.R. Loftus \& Mackworth, 1978). In order to control for the outstanding properties of an emotional stimulus, Christianson and colleagues included an unusual condition in their experiments /Christianson \& Loftus, 1991: Christianson al., 1991). On the whole, these studies yielded conflicting results. One study (Christianson et al., 1991) found that eye-movements and detail memory performance in the unusual and neutral conditions were rather similar. In contrast, Christianson and Loftus (11991) found that viewing the unusual scene resulted in impaired recall of both central and peripheral items. Put differently, in the unusual condition, central detail memory resembled that of the neutral condition, whereas peripheral detail memory matchad that of the emotional condition. These results may be attributed to the finding that the unusual scene was rated as less attention-catching than the emotional scene. Whatever the cause, the influence of unusualmess needs further clarification.

A second issue addressed in the present study pertains to ecological validity. A general criticism of laboratory studies on emotion and memory is that they are too far removed from reallife situations, because subjects are uninvolved bystanders in events of low limpact (see Yuille \& Tollestrup, 1992). For this reason, the present study attempted to maximize involvement by instructing the subjects to imagine that they were the main 
character in a slide story.

In sum, then, the present paper describes an experiment in which physiological arousal, visual attention, and memory were measured in subjects who saw either an emotional, unusual or neutrall slide. Given the problems with the unusual scene in the Christianson and Loftus (1991) study, we developed new stimulus material. This material was tested in a preliminary study that will be described first.

\section{Preliminary Study}

The purpose of this preliminary study was to evaluate our newly developed stimullus material with regard to dimensions such as emotionality and credibility. The stimultus material was modeled after that of Christianson and Loftus (1991).

\section{Method}

\section{Subjects}

Thirty female and three male undergraduates in Health Sciences were randomly assigned to one of three conditions 110 women and 1 man in each condition). Their mean age was 21.0 years (range $19-26$ years).

\section{Stimulus material}

The stimulus material consisted of a thematic series of 15 slides. The slide series was about a student who went on the way to university to do an oral exam. The slides depicted typicall scenes that a student would encounter in such a situation le.g., a bedroom, a kitchen: a street, etc./. Each slide contained two critical items, of which one was central and one was peripheral. The slide series were equal for three versions, with exception of the eighth, critical slide. In this critical slide, the central detail varied across conditions. In the emotional version, a nine-year old girl was lying on a pedestrian crossing, bleeding from a head injury. In the unusual version, the same girl was seen lying on the pedestrian crossing in a gymnastic position (i.e., holding both legs into the air). In the neutral version, the girl was walking on the pedestrian crossing. The position of the girl on the pedestrian crossing and the angle in which the photograph was taken were identical in each version. The peripheral detail in each of the critical slides was a pink bicycle standing near the right margin of the slide.

\section{Apparatus}

A Kodak carousel projected slides on a white wall approximately $2 \mathrm{~m}$ in front of the seated subjects. The projected images were $125 \times 85 \mathrm{~cm}$.

During slide presentation. Skin Conductance Responses (SCRs) were recorded through 
two Beckman Ag-AgCl electrodes attached to the second and third finger of the subject's non-dominant hand. Electrodermal recording sites were cleansed with distilled water. Electrodes were connected to a Schwartzer EDA coupler. To record SCRs, the method of constant voltage $1.5 \mathrm{~V}$ ) was used. SCRs were measuired in microsiemens and were defined as the largest response with onset during slide presentation.

\section{Procedure}

Subjects were told that the purpose of the study was measuring physiological reactivity to a series of slides. After SCR electrodes had been fastened, subjects were informed about the theme of the story. Subjects were instructed to imagine that they were the main character. They were told that every scene was photographed from their perspective, as if it were seen through their own eyes. In addition, subjects received the following taperecorded instruction immediately before presentation of the slides.

You are a student in Health Sciences. You are living with several people in a student dom. You like it there: you are always having a good time. In fact, you are having such al good time, that you spend too little time studying. Recently, you falled an exam for that reason. Only a few people failed the exam. Therefore, the professor did not think it was necessary to give another written test, but decided to give an oral exam. This time, you are wellprepared and you feell confident that vou will pass. Today is the diay of the exam. Your appointment is at 10.30 am. It is now morning and you just woke up. You slept well and you feel rested. This is what you see:

Slides were presented for $4 \mathrm{~s}$, with an interstimulus interval of $5 \mathrm{~s}$. After viewing the slide series, subjects were given several $100 \mathrm{~mm}$ Visual Analogue Scales (VASs) and were asked to rate the global story on the following characteristics: 1) the extent to which they could identify with the story $10=$ not at all, $100=$ very good ; 2$)$ the credibility of the story $(0=$ not at all, $100=$ very credibie); 3$)$ the emotionality of the story $10=$ not at all, $100=$ very emotional); 4) the pleasantness of the story $10=$ not at all, $100=$ very pleasant). In addition, subjects wrote down which slide they remembered best. Next, they chose from a list which slide they thought to be the most outstanding. In addition, they rated the oustanding properties of this selected slide on a $100 \mathrm{~mm}$ VAS $10=$ not at all. 100 - very outstandingl. Finally, the critical eighth slide was presented and subjects rated the following characteristics on $100 \mathrm{~mm}$ VASs: 1) the emotionality of the slide $10=$ not all al 100 very emotionall; 2) the pleasantness of the slide $10=$ not at all, $100=$ very pleasant); 3 ) the outstandingness of the girl $10=$ not at all, $100=$ very outstand$(i n g) ; 4)$ the outstandingness of the bicycle $10=$ not at all, $100=$ very outstanding $)$.

\section{Results and Discussion}

Means of the VAS and SCR scores for the three conditions are shown in table 4.1.1. The VAS and SCR data were analyzed by means of oneway Analyses of Variance (ANOVAs), with Tukey"s post hoc comparisons where appropriate. 
Table 4.1.1. Mean VAS Ratings and UsCRs for the Emotional, Unusual, and Neutral Conditions. Standard Deviations are in Parentheses

\begin{tabular}{llll}
\hline & $\begin{array}{l}\text { Emotional } \\
\text { Condition } \\
(n=11)\end{array}$ & $\begin{array}{l}\text { Unusual } \\
\text { Condition } \\
(n=11)\end{array}$ & $\begin{array}{l}\text { Meutrai } \\
\text { Condition } \\
(n=11)\end{array}$ \\
\hline $\begin{array}{l}\text { Global Story } \\
\text { Identification } \\
\text { Credibility }\end{array}$ & $53.6(18.1)$ & $59.9(23.3)$ & $57.7(1.4 .9)$ \\
Emotionality & $56.5(23.9)$ & $65.9(19.0)$ & $75.3(15.2)$ \\
Pleasantness & $43.9(17.3)$ & $29.0(16.0)$ & $33.6(17.3)$ \\
Critical Slide & $36.7(20.7)$ & $54.2(16.7)$ & $4.3 .3(20.1)$ \\
JSCR & $0.44(0.21)$ & $0.33(0.40)$ & $0.20(0.19)$ \\
Emotionality & $80.0(12.2)$ & $54.6(20.7)$ & $36.3(24.8)$ \\
Pleasantmess & $13.6(11.3)$ & $58.1(29.4)$ & $51.7(14.3)$ \\
Outstandingness Girl & $70.0(32.1)$ & $71.4(28.2)$ & $56.8(28.0)$ \\
Outstandingness Bicycle & $37.6(39.7)$ & $34.7(31.0)$ & $39.1(31.1)$ \\
\hline
\end{tabular}

Note. $\sqrt{ } \mathrm{SCR}=$ Square-rooted Skin Conductance Responses

\section{Global story ratings}

The three conditions did not differ regarding ratings of identification, $F(2,30)=.31, p=$ .74 , emotionality, $F(2,30)=2.34, p=.11$, or pleasantness, $F(2,30)=2.32, p=.12$. However, credibility ratings reached borderline silgnificance, $F(2,30)=2.51, p=.09$.

\section{Critical slide}

SCRs were normalized by means of a square-root transformation ( $\mathrm{S} S \mathrm{C}$ ). Due to experimental failure, the SCR data of one subject in the emotional condition were lost.

The oneway ANOVA did not yield a significant effect, $F(2,29)=1.92, p=.17$. However, the emotionality and pleasantness ratings of the critical slide showed highly significant differences between conditions, $F(2,30)=13.35, p<.001$, and $F(2,30)=$ $16.02, p<.001$, respectively. Post hoc comparisons indicated that these effects were accounted for by the high emotionality and low pleasantness ratings in the emotional condition. The outstanding properties of the central girl and the peripheral bicycle were not rated differently in the three conditions, $F(2,30)=0.82, p=.45$ and $F(2,30)=$ $0.05, p=.95$, respectively. Thus, the central item was judged equally outstanding within the context of the three critical slides. Within the context of the story, however, the critical slide was chosen to be the most outstanding by 8,9, and 1 subjects in the 
emotional, unusual and neutral conditions, respectively. This difference was significant, $X^{2}(2)=13.9, p<.001$. Separate $X^{2}$ analyses indicated that the critical slide was chosen more often in the emotional and unusual condition than in the neutral condition, Fisher's Exact $p<.01$, and $X^{2}(1)=11.7 . p<.001$, respectively. A $t$-test revealed that the subjects who chose the critical slide in the motional and unusual conditions judged this slide as being equally outstanding, $t(15)=0.26, p=0.23$.

The number of subjects who found the critical slide most memorable was 10 for the emotional condition, 4 for the unusuall condition, and 1 for the neutral condition. This difference was significant, $X^{2}(2)=15.4, p<001$. Separate $X^{2}$ analyses showed that the emotional condition significantly more often selected the critical slide than the unusual condition, Fisher's exact $p<.05$, and the neutral condition, $X^{2}(1)=14.7, p<.001$.

In sum, then, this preliminary study showed that the stimulus material we developed was appropriate for testing the attentional narrowing hypothesis. More specifically, the emotional slide was rated less pleasant and more emotionall than the unusual and the neutral slides. Accordingly, the emotional slide evoked higher SCRs than the other slides, although this difference failed to attain significance. This absence of differential SCRs may be due to the small sample sizes (and consequently, reduced power'. Furthermore, the unusual slide matched the emotional slide in terms of its outstanding properties. Thus, employing the unusual condition allowed controlling for the unexpected nature of an emotional event.

\section{Main Experiment}

The main purpose of experiment 1 was testing the attentional narrowing hypothesis. More specifically, two predictions were examined. First, with respect to eye-movements, it was predicted that the emotional scene would elicit longer fixations on the central item and shorter fixations on the peripheral item. A reverse pattern was expected in the unusual and neutral conditions. Given the sample sizes, it was also anticipated that subjects in the emotional condition would react with larger SCRs than subjects in the other conditions. The second prediction was that, compared to the neutral and the unusual conditions, the emotional condition would give rise to better memory for central information and impaired memary for peripheral information.

\section{Method}

\section{Subjects}

Subjects were 63 female undergraduate students in Health Sciences at Limburg University. Their mean age was 20 years (range $18-27$ years). They were randomly assigned to one of three conditions Emotional Condition, $n=22$; Unusual Condition, $n=21$; Neutral Condition, $n=20$ ). Subjects were paid the equivalent of $\$ 10$ for their participation. 


\section{Stimulus Material and Apparatus}

Stimulus material, as well as the methods and apparatus for slide projection and SCR recording were the same as in the preliminary study.

During slide presentation, eye-movements were registered using an Eyemark Recorder (model V. NAC Inc.). This recorder projected infrared lights on subjects' corneas, which were transformed into fixation spots. Fixation spots were imposed on the image recorded by a video camera on subjects' foreheads. Subjects' heads were fixated during slide presentation in order to avoid head movements.

\section{Procedure}

Subjects were tested individually in a sound-attenuated, dimly lit room. Upon arrival in the laboratory, subjects were told that the experiment involved recordling of their physiological reactions to a series of slides. No explicit mention of a memory task was made. Next, SCR electrodes were attached and the Eyemark Recorder was positioned and calibrated.

Following this, subjects were given the same instructions as in the preliminary study. Immediately after the tape-recorded instruction, the first slide (depicting a bedroom) was presented. Slides were presented for $4 \mathrm{~s}$, and intervals between slides were $6.6 \mathrm{~s}$. After slide presentation, the SCR electrodes and the Eyemark recorder were removed. Next, subjects completed filler questionnaires for 10 minutes.

Subsequently, subjects were given three memory tasks. First, they completed a Free Recall task in which they were asked to briefly describe all the slides they had seen. Second, a Cued Recall task was administered. Subjects were presented with a series of 15 slides, similar to the first series, with the exception that the central and peripheral items were removed. During presentation of each slide, subjects wrote down which items from that slide were missing. Third, subjects completed a Detalled Cued Recall task. For this purpose, the critical eighth slide without the central girl and peripheral bicycle was presented. Subjects were instructed to describe the missing items as detailed as possible, with respect to colour, shape, size, position, and so forth. For completion of all recall tasks, subjects were allowed as much time as they neaded. Finally, subjects were debriefed and were asked not to discuss the purpose of the studly with other students.

\section{Scoring of physiological data}

Due to apparatus failure, SCRs of one subject in the unusual condition were lost. SCAs to the critical slide were square-root transformed in order to normalize the distribution.

Eye-movements were scored as follows. First, a digital clock was recorded on the videotapes, which indicated time with an accuracy of $0.01 \mathrm{~s}$. Then, the videotapes were played back frame by frame. Three observers simultaneously scored the amount of time subjects looked at the central girl or the peripheral bicycle. In order to do so, the judges had to agree at which time the subjects' eyes arrived at a particular detail and at what time the eves shifted away again. The fixations within a particular detail le.g., shifting the eyes from the girl's head to her feet) were not scored separately, because the interfixation 
distances were to short to obtain accurate judgements. Due to calibration problems with the Eyemark recorder, the data of 12 subjects were unreliable (emotional condition, $n=$ 3; unusual condition, $n=6$; neutral condition $n=3$ ).

\section{Results}

SCRis

Table 4.1.2. gives the means and standard deviations of the $\sqrt{S C R}$ in the three conditions. A oneway ANOVA showed a significant difference between conditions, $F(2,59)=$ $7.35, p<.01$. Planned comparisons revealed that the emotional slide elicited significantly higher SCRs than either the unusual or the neutral slide $\mid p^{\prime} s<.05 \rrbracket$.

Table 4.1.2. Mean VSCRs in the Emotional, Unusual, and Neutral Conditions. Standard Deviations are in Parentheses

\begin{tabular}{llll}
\hline & $\begin{array}{l}\text { Emotional } \\
\text { condition } \\
(n=22)\end{array}$ & $\begin{array}{l}\text { Unusual } \\
\text { condition } \\
(n=20)\end{array}$ & $\begin{array}{l}\text { Neutrall } \\
\text { condition } \\
(n=20)\end{array}$ \\
\hline SSCR & 0.73 & 0.38 & 0.23 \\
& $(0.58)$ & $(0.36)$ & $(0.27)$ \\
\hline
\end{tabular}

$\checkmark S C R=$ Square rooted Skin Conductance Responses

\section{Eye-movement data}

Mean fixation times were subjected to a 3 (conditions) $\times 2$ (central vs, peripheral detail) ANOVA with repeated measures on the last factor. Significant main effects were found for condition, $F(2,48)=5.21, p<.01$, and detail, $F(1,48)=42.02, p<.001$. In addition, the critical interaction effect was significant, $F(2,48)=4.68, p<.05$ (see figure 4.1 .1$. .

In order to break down this interaction, three separate 2 (condition) $\times 2$ (detail) repeated measures ANOVAs were conducted. Relative to the neutral condition, the emotionall condition displayed longer fixations on the central girl and shorter fixations on the peripheral bicycle, as evidenced by a significant interaction effect $F(1,34)=7.11, p<$ .05. However, mean fixation time patterns in the emotional and unusual conditions did not differ, $F(1,32)=1.97, p=.17$. For the unusual and neutral groups the group by detail interaction effect attained borderline significance, $F(1,30)=4.16, p=.05$. 


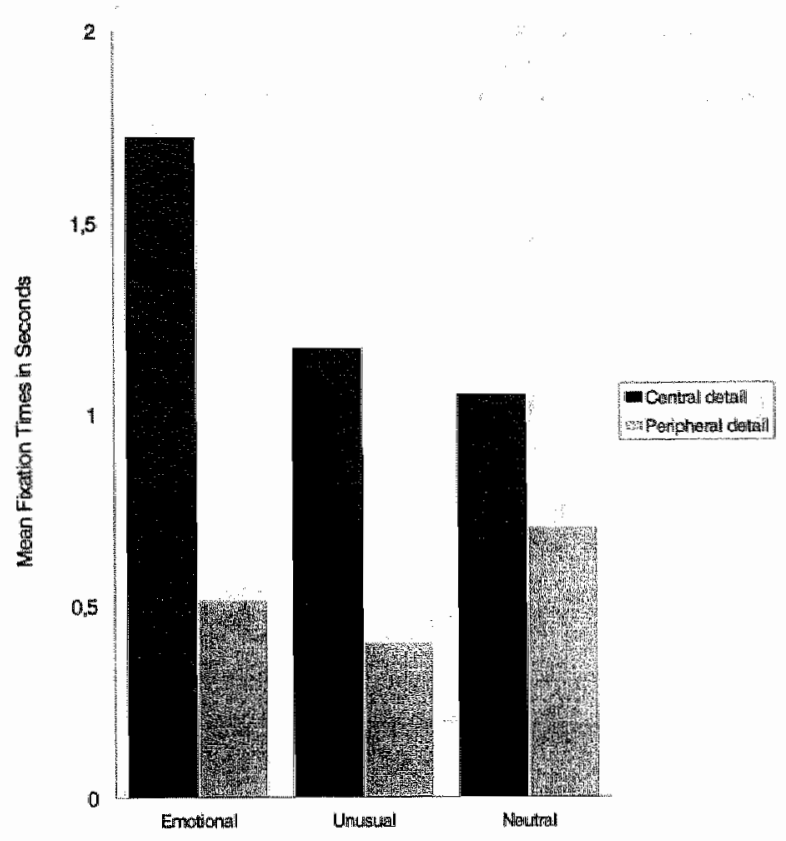

Figure 4:1.1.

Mean The per Flxation on the Contral and Perlpheral Item in the Emotional, Unusual and Neutral Conditions

Recall

The results of the memory tests are presented in table 4.1.3. For free recall, there was a significant difference between conditions with regards to number of subjects reporting the central girl, $X^{2}(2)=7.24, p<.05$. Separate $X^{2}$ tests showed that, compared to the neutral condition, significantly more subjects in the unusuall condition reported the central girl. $X^{2}(1)=7.43, p<.01$. The emotional condition did not differ from either the unusual or the neutral condition. There were no differences between conditions in free recall of the peripheral bicycle, $\mathrm{X}^{2}(2)=0.29, p=.86$. For cued recall, neither the central girl $X^{2}(2)=3.91, p=.14$, nor the peripheral bicycle, $X^{2}(2)=0.59, p=.74$, were differenty recalled across conditions.

Responses to the detailed cued recall test were first transformed into proportions of the total number of characteristics that could be mentioned for each item 112 for the bicycle in every condition; 18 for the central girl in the emotional and unusual slides; and 15 for the girl in the neutral slide). Next, these proportions were analyzed with a 3 (conditions) $x$ 2 (central vs, peripheral detail ANOVA with repeated measures on the last factor. A significant main effect for detail emerged, $F(1,60)=5.70, \rho<.05$. The main effect for condition was nonsignificant, $F(2,60)=0.33, p=.72$. The critical interaction effect, which would indicate differential recall of central and peripheral characteristics across conditions, did not reach significance, $F(2,60)=0.07, p=.93$. 
Table 4.1.3. Recall of Central and Peripheral Information of the Critical Slide in the Emotional, Unusual and Neutral Coinditions

\begin{tabular}{|c|c|c|c|}
\hline $\begin{array}{lll}2 & \\
\end{array}$ & $\begin{array}{l}\text { Emotional } \\
\text { Condition } \\
l n=22)\end{array}$ & $\begin{array}{l}\text { Unusual } \\
\text { Condition } \\
(n=21)\end{array}$ & $\begin{array}{l}\text { Neutral } \\
\text { Condition } \\
{[n=20 \mid}\end{array}$ \\
\hline \multicolumn{4}{|l|}{ Free Recall } \\
\hline Central & 72.7 & 95.2 & 60.0 \\
\hline Peripheral & 46.5 & 38.1 & 45.0 \\
\hline \multicolumn{4}{|l|}{ Cued Recalla } \\
\hline Central & 72.7 & 95.2 & 80.0 \\
\hline Peripheral & 68.2 & 57.1 & 65.0 \\
\hline \multicolumn{4}{|l|}{ Detalled Cued Recall } \\
\hline Central & $.28(.11)$ & $.25(.10)$ & $.26(.11)$ \\
\hline Peripheral & $.22(.98)$ & $.21(.16)$ & $.20(.16)$ \\
\hline
\end{tabular}

"Percentage of subjects who answered correctly; Mean proportion characteristics

\section{Correlational Analyses}

The attentional narrowing hypothesis explicitly states that a high level of physiological arousal leads to attentional narrowing. which, in turn, has ramifications for detail memory. Associations between arousal, eye-movements and detail memory were explored in the following way. First, correlations between mean fixation times and memory were calculated li.e., biserial correlations for free and cued recall; Pearson product-moment correlations for detailed cued recall). As can be seen in table 4.1.4a, central mean fixation times and central detail memory were mot significantly correlated.

However, inspection of table $4.1 .4 \mathrm{~b}$ reveals significant correlations between peripheral mean fixation time and cued recall, $r(51)=.33, p<0.01$, one-tailed as well as detailed cued recall, $r(51)=.25, \rho<0.05$, one-tailed. In order to explore to what extent these associations were mediated by arousal, SSCR was partialled out. The partial correlations were rather similar, that is, $r(50)=.34$, and $r(50)=.26$ for peripheral mean fixation time with peripheral cued recall and peripheral detailed cued recall, respectively".

The $n$ of 50 is due to missing SCR data for one subject. 
Table 4.1.4a. Correlations between Mean Fixation Time and Recall of the Central Item

\begin{tabular}{|c|c|c|c|}
\hline & $\begin{array}{l}\text { Free Recall } \\
\text { Central Item }\end{array}$ & $\begin{array}{l}\text { Cued Recall Cen- } \\
\text { tral litem }\end{array}$ & $\begin{array}{l}\text { Detailed Cued } \\
\text { Recall Central Item }\end{array}$ \\
\hline $\begin{array}{l}\text { Mean Fixation Time } \\
\text { Central ltem }\end{array}$ & $\begin{array}{l}16 \\
n=51 \\
p=.13\end{array}$ & $\begin{array}{l}16 \\
n=51 \\
p=.13\end{array}$ & $\begin{array}{l}.01 \\
n=51 \\
p=.48\end{array}$ \\
\hline
\end{tabular}

Significance levals are one-tailed

Table 4.1.4b. Correlations between Mean Fixation Time and Recall of the Peripheral Item

\begin{tabular}{|c|c|c|c|}
\hline & $\begin{array}{l}\text { Free Recall } \\
\text { Peripheral Item }\end{array}$ & $\begin{array}{l}\text { Cued Recall } \\
\text { Peripheral Item }\end{array}$ & $\begin{array}{l}\text { Detailed Cued } \\
\text { Recall Periphertil } \\
\text { Item }\end{array}$ \\
\hline $\begin{array}{l}\text { Mean Fixation Time } \\
\text { Peripheral Item }\end{array}$ & $\begin{array}{l}.23 \\
n=51 \\
p=.05\end{array}$ & $\begin{array}{l}.33 \\
n=51 \\
p<.01\end{array}$ & $\begin{array}{l}.25 \\
n=51 \\
p<.05\end{array}$ \\
\hline
\end{tabular}

Significance levels are one-tailed

\section{Discussion}

The main results can be summarized as follows. First, the emotional slide evoked substantially higher arousal responses (SCRs) than the unusual and the neutral slides. Second, relative to the neutral condition, subjects in the emotional condition spent more time looking at the central girll and less time looking at the peripheral bycicle. However, no such differential pattern emerged when the emotional condition was compared to the unusual condition. Third, regarding memory for central and peripheral information, the emotional group did not differ from either the neutral or the unusual group.

The eye-movement patterns elicited by the emotional scene are in line with earlier findings (Loftus et al, 1987) that people tend to focus for longer durations on a threaten. ing than on a neutral object. Yet, Christianson and co-workers (1991) found that emotional material elicited shorter fixation durations. The latter finding is not necessarily inconsistent with the present results. Christianson and co-workers (1991) reported a substantially higher number of fixations within a stimulus presentation time that was shorter (i.e., $2.7 \mathrm{sec}$ ) than the one employed in the present study (i.e., 4 sec). Presumably, these authors separately scored fixations on any part of an item, whereas the present study measured the amount of time subjects looked at a particular item as a whole. The relatively long fixation durations in the present study may thus reflect multiple fixations within one and the same item.

The finding that the emotional and neutral conditions yielded similar recall patterns is 
inconsistent with results of earlier detail memory studies le.g., Burke et al., 1992; Christianson \& Loftus, 1987; 1991). This may be due to methodological differences. Compare, for example, the present approach with the design employed by Christianson and Loftus 11991). To begin with, Christianson and Loftus tested recall of one particular characteristic of their central and peripheral items (the colour of the main characters' coat and the colour of a car in the background, respectively). It could be argued that our response categories of "girl" and "bicycle' were simply too crude and that testing recall for colours would have revealed differences between conditions. Yet the present finding that all groups reported a similar number of specific characteristics during the detailed cued recall task speaks against such an interpretation. We see no reason why only memory for colour-related characteristics would display a differential pattern. A second issue is that we used substantially longer presentation and interstimulus times than Christianson and Loftus did. It is conceivable that differences in detail memory are more pronounced when subjects have less time for encoding. A third methodological difference is that Christianson and Loftus merely instructed their subjects to closely attend to the stimulus material. In the present study, subjects were instructed to identify with the slide story in order to increase their involvement. Possibly, this instruction led to more elaboration and a more balanced encoding of both central and peripheral items in all conditions.

The attentional narrowing hypothesis predicts that under conditions of high physiologicral arrousal, attention will be focused on the central aspects of an event, at the cost of attention for peripheral information, resulting in differential recall. At first sight, a part of this prediction is supported by the finding that compared to the neutral condition, the emotional group displayed higher SCRs, longer fixations at the central girl, and shorter fixations at the peripheral bicycle. However, a number of considerations preclude a straightforward interpretation of these findings.

First, the correlational analyses did not show a direct link between fixation duration and central detail memory. The significant correlations between memory for peripheral dietail and peripheral fixation duration provide only weak support for the role of attentional narrowing in emotional memory. Partialling out arousal did not essentially change the correlations, indicating that arousal did not contribute to the association between peripheral fixation durations and recall.

Second, it caninot be ruled out that it is the unusual character of an emotional scene that alicits attentional narrowing. The unusual condition did not differ from the emotional condition with respect to eye-movement patterns. Moreover, compared to the neutral condition, the unusual condition displayed a tendency to look longer at the central girl and shorter at the peripheral bicycle. In addition, the unusual group more often reported the central item at free recall than the neutral condition, whereas the emotional group did not display such recall pattern.

In sum, then, the present data support the assumption that emotional material elicits narrowing of visual attention. However, the present data also indicate that attential narrowing in itself is not sufficient for producing differential recall patterns. Also, attentional narrowing may not be specific for ernotionality, but may also be brought about by the unusual nature of a scene. This issue, as well as methodological differences between the present study and earlier detail memory studies (e.g., short interstimulus intervals) need clarification. 


\section{2}

\section{Circumstantial Evidence for Attentional Narrowing}

\section{Summary}

The studies in the present section examined what specific experimental parameters could be responsible for the contradictory findings of Christianson and Loftus (1991) and the experiment described in section 4 . II. Two experiments are reported. Experiment 1 followed the same procedure as Christianson and Loftus, and rendered similar recall patterns. Experiment 2 followed the same procedure as described in section 4.1 , but systemat cally varied stimulus exposure and interstimulus interval durations The results indicated that such variations only played a minor rale in modulating recall patterns for emotional material. Taken together, the contradictory results of experiment 1 and 2 may be best explained by the type of instruction employed. It may be that identification insitructions encourage subjects to angage in a top-down encoding strategy, overshadlowing the acculrate encoding of perceptual information.

\section{Introduction}

The previous section described an experiment which attempted to evaluate the attentional narrowing hypothesis by concurrently measuring autonomic arousal, eye movement patterns, and central and peripheral memory. Although subjects in the emotional condition displayed eye-movement patterns consistent with this attentional narrowing hypothesis, no clear-cut effects on recall were observed. The latter finding contradicts the results of earlier attentional narrowing studies, indicating that central details of emotional scenes are better, and peripheral details are more poorly recalled le.g., Burke, Hewer \& Reisberg, 1992; Christianson \& Loftus, 19911.

The experiment in section 4.1. roughly followed the procedure employed by Christianson and Loftus (1991). Yet, it should be noted that both studies differed in three

The four studies reported in section 4.1 and 4.2 are described in a single paper: Wessel, 1 , van der Kooy, P., 8 Merckelbach, H. Arousal, attention and memory: Circumstantial evidence for the attentional narrowing hypothesis. Submitted for publication. 
important respects. To begin with, Christianson and Loftus specifically asked for colours associated with the central and peripheral items. In contrast, we employed various tasks involving memory for the central and peripheral items as a whole. Second, Christianson and Loftus instructed their subjects to closely attend to the slides, whereas we attempted to maximize involvement of our subjects by giving an extensive, self-relevant instruction. Third, compared to the Christianson and Loftus study (e.g., experiment 2), we employed longer stimulus presentation times ( 3 vs. 4 s) and interstimulus intervals (1) vs. $6.6 \mathrm{~s}$ ).

In light of this, the question arises whether attentional narrowing only interacts with memory under specific conditions le.g., the circumstances that were present in the Christianson and Loftus study). This point is of importance because attentional narrowing is thought to provide an explanation for real-life phenomena such as eyewitness memory (see Christianson, 1992y. Thus, it is assumed that the attentional narrowing effect on memory is an effect that occurs in a wide variety of situations rather than a phenomenon that critically depends on some subtle parameters. The present section describes two experiments that aimed to shed some light on this issue.

\section{Experiment 1}

The purpose of experiment 1 was replicating the Christianson and Loftus (1991) study, using the stimuli described in section 4.1. Specifically, subjects were merely instructed to attend to the slides, which were presented for relatively short durations. In addition, only memory for colours associated with the central and peripheral items was tested.

\section{Method}

\section{Subjects}

Subjects were 86 undergraduate volunteers. Their mean age was 20.6 years Irange 18 36 vears!. They were randomly assigned to one of three conditions (Emotional Condition. $n=32$; Unusual Condition; $n=24$; Neutral Condition, $n=30$ ).

\section{Stimulus Material and Apparatus}

The stimulus material consisted of the thematic slide series described in section 4.1. Slides were projected by a Kodak Carousel projector on a screen in front of a classroom.

\section{Procedure}

Subjects were tested in a classroom after an introductory psychology course about an unrelated topic. They were asked to participate in a short experiment. Next, the class was divided into three groups. One group was tested at a time, while the subjects in the other groups left for a coffee-break. First, the emotional condition was run, then the neutral 
version, and finally the unusual condition.

Subjects were told that they would see a series of slides and afterwards would perform a drawing task. Before the slide series was projected, subjects were informed that the slides depicted situations one could encounter on the way to university to take an oral exam. Contrary to the procedure described in section 4.1 , no further instructions were given to enhance identification with the story depicted in the slideseries. Subsequently, the slide series was presented. Slide duration was $3 \mathrm{~s}$, and interstimulus intervals were 1 s. Immediately after slide presentation, subjects performed a filler task. This task consisted of copying geometric figures that were presented on the screen by an overhead projector. Subjects were given $30 \mathrm{~s}$ time for each figure. In total, thev copled 8 figures. Next, a surprise cued recall task was administered. For this purpose, a version of the critical eighth slide was presented, from which the central girl and the peripheral bicycle were removed (see section 4.1 ). Subjects were asked to write down the colour of the blouse the person missing from the slide was wearing. They were also asked to write down the colour of the missing bicycle. Subjects were allowed 40 seconds for each question. Subjects were asked not to discuss the experiment with other students. To prevent them from talking, they left class through the emergency exit, while the subsequent group waited in front of the opposite main entrance.

\section{Results and Discussion}

Table 4.2.1. summarizes the percentages of subjects who accurately reported the colour of the central girl's blouse (white) and the colour of the peripheral bicycle (pink/red).

Conditions significantly differed with regard to memory for the central detail, $X^{2}(2)=$ $8.45, p<.05$. Separate $X^{2}$ analyses indicated that subjects in the emotional condition more often reported the accurate colour of the blouse than subjects in either the unusual condition, $\mathrm{X}^{2}(1)=5.73, p<.05$, or the neutral condition, $\mathrm{X}^{2}(1)=6.46, p<.05$. As for the colour of the peripheral bicycle, results were in the expected direction, but failed to reach significance, $X^{2}(2)=0.58, p=.75$.

In sum, the results on central detail information are in line with those reported by Christianson and Loftus (1991). As for peripheral detail information, there were slight, but nonsignificant differences in the expected direction. Taken together, these findings provide partial support for the attentional narrowing hypothesis.

Table 4.2.1. Percentages of Subjects who accurately reported the Colour of the Blouse and Bicycle

\begin{tabular}{llll}
\hline & $\begin{array}{l}\text { Emotional } \\
\text { Condition } \\
(n=32)\end{array}$ & $\begin{array}{l}\text { Unusual } \\
\text { Condition } \\
(n=24)\end{array}$ & $\begin{array}{l}\text { Neutral } \\
\text { Condition } \\
(n=30)\end{array}$ \\
\hline Blouse & 65.6 & 33.3 & 33.3 \\
Bicycle & 34.4 & 41.7 & 43.3 \\
\hline
\end{tabular}




\section{Experiment 2}

The results of experiment 1 suggest that when subjects are tested under similar conditions as in the Christianson and Loftus (1991) study, central detail recall is consistent with the atteritional narrowing hypothesis, Yet, our earlier study $(44.1)$, using the same stimulus material, failed to obtain such recall pattern. Bearing the attentional narrowing hypothesis in mind, a plausible interpretation for the contradicting results of experiment 1 and our earlier study is one in terms of stimulus exposure time and interstimulus intervals. That is, longer stimulus durations and/or interstimulus intervals may undermine systematic effects of attentional direction on recall. In order to test this assumption, experiment 2 emploved the same procedure as the experiment in section 4.1 , but systematically varied stimulus durations and interstimulus intervals.

\section{Method}

\section{Subjects}

Subjects were 180 undergraduate students in health sciences. Their mean age was 18.8 years (range $17-27$ years). Subjects were randomly assigned to one of six conditions Isee below; $n=30$ in each conditionl. They were tested either individually or in small groups with a maximum of three subjects in each group. Subjects were paid for their participation.

\section{Stimulus Material and Apparatus}

The stimulus material was identical to that used in experiment 1.

A Kodak Carousel projected slides on a white wall approximately $2 \mathrm{~m}$ in front of the subjects. The size of the projected image was $125 \times 85 \mathrm{~cm}$. Stimulus durations and interstimulus intervals were regulated by a Compaq deskpro 486 personal computer. controlling a Compur shutter.

\section{Procedure}

Subjects were tested in a sound-attenuated, dimly lit room. Upon arrival in the laboratory, they were told that the purpose of the experiment was measuring physiological reactions theart ratel while viewing slides. Then, a plethysmograph was attached to one of the subjects' index fingers. This transducer was not connected to any measurement device, but was intended to provide a credible coverstory. The coverstory was intraduced to prevent subjects from expecting some kind of memory test.

Next, subjects were informed that the story depicted in the slide series was that of a student on the way to university to take an oral exam. They were asked to identify with this story as closely as possible, by imagining that they were the main character. To aid imagination, subjects received a tape-recorded instruction in which the background of the 
story was given (see \$4.1).

Immediately following instructions, the slide series was presented. Subjects saw either the emotional, unusual or neutral version. Each version was presented under either of two conditions. In the short presentation condition, each slide was presented for $3 s_{\text {, with }}$ interstimulus intervals of $1 \mathrm{~s}$. In the long presentation condition, slides ware shown for 4 $s_{s}$ and interstimulus intervals were $6.6 \mathrm{~s}$. Thus, there were six conditions in a 3 (versions) $\times 2$ (presentation times) between-subjects design.

After slide presentation, subjects were taken to another room to complete some filler questionnaires. The filler task took 10 minutes. Following this, several recall tasks were administered. First, subjects were asked to complete a Free Recall task. They were to describe as many slides as they could remember, giving at least two characteristics of each slide. Second, a Cued Recall task was administered. For this purpose, 15 slides similar to the original slides were presented. However, from each slide the central and peripheral detail were removed. Subjects were asked to write down what items were missing from these slides. Third, subjects completed a Detailed Cued Recall task. The eighth slide of which the critical items were removed was again presented. Subjects were to describe as many features as they could remember from those ittems le.g., colours, positionl. Furthermore, they answered two additional questions, regarding the colour of the central girl's blouse and the colour of the peripheral bicycle. Finally, subjects were fully debriefed and paid. The total procedure took about 45 minutes.

\section{Resultts}

\section{Statistical Analyses}

In order to explore the effect of presentation times and interstimulus interval durations on recall, logistic regression analyses were performed on memory tasks involving dichotomous variables (i.e., Free Recall, Cued Recall and the Additional Questions). Performance on the various recall tasks concerning either the central girl or the peripheral bicycle were dependent variables, whereas version (emotionall vs unusual vs neutral), presentation duration (short vs longl, and the version by presentation duration interaction served as predictors.

For the Detailed Cued Recall test, data were first transformed into proportions of the maximal number of correct characteristics that could be mentioned $\$ 12$ for the peripheral bicycle in every version; 18 for the central girl in the emotional and unusual versions; and 15 for the girl in the neutral version). Next, a 3 (versions: emotional, unusual, neutral) $\times 2$ (conditions: long vs. short presentation) $\times 2$ (detail: central vs. peripheral) ANOVA with repeated measures on the last factor was performed.

The results an all memory measures are presented in table 4.2.2. 


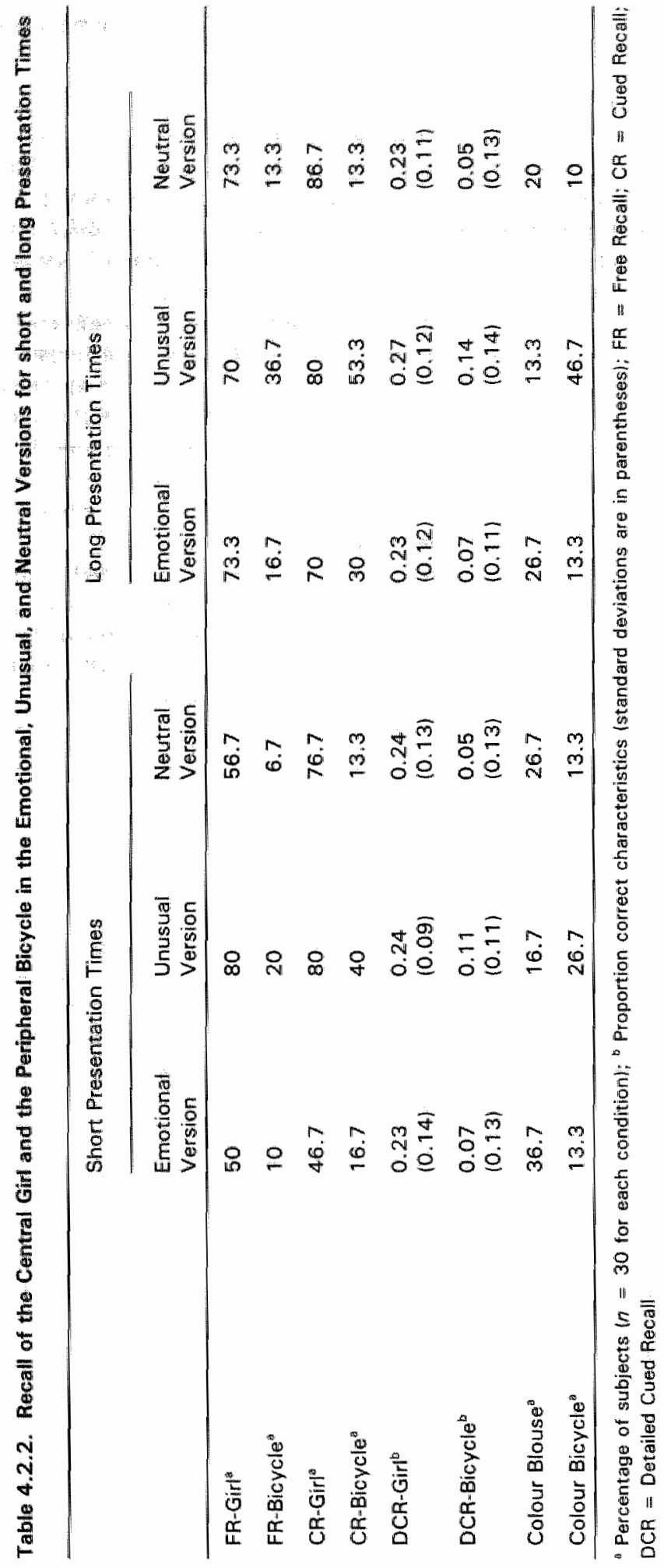




\section{Free Recall, Cued Recall and Additional Questions}

Central girl. For Free Recall, the logistic regression analysis rendered a borderline significant interaction term of presentation time and the contrast between the emotional and unusual version, $\beta=1.55$, se $=0.82, p=0.06$. In other words, the unusual version tended to produce more reports of the central girl than the emotional version during short but not during long presentation times.

Logistic regression analysis of Cued Recall results did not show any significant interactions between presentation times and version. However, the presentation time main effect was marginally significant, $\beta=-0.98$, se $=0.54, p=.07$, indicating that long presentai tion times tended to elicit more frequent reports of the centrall girl than short presentation times. Furthermore, significant effects occurred for the contrasts between the emotional and unusuall version, $\beta=-1.52$, se $=0.59, p<.01$, and neutral version, $\beta=-1.32$, se $=0.57, p<.05$. Thus, overall, the emotional version elicited poorer performance than the other versions.

As for the colour of the central girl's blouse, no significant interaction between presentation times and version occurred. The contrast between the emotional and unusual versions reached borderline significance, $\beta=1.06$, se $=0.62, p=0.09$. Thus, the emotional version tended to elicit more frequent reports of the accurate colour of the blouse than the unusual version.

Peripheral bicycle. Logistic regression of the Free Recall results rendered no significant main effects or interactions.

Although there were no significant interactions for Cued Recall, the contrast between the emotional and unusual version reached borderline significance, $\beta=-1.2, s e=0.62, p$ $=.05$. Thus, overall, subjects who saw the unusual version tended to outperform subjects who saw the emotional version in reporting the peripheral bicycle. No significant main or interactions effects were found for reporting the colour of the bicycle.

\section{Detailed Cued Recall}

The ANOVA showed that the critical three way interaction was nonsignificant. However, significance was reached for the main effects of detail, $F(1,174)=173.44, p<.001$, and of version, $F(2,174)=5.66, p<.01$. Separate $t$-tests were performed to break down this main effect of version. Subjects who saw the unusual version reported significantly more characteristics than subjects. who saw either the emotional version, $t(118)=-2.51, \rho<.05$, or the neutral version, $t(118)=3.24, p<.01$. Subjects who saw the emotional and the neutral versions did not differ with regard to the number of characteristics reported. 


\section{Discussilon}

The main results of this study cain be summarized as follows. First, no support was found for the assumption that relatively long stimulus presentation and interstimulus interval durations suppress differential recall of central and peripheral details of emotional material. There were merely a few nonsignificant trends in that direction. The emotional version tended to elicit poorer free recall of the central girl than the unusual version, whereas this recall pattern disappeared during long presentation times. In addition, long presentation times tended to elicit better cued recall of the central girl than short presentation times.

Second, contrary to expectations derived from the attentional narrowing hypothesis, subjects who saw the emotional version displayed poorer cued recall of the central girl than subjects who saw either an unusual or a neutral version. In addition, irrespective of detail category, the unusual group recalled more characteristics than either other group. However, the present data pattern displays some nonsignificant trends that are in line with the attentional narrowing hypothesis. That is, the emotional group was more likely to report the eolour associated with the central item. Likewise, compared to the unusual group, the emotional group displayed a trend towards poorer cued recall of the peripheral bicycle.

\section{General Discussion}

The primary aim of the current studies was to examine how specific conditions interact with central and peripheral detail memory. More specifically, we tried to determine what experimental parameters could possibly be responsible for the contradictory findings of Christianson and Loftus (1991) and our earlier experiment (section 4.1).

Experiment 1 followed the same procedure as Christianson and Loftus (1991), but relied on different stimuli. This straightforward replication of Christianson and Loftus (1991) rendered similar results: the central detail of an emotional slide was more likely to be recalled than that of either an unusual or neutral slide. Although the difference between groups concerning recall of the peripheral detail did not reach a statistical significance, results were in the expected direction. In addition, inspection af table 4.2 .1 reveals that the emotional group more frequently reported the central detail than the peripheral detail. The unusual and neutral groups showed an opposite recall pattern.

Taken together, the results of experiment i indicate that our previous failure isee $\$ 4.1$ ) to replicate the resullts of Christianson and Loftus is not related to the stimulus material used, but probably to the instructions given to the subjects or relatively long stimulus durations. With this in mind, experiment 2 employed the procedure of section 4.1 , yet systematically varied presentation times and intervals. Contrary to expectations, the results of this study suggest that such variations play only a minor role in modulating recall of emotional information. Furthermore, there are some indications that unusual, rather than emotional material elicits superior recall of central information.

How can the contradictory findings of experiment 1 and 2 be interpreted? The most obvious difference between methods concerns the instructions that were employed. In experiment 1. subjects were merely asked to closely attend to the stimuli, whereas the subjects in experiment 2 received extensive instructions to identify with the main 
character in the story. These self-relevant instructions were introduced in order to enhance the involvement of the subjects in the experimental situation. However, this manipulation may well have had the undesired side-effect of decreasing the encoding of perceptual information. That is, it may be the case that the identification instructions led to ruminations about how to integrate particular slides in the story, instead of accurate encoding of isolated detail information. Perhaps as a result of the encouragement to identify with the slidestory, subjects may have followed a top-down encoding strategy and needed few perceptual cues for interpreting the emotional and neutral slides. It is conceivable that this overshadows attentional narrowing effects on emotional detail memory. Consistent with this interpretation is the observation that overall, extensive instructions elicited fewer accurate reports of colour information (see table 4.2.2) than "mere viewing" instructions (see table 4.2.1). Yet, the situation depicted in the unusual slide might have been less self-evident for the subjects. It is conceivable that this led them to encode any feature that could possibly be useful for understanding the situation. It has been proposed le.g. Hunt, 1995), that such deeper and richer elaboration leads to more distinctive memory traces, thus facilitating recall.

Yet, another difference between the methods of experiment 1 and 2 should be noted. In experiment 1 , subjects only were asked to recall the colours of the central and peripheral items of the critical eighth slide. In contrast, subjects in experiment 2 performed various recall tasks for all slides they had seen. An alternative explanation for the findings of the latter experiment is that engaging in various recall tasks may have interfered with attentionall narrowing effects.

Taken together, the contradictory results of experiments 1 and 2 may be best explained by differences in the instructions or the memory tests that were employed. This implies that obtaining memory effects consistent with attentional narrowing in the laboratory may critically depend on rather specific circumstances. Especially the presumed influence of instruction may cast doubts on the extent to which result obtained with this type of laboratory approach can be generalized to real-life emotional events. Yuille and Tollestrup 11992) argue that laboratory situations differ from real-life traumatic events in two important respects: involvement and low-impact (i,e., only mildly emotionall stimuli. Our attempt to increase involvement through self-relevant instructions was unsuccessful in that recall patterns consistent with attentional narrowing were not abtained. Thus, manipulating involvement alone, without making stimuli more emotional, may be inisuff: cient. Moreover, it can be argued that in naturalistic situations, people do not constantly make controlled and deliberate efforts to integrate the world around them in their autobiagraphy. In this sense, the instructions employed in experiment 2 may have been just as artificial as the 'mere viewing' instructions in experiment 1 . In conclusion, it seems that experiment on attentional narrowing could profit from enhancing involvement by increasing levels of emotion. 


\section{3}

\section{"Spider Focus" and Detail Memory}

\section{Summary}

According to the attentional narrowing account of emotional memory, physiological arousal results in attention being directed towards centrall rather than peripheral characteristics of the situation. Consequently, menory for central details would be relatively good, whereas memory for peripheral information would be impaired. The present experiment sought to test this attentional narrowing hypothesis under highly sitressful conditions. Spider phobics and low-fear controls were confronted with a large live spider, eliciting high levels of omotion in the phobic group. Afterwards, subjects' memory for the experimental situation was tested. On a cued recall test, phobics displayed a poor memory for peripheral detail information relative to control subjects. There were: no differences between phobics and controls with respect to central detail information. Thus, the present date provide partial support for the attentional narrowing account of emotional memory.

\section{\|lntroduction}

The question of how emotional events are remembered has intrigued many researchers. Christianson (1992) noted that the type of information that is involved in memory testing should be taken into account in emotion and memory research. Following Easterbrook"s (1959) cue-utilization hypothesis, Christianson (1992) argued that physiological arousal experienced during a traumatic event causes attentional narrowing. This, in turn, would result in hyperattention for information reflecting the gist of the traumatic event icentral details) and hypoattention for irrelevant (peripheral) information. Due to such differential encoding, memory for central details of the emotional situation would be relatively good, whereas memory for peripheral details would be relatively poor.

This chapter will be published as: Wessel, 1., Merckelbach, H. (1997). The impact of anxiety on mamory for detalls in spider phobics. Applied Cognitive Piswchology, in press. 
There is empirical evidence to support Christianson's attentional narrowing hypothesis. Field studies examining the memory of witnesses for robberies (Christianson \& Hubinette, 1993), or that of college students for idiosyncratic emotional events (Christianson \& Loftus, 1990; Wessel \& Merckelbach, 1994) suggest that central information is, indeed, better remembered than peripheral information. There are, however, a number of serious limitations to this type of research. To begin with, in these studies retrospective emotionality ratings were related to central and peripheral detail memory. Yet, such retrospective reports do not always accurately reflect original emotion (Neisser \& Harsch, 1992). Therefore, such a retrospective procedure may vield imprecise and, as a result, mixed findings: (see also, Wessel \& Merckelbach, 1994). A second problem with these studies is the circularity implicated by their correlational approach. Especially in the case of questionnaire studies, it is quite possible that subjects classify remembered details as central for no other reason than that these details are remembered (Wessel \& Merckelbach, 1994).

Laboratory studies do not suffer from the problems inherent in retrospective reporting. That is, emotionality can be manipulated and detail information can be a priori defined. The results of laboratory studies testing the attentional narrowing hypothesis indicate that compared to neutral slides, emotional slides render a better memory for central details and e poorer memory for peripheral details (Burke et al 1992; Christianson \& Loftus, 1987, 1991; but see Hewer \& Reisberg, 1990). However, this type of research has been heavily criticized (e.g., Terr, 1994; Yuille \& Tollestrup, 1992). For example, Yuille and Tollestrup 1992) argue that laboratory experiments involve normal, healthy subjects, acting as uninvolved bystanders in events of low impact. These authors maintain that the results obtained under laboratory conditions cannot be generalized to genuine traumatic situations.

In sum, field studies on memory for highly emotional events may suffer from retrospective and report biases, whereas experimental studies may not be generalized to reallife situations. Of course, ethical considerations make it impossible to expose normal, healthy subjects to highly emotiomal and traumatizing events. Confronting phobic patients with the object of their fear (e.g., a spider in case of a spider phobial results in acute and high levels of fear. This, then, may provide an approach to elucidate the effects of intense emotion on memory for details.

The present study explored this possibility. Central and peripheral detail memory was tested in spider phobics and low-fear controls after confrontation with a large live spider. This approach has two advantages over usual methods for studying emotional memory in the laboratory. First, upon confrontation with a phobic cue, phobics experience substantially higher levels of fear than normals viewing unobtrusive silides. Second, problems involving differences in stimulus material are circumvented. In experiments with normal subjects, entionality is manipulated by using slides differing in content. Such a procedure does not control for the possibility that stimulus characteristics other than emotionality (e.g. saliency) are responsible for the memory effects observed. In the present experiment, stimulus material was identical across conditions. All subjects saw the same (phobic) cue.

In order to eliminate possible side-effects from exposure to high levels of fear, spider phobics were offered therapy after participating in the experiment. Therapy was modeled after the brief exposure treatment developed by Öst (1989). This treatment has been established to be effective (e.g., Arntz \& Lavy, 1993; Öst, 1989). In this manner, ethical 
constraints were circumvented.

To recapitulate, spider phobics and low-fear controls were exposed to a spider. Naxt, their memory for different aspects of this situation was tested. Following the attentional narrowing hypothesis (Christianson, 1992), it was predicted that compared to low fear controls, spider phobics would display enhanced memory for central information, and impaired memory for peripheral information.

\section{Method}

\section{Subjects}

Spider Phobics. Thirty-nine female spider phobics participated in the study. Their mean age was 29.6 years (range $16-60$ yrs); $74 \%$ of the phobics had completed a medium to high level of education ". Phobic subjects were recruited through articles about spider phobia in local newspapers and magazines. They agreed to participate in various experiments as part of a large spider phobia project. In exchange for participating, phobic subjects received exposure treatment.

Low Fear Controls. Twenty-five women served as controls. Mean age was 31.9 years (range $20-40 \mathrm{yrs}$ ); $66 \%$ of the controls had completed a medium to high level of education. They were recruited through an advertisement in a local newspaper and were paid for participating in various experiments. Phobic and control subjects did not differ with respect to age, $t(62)=-1.17, p>.05$, or education, $X^{2}(4, N=64)=1.66, p>$ .05 .

\section{Stimulus Material}

During the experimental procedure isee below), five central details and five peripheral details were present in the laboratory. Central details were: (a) a live brown house spider (Tegenaria Atrical; (b) a glass jar closed with a bright blue lid; (c) a dark blue cloth with a yellow/green/red flower pattern; (d) a white plywood shelf; and (e) a transparent plastic box. Peripheral details were: (a) an old fashioned black alarm clock; (b) a poster with various Mickey Mouse figures; (c) a black fan depicting a chinese farmhouse in different colors; (d) two toy animals; and (e) a bunch of artificial tulips in a white vase. The peripheral items were deliberately made outstanding (i.e.. not to be expected in a laboratoryl to diminish the possibility that central items would be more memorable dule to differences in salience.

\footnotetext{
"Medium education level reflects an intermediate wocational qualification (MBO); high oducation lowel refars to a high vocationat qualification (HBO) or uniwersity degree.
} 


\section{Assessment}

The Spider Phobia Questionnaire (SPO; Kllorman, Weerts, Hastings, Malarned \& Lang, 1974) was used as a self-report measure of spider phobia severity (range 0 - 31 ).

A Behavioral Approach Test (BAT, range 0.8) assessed to what extent subjects were able to approach a spider Isee for a detailed description, de Jong, Visser \& Merckelbach, 1996). In addition, subjects rated their anxiety level at the closest point af approach (BAT. Anxiety, range $0=$ absolutely not anxious to $100=$ extremely anxious).

Subjects ratted their subjective anxiety levels during confrontation with a large spider on a $100 \mathrm{~mm}$ Visual Analogute Scale IVAS; range $0=$ absolutely no anxiety to $100=$ extreme anxiety). The mean of four VASs (see procedure) was used as an indication of subjective anxiety level during the experiment.

Subjects: memory for centrall and peripheral details was evaluated with an interview. They were instructed to focus specifically on the characteristics of the experimental situation, and not on their feelings or cognitions during the experiment. Then, they were asked to describe as many details as they could remember from the experimental situation (Free Recall, FRI. Next, subjects were asked to describe each of the target items in detail (Cued Recall, CR). When not mentioned spontaneously by the subjects, the interviewer explicitly inquired about certain characteristics of that target item le.g., "What colour was the spider?"1. The audiotaped interviews were scored by counting correct responses. Four scores were obtained: (a) Free Recall, Central Detalls (FR-C, range 0-5), (b) Free Recall, Peripheral Details (FR-P, range 0-5), (c) Cued Recall, Central Details (CR-C, range $0-18$ ), and (d) Cued Recall, Peripheral Betails (CR-P, range $0-26$ ).

\section{Procedure}

First, subjects completed the SPO and performed the BAT. Next, they participated in an experimental task that is reported elsewhere. Regarding this task, the following is of importance for the present study. Subjects were seated in the laboratory, in which the five peripheral details were already present. The peripheral items were within the subjects" viewing range. The central details were part of the experimental procedure. After a short instruction, subjects were asked to perform a behavioral test involving a medium sized spider in a transparent box (Central Detail) on a white shelf (Central Detail). Next, the experimenter entered the room, holding a glass jar (Central Detail) containing a large live spider ${ }^{2}$ (Central Detail). The jar was covered with a cloth (Central Detail) and was held at $50 \mathrm{~cm}$ distance from the subject. Subjects were told that the covered jar contained a live spider and were instructed to watch closely when the experimenter pulled the cloth away.

2 In the experiment, two different spiders were used: one during the behavioral test and one during confrontation. We chose to only test subjects" memory for the spider used during confrontation for the fallowing reason. The distance of the medium sized spider to the subject ranged between 3 and $0 \mathrm{~m}$. Bewause this spidur was not dearly visible et distance $3 \mathrm{~m}$, detailed descriptions of it could not be expected. The largle splder was held at a standardized and relatively short $(50 \mathrm{~cm})$ distance of subjects. Therefore, this spider was aqualy visible for every subject. 
The experimenter uncovered the jar five seconds after the instruction was given. Next; subjects were exposed to the gllass jar and spider for five seconds. Directly following this confrontation, subjects completed the Subjective Anxiety VAS. This sequence (behavioral test and confrontation) was carried out four times consecutively. The entire experimental procedure took approximately 30 minutes.

After participating in the experiment, subjects were taken to another room by a different experimenter. No reference was made to the upcoming recall test. Subjects completed a filler questionnaire which was unrelated to fear of spiders and were left alone for 10 minutes. Finally, the memory interview was conducted by either a research assistant or the first author. The total time between the last confrontation with the spider and the start of the interview varied somewhat, but never exceeded 15 minutes. After subjects gave their consent, the interview was recorded on audiatape. The interview took approximately 20 minutes. Afterwards, subjects were debriefed.

\section{Results}

\section{Anxiety measures}

On all anxiety measures, scores of control subjects were distributed in a non-normal fashion. Therefore, Mann-Whitney $U$ tests were used in order to evaluate differences between phobic and control subjects. On the pre-test anxiety measures, Mann-Whitney $U$ tests resulted in highly significant differences between phobic and control subjects, SPQ, $z=-6.74, p<.001$; BAT, $z=-6.31, p<.001$; and BAT.Anxiety, $z=-6.25, p<$ .001 . These results confirm that phobic subjects displayed substantially more fear of spiders than controls. Likewise, during the experiment, phobic subjects reported considerably more anxiety upon confrontation with a large live spider than control subjects, $z=$ $-6.52, p<.001$. Table 4.3 .1 gives the means and standard deviations of all dependent variables.

\section{Detail Memory}

Free recall data. Scores on the free recall test were analyzed with a 2 (Group) $\times 2$ (Type of Detail) analysis of variance with repeated measuires on the lasit factor. In general, controls remembered more details than phobics, as shown by a significant main effect for group, $F(1,62)=4.97, p<.05$. In addition, a significant main effect for type of detail, $F(1,62)$ $=95.3, p<.001$, indicated that overall, more central than peripheral information was remembered. The critical group $x$ type of detail interaction did not reach statistical significance, $F(1,62)=0.61, p>0.05$.

Cued recall data. Because different total scores could be obtained for central and peripheral detail characteristics on the cued recall test $(18 \mathrm{vs}$. 26 , respectively), these data were first transformed into proportions. Next, the cued recall data were analyzed in the same way as the free recall data. Significant main effects for group, $F(1,62)=15.9, p<$ .001 , and type of detail, $F(1,62)=387.4, p<.001$, were found. That is, controls 
Table 4.3.1, Means on SPQ, BAT, BAT-Anxiety, Subjective Anxiety, FR-C, FR-P, CR-C, and CR-P. Standard Dewiotions are given between Parenthesess.

\begin{tabular}{lll}
\hline & $\begin{array}{l}\text { Spider Phobics } \\
(n=39)\end{array}$ & $\begin{array}{l}\text { Mean } \\
(n=25) \\
\text { Mean }\end{array}$ \\
\hline SPQ & $\begin{array}{l}23.4(2.9) \\
\text { BAT }\end{array}$ & $\begin{array}{l}\text { Low Fear Controls } \\
\text { BAT-Anxiety }\end{array}$ \\
Subjective Anxiety & $68.7(1.9)$ & $7.8(1.8)$ \\
FR-C & $47.9(25.1)$ & $8.6(1.6)$ \\
FR-P & $3.0(1.3)$ & $2.4(3.2)$ \\
CR-C & $0.5(0.9)$ & $3.2(1.4)$ \\
CR-P & $0.63(0.15)$ & $1.1(1.2)$ \\
\hline
\end{tabular}

- High scoresi on the BAT reflect better performance; "Number correct out of 5; "Proportion conrect; SPO = Spider Phobla Questionnaire; BAT = Behavioral Approach Test; FR-C = Free Recall, Central details; FR-P' = Free-Recall, Peripheral details; $C R-C=$ Cued Recall, Central details; $C R-P=$ Cued Recall; Peripheral details.

remembered more details than phobics and overall, more central than peripheral details were remembered. In addition, there was a significant group $x$ type of detail interaction, $F(1,62)=6.41, p<.05$. A post hoc $t$-test revealed that phobic and control subjects differed significantly with respect to peripheral details: phobics had lower cued recall scores for peripheral details than controls, $t(62)=-4.87, p<.001$. The groups did not differ on memory for central detail information, $t(62)=-1.43, p>.05$.

\section{Discussion}

The results of the present study can be summarized as follows. First, the manipulation was successful in that during confrontation with a large live spider, phobic subjects experienced substantially higher levelsi of anxiety than low-fiear control subjects. Second, all subjects remembered more central than peripheral details both on free and cued recall tests. Third, irrespective of detail category and type of test, control subjects remembered more details than phobic subjects. Fourth, phobic and control subjects did not differ with respect to the number of target items reported during free recall. However, when asked about the specific characteristics of those items, phobics remembered significantly less peripheral details than controls. This finding is consistent with the notion that during an emotional state (i.e., anxiety), attentional narrowing takes place (Christianson, 1992). The attentional narrowing hypothesis predicts that peripheral details are poorly encoded and consequently, poorly remembered. Note that the peripheral details in the present study 
were deliberately made outstanding. Moreover, the peripheral details were present during the entire experimental procedure lapproxilmately 30 minutes), whereas subjects were exposed to central details for considerably shorter periods of time.

The present data do not support the prediction that attentional narrowing results in better encoding and remembering of central information: on the cued recall test, phobic and control subjects remembered central details equally well. One possible explanation for this observation is as follows. An implicit assumption of the attentional narrowing hypothesis is that in emotional and meutral situations, an equal amount of attention would be directed to the environment. Such outwardly directed attention would be distributed differently among central and peripheral information as a function of emotionality. Alternatively, Yuille and Tollestrup (1992) proposed that under stressful conditions, attention may also be focussed internally (e.g., on emotional responses) resulting in poor memory for peripheral as well as central information. The question arises whether directing attention internally or externally is such an all-or-none phenomenon as Yuille and Tollestrup proposed. Perhaps the spider phobics' relatively poor peripheral detail memory was a result of directing part of their attention inwardly. Perhaps peripheral details are prone to suffering from such a decrease in external attention, because attending toward a threatening stimulus has survival value for phobics. Admittedly, this is a speculative line of reasoning as direction of attention was not measured.

A second possible explanation for the lack of difference between the groups on central detail memory may have to do with the classification of details as either central or peripheral. We defined central details as those details that were associated with the source of threat, that is, the spider. It may be argued, however, that some details le.g., the cloth covering the spider) may not be as central as the spider itself. Thus, a stricter definition of central details, based on spider-related stimuli only, might provide a more sensitive test. However, an exploratory $t$-test indicated that compared to controls, spider phobics did not report significantly more spider characteristics $I m=1.54, S D=0.72$, and $m=1.48$, SD $=0.77$, respectively; $(62)=0.31, p>0.051$. Yet, this index of central details may have been too crude, due to its relatively small range (0-3). Clearly, future studies should use a wider range of strictly threat-related stimuli to examine whether phobics show enhanced memory for central details.

The present study assumed that exposing clinically phobic subjects to their feared object might provide an opportunity for studying the effects of intense emotion on memory. However, some might argue that relying on a clinically anxious sample may have confounded the present results. Meanwhile, there is liftle evidence for a memory bias in the phobic disorders (Williams, Watts, MacLeod \& Matthews, 1988). Furthermore, individuals with a specific phobia do not differ from normals in domains other than memory (e.g., personality traits, van Zuuren, 1987). Taken together, spider phobics appear to be relatively normal people. For this reason, others might argue that phobic fear is too mild to be compared to the terror involved in trauma. Yet, phobics react to their phobic object with intense levels of fear that may even take the form of a panic attack (APA, 1994). Thus, it seems safe to conclude that the current approach may provide a more appropriate analogue to traumatic anxiety than usual laboratory methods relying on college student samples (e.g., Christianson \& Loftus, 1991).

Although the current data are partially consistent with the attentional narrowing hypothesis, several limitations preclude firm conclusions as to the origins of the observed 
effects. First, it is unclear whether the phobics" relatively poor peripheral detail memory performance was caused by shallow encoding due to attentional narrowing or by other memory processes. For example, impaired memory for information presented prior to arousal-eliciting stimuli (retrograde amnesia) has sometimes been observed le.g." Christianson, 1984. Loftus \& Bums, 1982) Note that in the present study, peripheral items were not only present during confrontation with the spider, but also prior to this confrontation. Thus, the observed effect might be interpreted as retrograde amnesia, resulting from storage or retrieval problems (see Christianson \& Nilsson, 1984). Second, the attentional narrowing hypothesis (Christianson, 1992) assumes that physiological arousal is responsible for an attentional focus. However, the present study did not measure physiological arousal and attention. Therefore, the present data cannot elucidate causal relations between arousal, attention, and memory.

In sum, the current data partially support Christianson's (1992) account of emotional memory. Under highly stressful conditions, phobics displayed a disadvantage in memory for the characteristics of peripheral stimulli. Thus, confronting phobic subjects with their feared object may provide a fruitful approach for studying the influence of high levels of anxiety on memory. 


\section{4}

\section{Memory for Phobic Cues}

\section{Summary}

The present study investigated whether confronting phobic individuals with their feared object provides a laboratory approach for studying the effects of high emotion levels on memory for central (threat-rolevant) and peripheral (threat-irrelevant) information. Twenty-two spider phobic and 24 low-fear control subjects were exposed to one of two versions of a bulletin board ta which central (spiders) and peripheral (babies and pens) stimuli were attached. During exposure to the stimuli, spider phobics displayed an increase in electrodermal activity. The results of a subsequent free recall test indicate that relative to controls, spider phobicis showed enhanced memory for central information and impaired memory for peripheral information. The free recall data are consistent with an interpretation in terms of the attentional narrowing hypothesis of emotional memory.

\section{Introduction}

According to the attentional narrowing hypothesis (Christianson, 1992), memory for emotional events is mediated by differential attention allocation. That is, an increase in emotional arousal would result in an attentional focus on information reflecting the gist of the event (central detail information), at the expense of attention for irrelewant information (peripheral detail information). Consequently, memory for central information would be enhanced, whereas memory for peripheral information would be impaired. The attentional narrowing hypothesis is supported by two lines of research.

To begin with, field studies (Christianson \& Loftus, 1990; Wessel \& Merckelbach, 1994) suggest that central information of emotional events is better remembered than peripheral information. However, these studies mav have suffered from retrospective biases. That is, subjects were asked whether the aspects of an emotional event that they

A version of this chapter will appear as a brief report entitled: Wessel, I. \& Merckelbach, H. Memory for threat-relevant and threat-irrelevant cues in spider phobics. Cognition and Emotion, in press. 
recalled were central or peripheral. Perhaps some details were classified as central for no other reason than that they were well remembered.

The second line of research consists of laboratory experiments, involving normal, healthy subjects. In these experiments, subjects are typically shown a series of slides ${ }_{\text {. }}$ of which the middle portion is either emotional or neutral. Consistent with the notion of attentional narrowing, these studies demonstrate enhanced memory for central details, and impaired memory for peripheral details of emotional slides (Burke, Hever \& Reisberg, 1992; Christianson \& Loftus, 1987, 1991; but see Heuer \& Reisberg, 1990). The advantage of the laboratory approach is that retrospective biases are circumvented, because information can be a priori classified as central or peripheral. However, the disadvantage of such an approach is that the gieneralizability to real-life emotional situations can be questioned (see Yuille \& Tollestrup, 1992).

Given the advantages of an experimental appraach, it thus seems that research on emotional memory would profit from methods that increase levels of emotion in the laboratory. Of course, ethical considerations put strict limitations on exposing normal, healthy subjects to highly emotional events. Subjects with specific phobias are relatively normal people, apart from their fear for a narrow range of cues (e.g., van Zuuren, 198.7). Confronting these subjects with their feared object elicits substantial levels of emotion. This, then, may provide a strategy for studying emotion and memory under controlled circumstances. Following this strategy, Wessel and Merckelbach (1996) found preliminary ewidence supporting the attentional narrowing hypothesis in a spider phobic sample.

What is known about spider phobics memory for phobic materiall? Earlier studies comparing spider phobic and normal subjects' memory for phobia-related words le.g., Watts \& Covle, 1992, 1993; Watts \& Dalgleish, 1991) or real, albeit dead, spiders (Watts, Trezise \& Sharrock, 1986) produced mixed results. Some (Watts et all., 1986; Watts \& Dalgleish, 1991) found that phobics poorly recall fear-relevant material, whereas others (Watts \& Coyle, 1992; 1993) failed to find such phenomenon. Note that these studies were inspired by an information processing approach to the emotional disorders (Williams, Watts, Macleod \& Mathews, 1988). Williams and colleagues argue that phobics direct processing resources away from threat-relevant material, rendering it less retrievable. Thus, this account predicts that due to cognitive avoidance, phobics show an impaired memory for phobic cues (Dalgleish \& Watts, 1990; Williams et al., 1988). In contrast, the attentional narrowing hypothesis predicts that phobics show an enhanced memory for these cues, because they are central information for phobics.

The present study sought to test these predictions in a spider phobic sample. Two subsidiary issues were addressed. The first issue concerns the role of saliency in the central/peripheral distinction. That is, a spider may be non-emotional for low-fearful persons, yet it may be more interesting than a neutral stimulus. Therefore, the current study amployed positively valenced stimuli (i.e., babies) in addition to threat-related (i.e., spiders) and neutral stimuli (i.e., pens). A second issue pertains to the definition of central and peripheral information. Peripheral information may be irrelevant to the gist of an amotional event or spatially peripheral to that gist (Christianson, 1992). This raises the question whether it is conceptual (i.e., threat vs. non-threat) or perceptual relevance (i.e., central or peripheral to the visual field) that leads to differential recall (see also Burke et al. 1992). Therefore, in the present study, perceptual organization of conceptually relevant and irrelevant stimuli was manipulated. 


\section{Method}

\section{Subjects}

Spider Phobics. Twenty-four female spider phobics participated in the study. At the end of the experimental session, two subjects said they had expected a memory test. These subjects were excluded from the analyses, leaving 22 phobic subjects in the final sample. Their mean age was 28.1 years (range 17.56 years). Fifty-nine percent af the phobic subjects completed a medium or high level of education. Phobics were randomly assigned to one of two conditions (see below; $n=12$ and $n=10$ ). Phobic subjects were recruited by newspaper and magazine advertisements. They met criteria for DSM-IV specific phobia. Phobics completed several self-report measures of psychopathology at home. They participated in a spider phobia project involving various experiments. In exchange for participation, they received one-session exposure therapy (see Öst, 1989).

Low-fear controls. Twenty-nine females who were not afraid of spiders served as controls. At the end of the experiment, five subjects said they had expected a memory test, and thus were excluded from the analyses. Mean age of the final control group $(n=24)$ was 31.6 years (range $17-52$ years). Sixty-seven percent of the control subjects completed a medium or high level of education. Controls were randomly assigned to one of two conditions (see below, $n=13$ and $n=11$ ). They were recruited by a newspaper advertisement, specifically asking for non-spider-fearful individuals. Respondents were interviewed by telephone to confirm that they did not fear spiders. Contrals were payed for their participation.

\section{Assessment}

The Spider Phobia Questionnaire (SPQ; Klorman, Weerts, Hastings, Malamed \& Lang, 1974 ) was used as a self-report measure of spider phobia severity (range $0-31$ ).

A Behavioural Approach Test (BAT, ranging from $0=$ total avoidance to 8 total approach; see de Jong. Visser \& Merckelbach, 1996, for a detailed descriptionl, assessed to what extent subjects were able to approach a spider.

\section{Stimulus material}

There were 24 stimuli, divided into three categories of eight stimuli each: (a) spider related (e.g., a dead spider, a photograph of a spider, a drawing of a spider, the word spider); (b) baby-related le.g., a baby doll, a photograph of a baby, a drawing of a baby, the word baby); and (c) pen-related (e.g., a red pen, a photograph of a pen, a drawing of a pen, the word pen 1 . The cues were attached to a $120 \times 80 \mathrm{~cm}$ bulletin board. There were two versions of the bulletin board (see figure 4.4.1). In the spider-centered version, all spider cues were in the middle, whereas babies and pens were at the margins of the board. In

\footnotetext{
1 Stimulus words were matched for number of characters in Dutch.
} 
the spider-scattered version, stimuli with similar characteristics (e.g., three drawings, three photographs, etc.) were grouped together.

\section{Apparatus}

Spontaneous skin conductance fluctuations (SFs) were recorded with two Beckman AgAgcl electrodes attached to the second and third finger of the subject's non-dominant hand, SFs were recorded with a Schwartzer EDA coupler, using the constant voltage 1.5 V) method. SFs were defined as a skin conductance increase of at least 0.05 microsiemens within two seconds after response onset.

Respiration rate was recorded with a Beckman respiration belt in order to detect artefacts in skin conductance due to sighing, coughing, and so forth. Such artefacts were omitted from the data.

\section{Procedure}

To avoid priming effects, the experiment was conducted prior to any other experiments. Subjects were told that the purpose of the experiment was measuring physiological responses to stimull attached to a bulletin board. They were seated approximately $1 \mathrm{~m}$ in front of the bulletin board, that was hidden behind a venetian blind. Following instructions, measurement devices were attached and subjects were left alone for three minutes. The llast minute served as a baseline during which SFs were recorded. Following this, the experimenter returned and instructed the subjects to look at the bulletin board. Then, the blind was raised and subjects were left alone for one minute while SFs were recorded. After this experimental phase, the blind was lowered and subjects rated their anxiety level during stimulus presentation using a $100 \mathrm{~mm}$ Visual Analogue Scalle $(V A S ; 0=$ not anxious at all, $100=$ extremely anxious $)$.

Next, subjects were told that the experiment had finished. They were escorted to an other room and completed questionnaires about an unrelated topic for 10 minutes. Then, subjects ware given three surprise memory tests. They were instructed to (a) write down a brief description of as many items as they could remember (free recall); (b) indicate the correct position of any item they could remember in a rectangle that was divided into 24 compartments, representing the bulletin board (i.e., position recall); (c) complete a forced choice (yes/no) recognition test. The recognition questionnaire consisted of descriptions of the 24 stimuli and $\$ 2$ foils, distributed equally over stimulus categories. Subjects were allowed a maximum of five minutes for each recall task. Finally, they were asked whether they had expected a memory test. Subjects who answered affirmatively were excluded from the analyses (see above).

All subjects performed the BAT after participation in several other experiments. For phobics, the SPQ was part of the questionnaire package that they completed prior to participation in the spider phobia project. Controls filled out this questionnaire after participating in the experiments that were part of the project. 
Figure 4.4.1

Schematic Overview of the Spider-Centered Version of the Bulletin Board

\begin{tabular}{|c|c|c|c|c|c|}
\hline $\begin{array}{l}\text { red } \\
\text { pen }\end{array}$ & $\begin{array}{l}\text { drawing } \\
\text { of pen } \\
\text { (yellow) }\end{array}$ & $\begin{array}{l}\text { photo } \\
\text { baby in seat }\end{array}$ & $\begin{array}{l}\text { word } \\
\text { ink } \\
\text { (blue) }\end{array}$ & $\begin{array}{l}\text { doll } \\
\text { with dress }\end{array}$ & $\begin{array}{l}\text { exercise } \\
\text { book }\end{array}$ \\
\hline $\begin{array}{l}\text { naked } \\
\text { dall }\end{array}$ & $\begin{array}{l}\text { web } \\
\text { (black } \\
\text { wool) }\end{array}$ & diead spider & $\begin{array}{l}\text { photo } \\
\text { spider } \\
\text { (front) }\end{array}$ & $\begin{array}{l}\text { word } \\
\text { web } \\
\text { (vellow) }\end{array}$ & $\begin{array}{l}\text { orange } \\
\text { marker }\end{array}$ \\
\hline $\begin{array}{l}\text { word } \\
\text { baby } \\
\text { (yellow) }\end{array}$ & $\begin{array}{l}\text { photo } \\
\text { spider } \\
\text { (dorsal) }\end{array}$ & $\begin{array}{l}\text { word } \\
\text { spider } \\
\text { (green) }\end{array}$ & $\begin{array}{l}\text { drawing } \\
\text { of spider } \\
\text { (blue) }\end{array}$ & $\begin{array}{l}\text { black toy } \\
\text { spider }\end{array}$ & $\begin{array}{l}\text { photo } \\
\text { blue } \\
\text { pen }\end{array}$ \\
\hline $\begin{array}{l}\text { word } \\
\text { playpen } \\
\text { (blue) }\end{array}$ & $\begin{array}{l}\text { photo } \\
\text { pencil }\end{array}$ & bib & $\begin{array}{l}\text { word } \\
\text { pen } \\
\text { (green) }\end{array}$ & $\begin{array}{l}\text { photo } \\
\text { baby } \\
\text { with hat }\end{array}$ & $\begin{array}{l}\text { drawing } \\
\text { of baby } \\
\text { (green) }\end{array}$ \\
\hline
\end{tabular}

Schematic Overview of the Spider-Scattered Version of the Bulletin Board

\begin{tabular}{|c|c|c|c|c|c|}
\hline $\begin{array}{l}\text { word } \\
\text { spider } \\
\text { (green) }\end{array}$ & $\begin{array}{l}\text { word } \\
\text { baby } \\
\text { (yellow) }\end{array}$ & $\begin{array}{l}\text { word } \\
\text { ink } \\
\text { (blue) }\end{array}$ & dead spider & $\begin{array}{l}\text { naked } \\
\text { dioll }\end{array}$ & $\begin{array}{l}\text { orange } \\
\text { marker }\end{array}$ \\
\hline bib & $\begin{array}{l}\text { exercise- } \\
\text { book }\end{array}$ & $\begin{array}{l}\text { web } \\
\text { (black } \\
\text { waol) }\end{array}$ & $\begin{array}{l}\text { drawing } \\
\text { of baby } \\
\text { (green) }\end{array}$ & $\begin{array}{l}\text { drawing } \\
\text { of pent } \\
\text { (vellow) }\end{array}$ & $\begin{array}{l}\text { drawing } \\
\text { of spider } \\
\text { (blue) }\end{array}$ \\
\hline $\begin{array}{l}\text { photo } \\
\text { blue } \\
\text { pen }\end{array}$ & $\begin{array}{l}\text { photo } \\
\text { spider } \\
\text { (front) }\end{array}$ & $\begin{array}{l}\text { photo } \\
\text { baby } \\
\text { with hat }\end{array}$ & $\begin{array}{l}\text { word } \\
\text { pen } \\
\text { (green) }\end{array}$ & $\begin{array}{l}\text { word } \\
\text { web } \\
\text { (vellow) }\end{array}$ & $\begin{array}{l}\text { word } \\
\text { playpen } \\
\text { (blue) }\end{array}$ \\
\hline $\begin{array}{l}\text { black toy } \\
\text { spider }\end{array}$ & $\begin{array}{l}\text { doll } \\
\text { with dress }\end{array}$ & $\begin{array}{l}\text { red } \\
\text { pen }\end{array}$ & $\begin{array}{l}\text { photo } \\
\text { spider } \\
\text { (dorsal) }\end{array}$ & $\begin{array}{l}\text { photo } \\
\text { baby in seat }\end{array}$ & $\begin{array}{l}\text { photo } \\
\text { pencill }\end{array}$ \\
\hline
\end{tabular}


Data Analysis

Demographic Variables and Phobia Severity. Mean age and SPO scores were analyzed with $t$-tests. Level of education was subjected to a $X^{2}$ test. Statistical analysis of the BAT data was not meaningful, because all contral subjects obtained the maximum BAT score.

SFs and Subjective Anxiety. Due to experimental failure, SF data for one phabic and one control subject were missing. SFs were analyzed using a 2 (group: phobics vs. controls) $x$ 2 (version: spider-centered vs. spider-scattered) $\times 2$ (phase: baseline vs experiment) Analysis of Varience (ANOVAl with repeated measures on the last factor. Due to nonnormality of the distribution, subjective anxiety scores were analyzed with separate Kruskall-Wallis oneway ANOVAs with groups or versions as between-subjects factor.

Memory tasks. For practical reasons, the memory tasks were scored by the first author, who was not blind to phobla condition. For free recall and position recall, responses were scored correct if the descriptions contained information about both the stimulus category (e.g., spider) and stimulus properties (e.g., word). For all memory tasks, proportions were calculated by dividing the number of correct responses by the total number of cues in each stimulus category (i.e, eight items in the free recall, position recall and recognition tasks; four foils in the recognition task). Recognition scores were corrected for guessing by subtracting the proportion of affirmative answers to foils (false alarms) from the proportion correct responses (hits). All proportions were analyzed using 2 (group: phobics vs. controls) $\times 2$ (version: spider-centered vs. spider-scattered) $\times 3$ (stimulus category: spiders vs. babies vs. pens) ANOVAs with repeated measures on the last factor. Followup $t$-tests or ANOVAs were performed when appropriate.

\section{Results}

Demographic Variables and Phobia Severity

Phobics and controls did not differ regarding age, $t(44)<1.3$, or educational level, $X^{2}(3)$ $<2.2$. SPO scores were significantly higher for phobics than for controls $m=22.95, S D$ $=3.51$, and $m=2.13 .50=2.03$, respectively), $t(31.07)=23.90, p<.001$ (adjusted DF). The mean BAT score in the phobic group was 3.2 (SD $=1.97$ ). All controls obtained a score of 8 , indicating total approach.

\section{SFis and Subjective Anxiety}

None of the analyses yielded any significant main or interaction effects of version, Fs $<1$ and $X^{2}<1$. Therefore, table 4.4.1 summarizes SFs and subjective anxiety scores for spider phobic and control subjects, collapsed over versions.

Regarding SFs, the ANOVA yielded no significant main effect of group $F<1.3$. Relative to baseline, a larger number of SFs occurred during the experiment, a shown by a significant phase main effect, $F(1,42)=10.85, \rho<.01$. 
Table 4.4.1. Mean Spontaneous Skin Conductance Fluctuations and Mean subjective Anxiety Ratings. Standard Deviations are in Parentheses

\begin{tabular}{lll}
\hline & $\begin{array}{l}\text { Spider Phobics } \\
(n=22)\end{array}$ & $\begin{array}{c}\text { Controls } \\
(n=24)\end{array}$ \\
\hline $\begin{array}{l}\text { Fluctuations } \\
\text { Baseline }\end{array}$ & $2.65(2.89)$ & $2.57(2.76)$ \\
Experiment & $4.70(3.42)$ & $2.65(2.76)$ \\
Subjective Anxiery & $32.68(24.87)$ & $5.63(8.57)$ \\
\hline
\end{tabular}

"Missing data for 1 subject in the phobic group and 1 subject in the control group

A significant group by phase interaction, $F(1,42)=9.08, p<.01$, indicated that this increase was larger in phobics than in controls. In addition, phobics reported significantly more subjective anxiety than controls, $X^{2}=21.63, p<.001$.

\section{Memory tasks}

Free Recall. Table 4.4 .2 gives an overview of the results of the free recall test. A significant stimulus category main effect, $F(2,84)=62.24, p<.001$, indicated that spiders were more frequently recalled than babies, $t|45\rangle=4.91, \rho<.001$, and that babies were more frequently recalled than pens, $t(45)=5.35, p<.001$.

The critical group by stimulus category interaction effect was significant, $F(2,84)=$ $6.96, p<01$. Three follow-up ANOVAs with group as between-subjects and stimulus categary as within-subjects factor were performed. The 2 (group) $\times 2$ (spiders vs. babies) interaction reached significance, $F(1,44)=6.51, p<.05$. Likewise, a significant 2 (group) $\times 2$ (spiders vs. pens interaction emerged, $F(1,44)=11.37, p<.01 . A 2$ (group) $\times 2$ (babies vs. pens) ANOVA yielded no significant interaction effect, $F<1$. Taken together, the separate ANOVAs indicate that compared to controls, spider phobics had superior recall of spider-related material and impaired recall of threat-irrelevant material.

A borderline significant version main effect, $F(1,42)=3.63, p=.06$, indicated that subjects who saw the spider-centered version tended to recall more stimuli. This tendency was the most obvious for pens and the least obvious for spiders, as shown by a borderline significant version by stimulus category interaction, $F(2,84)=3.87, p=.06$. No other main or interaction effects reached a significant level, all $F_{\mathbb{S}}<1.4$. 
Table 4.4.2. Mean Proportions of Items recalled. Standard Deviations are in Parentheses

\begin{tabular}{|c|c|c|c|c|}
\hline & \multicolumn{2}{|c|}{ Spider Phobics } & \multicolumn{2}{|l|}{ Controls } \\
\hline & $\begin{array}{l}\text { Spider } \\
\text { Centered } \\
(n=12)\end{array}$ & $\begin{array}{l}\text { Spicler } \\
\text { Scattered } \\
(n=10)\end{array}$ & $\begin{array}{l}\text { Spider- } \\
\text { Centered } \\
(n=13)\end{array}$ & $\begin{array}{l}\text { Spider- } \\
\text { Scattered } \\
(n=11)\end{array}$ \\
\hline Spiders & $68(.15)$ & $.73(.12)$ & $.60\{.15\}$ & $.58(.17)$ \\
\hline Babies & $.47(.23)$ & $.39(.19)$ & $.56(.23)$ & $.42(.10)$ \\
\hline Pens & $.34(1.16)$ & $.18(.16)$ & $.39(.16)$ & $.33(.17)$ \\
\hline
\end{tabular}

Table 4.4.3. Mean Proportion of Positlons recalled. Standard Deviations are in Parentheses

\begin{tabular}{|c|c|c|c|c|}
\hline & \multicolumn{2}{|c|}{ Spider Phobies } & \multicolumn{2}{|l|}{ Controls } \\
\hline & $\begin{array}{l}\text { Spider- } \\
\text { Centered } \\
(n=12)\end{array}$ & $\begin{array}{l}\text { Spider- } \\
\text { Scattered } \\
(n=10)\end{array}$ & $\begin{array}{l}\text { Spider } \\
\text { Centered } \\
(n=13)\end{array}$ & $\begin{array}{l}\text { Spider- } \\
\text { Scattered } \\
(n=11)\end{array}$ \\
\hline Spiders & $.37(.22)$ & $.30(.11)$ & $.25(.14)$ & $.23(.16)$ \\
\hline Babies & $.27(. \| 3)$ & $.21(.10)$ & $.23(.17)$ & $.19(.19)$ \\
\hline Pens & $.13(.93)$ & $.03(.05)$ & $.12(.14)$ & $.03(.06)$ \\
\hline
\end{tabular}

Position Recall. The results of the position recall test are displayed in table 4.4.3. The spider-centered version elicited more accurate reports of position than the spider-scattered version, as shown by a significant version main effect, $F(1,42)=5.19, p<.05$. In

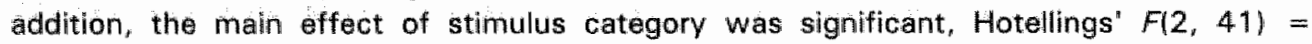
$1.98, p<.001$. Spider positions tended to be better recalled than baby positions, $t(45)=$ $1.81, p=.08$. Position recall was significantly better for babies than for pens, $t(45)=$ $6.36, p<.001$. The main effect for group was not significant $F<2.4$. No significant interaction effects emerged, Fs $<1.5$.

Recognition. Table 4.4.4 summarizes the proportions of false alarms and the proportions correctly recognized items, corrected for guessing. For false alarms, only the stimulus category main effect approached significance, $F(2,84)=2.92, p=.06$. Spider foils tended to be the most and baby foils tended to be the least rejected. No other significant main effects $F_{\mathbf{S}}<2.6$, or interaction effects, $F_{\mathrm{s}}<1$, emerged. 
Table 4.4.4. Mean Proportion of False Alarms and Mean Proportion reciognized (thits minus False Alarms). Standard Deviations are in Parentheses

\begin{tabular}{|c|c|c|c|c|}
\hline & \multicolumn{2}{|c|}{ Spider Phobics } & \multicolumn{2}{|l|}{ Controls } \\
\hline & $\begin{array}{l}\text { Spider } \\
\text { Centered } \\
(n=12)\end{array}$ & $\begin{array}{l}\text { Splder- } \\
\text { Scattered } \\
(n=10)\end{array}$ & $\begin{array}{l}\text { Spider- } \\
\text { Centered } \\
(n=13)\end{array}$ & $\begin{array}{l}\text { Spider- } \\
\text { Scattered } \\
(n=11)\end{array}$ \\
\hline \multicolumn{5}{|c|}{ False alarms } \\
\hline Spiders & $.13(.17)$ & $.10(.18)$ & $.29(.30)$ & $.21\{.25\}$ \\
\hline Babies & $.29(.23)$ & $23(.14)$ & $.29(.41)$ & $.36(.28)$ \\
\hline Pens & $.19(.29)$ & $.23(.25)$ & $.27\{.24\}$ & $.27(.24)$ \\
\hline \multicolumn{5}{|c|}{ Recognition } \\
\hline Spiders & $.62(.27)$ & $.63(.20)$ & $.36(.34)$ & $.46(.33)$ \\
\hline Babies & $.26(.30)$ & $.25(.24)$ & $.41(.37)$ & $.16(.32)$ \\
\hline Pens & $.32(.34)$ & $.14(.32)$ & $.23(.21)$ & $.16(.26)$ \\
\hline
\end{tabular}

For recognition (i.e., hits minus false alarms), the main effect of stimulus category was significant, $F(2,84)=16.07, p<.001$. Spiders were more frequently recognized than babies, $t(45)=3.85, p<.001$, and pens, $t(45)=5.07, p<.001$. Recognition of babies and pens did not differ significantly, $t<1.1$. The group by stimulus category interaction showed a non-significant trend, $F(2,84)=2.57, p=.08$. This pattern was similar to the free recall findings. No other significant main effects, Fs $<1.6$, or interaction effects, Fs $<1.9$, were found.

\section{Discussion}

The present results can be summarized as follows. Compared to controls, phabics displayed (a) more fluctuations in skin conductance accompanied by higher anxiety scores when confronted with a bulletin board that contained threat information; and $(b)$ a relatively enhanced free recall of central, threat-relevant information, and a relatively impaired free recall of peripheral, threat-irrellevant information.

The present data are reminiscent of recall patterns found in earlier studies on attentional narrowing (e.g., Burke et al., 1992; Christianson \& Loftus, 1991). Meanwhile, the present observation that phobics showed enhanced recall of spider-cues clearly contradicts the finding of Watts and co-workers (1986) that phobics display poor memory for real, dead spiders. Watts and colleagues interpret their findings in terms of information processing biases (i.e., cognitive avoidance) in phobics. However, perhaps methodologicall issues may account for these conflicting findings. Watts and colleagues studied spider recognition. 
For this purpose, spiders were presented at encoding as well as retrieval. It is conceivable that high levels of emotion during retrieval may hamper accurate recognition. Consistent with this interpretation. Watts and co-workers found impaired recognition of big spiders. but not small spiders.

By and large, the present data support an attentional narrowing account (Christianson. 1992) rather than a cognitive avoidance account of emotional memory (Dalgleish \& Watts. 1990; Willams et al, 1988). The present study examined two subsidiary issues pertinent to the attentional narrowing hypothesis. The first issue concerned stimulus salience. The lack of differential recall for babies and pens suggests that adding sallience to peripheral items does not dramatically affect recall patterns. However, all subjects recalled more spiders than babies. In the absence of saliency ratings, it cannot be ruled out that even for the non-fearful controls, spiders were far more salient than babies.

The second issue concerned the ffects of conceptual versus spatial differences on recall. The absence of reliable interaction effects of bulletin board version with group suggests that it was conceptual relevance, rather than centrality to the visual field, that resulted in free recall patterns consistent with the attentional narrowing hypothesis "Still, it would be premature to conclude that perceptual organization does not play a role in recall of emotional material. Position recall clearly differed across versions and this may be due to the fact that the spider-centered version was more obviously clustered than the spider-scattered version. However, the free recall data showed a nonsignificant trend for subjects who saw the spider-centered version to remember less central and more peripheral items than subjects who saw the spider-scattered version. If clustering were an issue, a reverse data pattern would be expected. Nevertheless, small sample sizes may have precluded detection of perceptual organization effects.

Although the present findings are in line with the attentional narrowing hypothesis, a number of differences between this method and the designs of earlier experiments testing this hypothesis (e.g.; Burke et al., 1992; Christianson \& Loftus, 1991) should be noted. First, earlier studies tested normal subjects, whereas the present study relied on a clinically anxious sample. One might argue that the present results are due to differences between phobic and normal subjects, for example, in general memory functioning. To the present authors" knowledge, the literature is silent about general memory deficits in phobics. Also, for the present memory data none of the analyses yielded significant group main effects. This indicates that overall, phobics and controls performed at a similar level.

Second, earliep experiments (e.g." Christianson \& Loftus, 19911 employed slide sequences depicting a story, in which the central information in a criticall slide determined the meaning of the scene (e.g., seeing an injured person means that there was an accident). In contrast, the present study used stimuli without a context, with no apparent meaning to be established. Furthermore, earlier studies tested memory for details le.g., colours), whereas the present study tested memory for for various items. Thus, rather different definitions of central and peripheral detail preclude direct comparisons of the present data with earlier findings.

In sum, the current study tested memory for central and peripheral items, encoded under relatively high levels of emotion. The free recall results support the attentionall narrowing account of emotional memory. Thus, the present method might provide a useful approach for studying attentional narrowing phenomena. 


\section{5}

\section{Characteristics of Traumatic Memories in Normal Subjects}

\section{Summary}

In recent years, there has been considerable debate about how accurately people remember emotionally significant information. Early sudies concermed with 'flashbulb memories' claimed that emotional memories are accurate and persistent. However, recent studies indicate that flashbulb memories are stibject to deterioration over time. This finding fits with the idea that indiwiduals who have oxperienced a traumatic event do not retain all the details of the trauma equally well. Instead, they have relatively good memory for central detail information and relatively poor memory for peripheral details of the traumatic situation. Using salfwreport data of a normal, healthy sample. Christianson and Loftus 11990 ) found evidence for this idea. The current study is an attempt to replicate Christianson and Loftus' finding in a normal student population (N $=106$. Subjects were asked to describe their most traumatic situation. They rated the vividness of the memory, the intensity of emotion at time of the trauma and at the time of recall, the amount of reliving, and the amount of central and peripheral detail information remembered. Results indicate that subjects who reported strong emotion at the time of the trauma remembered significantly more central detail intormation than subjects with relatively low past emotionality ratings. However, no differences in the amount of peripheral detail information remembered were found.

\section{Introduction}

There are conflicting ideas about the effect of traumatic incidents an memory. Some authors have claimed that traumatic events potentiate memory. An example of this position can be found in early studies of flasthbulb memories le.g. Brown \& Kulik, 1977; Pillemer, 1984). Brown and Kulik (1977) found that people claim having remarkably vivid memories (flashbulb memories) for the circumstances in which they learned about a shocking event. The observation that some people even report remembering trivial details 
of those circurnstances led the authors to propose an underlying, biologically adaptive 'now print" mectanism: in times of stress, the brain would take a 'picture of the event: Though Brown and Kulik (1977) explicitly stated that these pictures are far from complete, their 'now print' hypothesis irriplies that flashbulb memories are indiscriminate with respect to detail caitegory. A further implication of this hypothesis is that flashbulb. memories are accurate and not subject to detoriation over time. Most studies on flashbulb memories have looked at memories for newsworthy events le.g., the assassination of John F; Kennedy; see Brown \& Kulik, 1977; Winograd \& Killinger, 1983). Yet, Brown and Kulik (1977) suggested that the flashbulb memory phenomenon also occurs when awersive incidents of a more idiosyncratic nature are involved. This notion is supported by the results of a field study conducted by Yuille and Cutshall (1986). These authors studied the memory of witnesses to a shooting incident and found that memories for this event showed little loss of accuracy and detail over a 5 to 6 month period. However, recent studies on flashbulb memories cast doubts on the tenability of the "now print" hypothesis and indicate that the accuracy of flashbulb memories deteriorates over time (Bohannon, 1988: Christianson, 1989; Neisser \& Harsch, 1992).

Some authors have gone even further by arguing that emotional events are less well retained than neutral events (Kopelman, 1987; Schachter, 1986). According to these authors, emotional events may disrupt rather than enhance memorization processes, thus resulting in ammesia. There are some laboratory studies that sustain this notion (e.g., Loftus \& Burns, 1982). In addition, amnesia following psychological trauma (1.e., psychogenic amnesia) has been described in several clinical case reports le.g., Christianson \& Nilsson, 1989; van der Kolk \& Kadish, 1987; Schachter, Wang, Tulving, \& Freedman; 1982). Furthermore, the DSM-llI-R (APA, 1987) describes psychogenic amnesia as a posibible symptom of Post Traumatic Stress Disorder (PTSD).

An attractive hypothesis that reconciles both the flashbulb memory and the amnesia phenomena was forwarded by Christianson and coworkers (sere Christianson, 1992). Fo" llowing Easterbrook's (1959) cue-utilization hypothesis, Christianson (1992) argued that arousal causes narrowing of attention. Thus, in a traumatic situation the attentional focus is on information that is relevant and directly related to the event (central details). In addition, less attention will be directed to information that is not relevant and directly associated with the traumatic event (peripheral details). Christianson (1992) further speculated that narrowing of attention is associated with more elaborative processing of the details attended to. Consequently, central detail information is better retained than peripheral information.

There is some empirical avidence for Christianson's line of reasoning. To begin with, laboratory studies by Christianson and Loftus (1991) show that normal subjects recall central details of an aversive slide better than peripheral information of that slide. Second, Christianson and Hubinette (1993) investigated the memory of witnesses to robberies. They found that accuracy rates were high for memories about details associated with the robbery itself, such as weapon or clothing of the robber. In contrast, low accuracy scores were obtained for certain, perhaps not so visible details (e.g., eye.colour of the robber) and for the specific circumstances (time, date etc.) under which the event took place. Third, Christianson and Loftus (1990) asked college students about the characteristics of their most traumatic memories. They found that the subjects reported remembering more central details than peripheral details of idiosyncratic trauma's. In addition, negative 
emotion at time of the event was positively correlated with the amount of central rather than peripheral detail information remembered.

Christianson's (1992) hypothesis is of particular interest as it may shed light on the etiology of psychogenic amnesia. A common view among clinicians is that psychogenic amnesia is the result of repression of traumatic memories. In order to avoid psychological pain, the individual would block memories of the traumatic event le.g., van der Kolk \& Kadish, 1987). However, the repression hypothesis does not account for the observation that some dletail information of the trauma is remembered quite well (Christianson, 1992). The attentional narrowing hypothesis offers an alternative and more parsimonious account for the origins of psychogenic amnesia.

Given the relevance of Chrilstianson and Loftus' (1990) study to the phenomenon of psychogenic amnesia, the present study aimed at replicating their findings in a Dutch population. Thus, undergraduate students were asked to describe their most traumatic memory and to report a number of characteristics of this memory leag, amount of emotion experienced during the traumatic event and at recall; amount of central and peripheral detail information remembered, etc.).

\section{Method}

\section{Subjects}

Subjects were 106 undergraduate students at Limburg University: $86(81.1 \%)$ subjects were women and $20(18.9 \%)$ were men. Mean age of the subjects was 21.4 years (range: $19-31$ years).

\section{Procedure and assessment}

Data were collected as part of a larger survey, in which subjects also completed questionnaires concerning smoking habits, fear of small animals, etcetera. Since these questionnaires are not rellevant to the current topic, they are left out of consideration here. The questionnaires were completed in groups of approximately 10 subjects. Subjects were given the opportunity to participate anonymously and were paid for their participation.

Subjects were instructed to think about the most traumatic experience they had ever encountered. A traumatic event was defined as an extremely sudden and disturbing incident in which the subject was overwhelmed by negative emotions (see Christianson \& Loftus, 1990). Next, subjects had to answer four questions, using $100 \mathrm{~mm}$ Visual Analogue Scales (VASs). The questions concerned vividness of the memory $10=$ 'extremely vague", $100=$ 'extremely vivid' $)$, intensity of emotional reactions $10=$ 'not intense at all", $100=$ 'extremely intense') both at the time that the event took place (past emotion) and at the time of retrieving the memory (present emotion), and the number of times the subject relived the event $10=$ 'never', $100=$ 'extremely often'l. Reliving was defined as having intrusive memories, thoughts, or nightmares about the traumatic event. In addition, subjects were asked whether one specific detail of the situation was remembered better than other details. If this question was answered affirmatively, subjects were 
asked to give a short description of this detail and to classify it as either centrall (i.e., important for and directly related to the event itself) or peripheral (i.e., not important or directly related to the event itself). Next; the subjects scored the amount of central and peripheral detail they remembered about the event on two $100 \mathrm{~mm}$ VASs $10=$ 'none', $100=$ alli". Finally, subjects were asked to write down how long ago the event accurred, and to give a brief description of the event.

\section{Results}

Table 4.5.1 summarizes the traumatic experiences reported by the subjects. Almost a third of the traumatic experiences involved death of either a family member $(22.6 \%)$ or a friend or acquaintance $(8.5 \%)$. Other traumas concerned relational problems involving the subject $(10.4 \%)$ or the subject's parents $(5.7 \%)$, illness or injury of either the subject $(10.4 \%)$ or a family member $(7,6 \%)$, being threatened, robbed or attacked $(8.5 \%)$, being in accidents $(5.7 \%)$ and failing an exam $(5.7 \%)$. Four subjects $(3.8 \%)$ refrained from giving a description. The remaining $11.3 \%$ of the memories pertained to various situations, including among others having a conflict with a parent or a landlord, confrontation with an intoxicated parent, death of a pet and being rejected during a job interview. The mean time elapsed since the events was 44.4 months $(s d=43.4$, range: $1-243$ months).

Table 4.5.1. Overview of traumatic experiences $(N=106)$.

\begin{tabular}{lcc}
\hline Traumatic experience & $n$ & $\%$ \\
\hline Death of a family member & 24 & 22.6 \\
Illness or being injured & 11 & 10.4 \\
Problems with partner/brealking up & 11 & 10.4 \\
Death of a friend/acquaintance & 9 & 8.5 \\
Being threatened/robbed/attacked & 9 & 8.5 \\
Ilthess of a family member & 8 & 7.6 \\
Being in an accident & 6 & 5.7 \\
Failing an exam & 6 & 5.7 \\
Problems between parents/divorcie & 6 & 5.7 \\
Miscellaneous & 12 & 11.3 \\
No desicription given & 4 & 3.8 \\
\hline
\end{tabular}


Subjects reported their memories being reasonably vivid $(m=58.6$, sd $=28.3)$ and the incidents were perceived as highly emotional at the time (past emotion: $m=75.2$. sid $=$ 19.8). The present emotionality scores were significantly lower $\lim =4.0, s d=25.4$; $t(105)=11.12, p<.01$, two-tailed]. By and large, subjects recalled more central $(m=$ $56.5 . \mathrm{sd}=24.9)$ than peripheral details $(m=45.9, \mathrm{sd}=28.3)$. Fifty-one subjects $(48.1 \%)$ reported remembering one specific detail better than other details: of this subgroup, the majority $(74 \%)$ classified the outstanding detail as ceritral. Examples of outstanding details that were rated as central are 'getting the bad news", 'the gun against my cheek' and "seeing my grandfather lying in his coffin". Details that were rated being peripheral were for example "the sun was setting", "the place where it happened and the faces of the people present" and 'the colours of the clothes".

Table 4.5 .2 presents the Pearson praduct-moment correlations between the various VASs. As can be seen in this table; present emotion was more strongly associated than past emotion with vividness, reliving, and memory for both central and peripheral datails.

In order to look more closely at the effects of negative emotion at the time of the traumatic event on memory, a group of subjects who reported relatively low past emotion was compared with a group of subjects reporting relatively high past emotion. In order to control for possible time effects, the sample was restricted to those subjects who reported that the event occurred within the past five vears $(n=79)$. On the basis of the distribution of past emotion scores in this sample, subjects scoring in the lower 30th percentile (Low Past Emotion: Group; LPEG) and subjects scoring in the upper 30th percentile (High Past Emotion Group; HPEG) were selected. Both groups contained 23 subjects.

Table 4.5.2. Pearson $\mathrm{p}-\mathrm{m}$ correlations between vividness, past and present emotion, reliving and central and peripheral details.

\begin{tabular}{|c|c|c|c|c|c|}
\hline & Vividness & $\begin{array}{l}\text { Past } \\
\text { Emation }\end{array}$ & $\begin{array}{l}\text { Present } \\
\text { Emotion }\end{array}$ & Reliving & $\begin{array}{l}\text { Central } \\
\text { Detaills }\end{array}$ \\
\hline $\begin{array}{l}\text { Pást } \\
\text { Emotion }\end{array}$ & $36 * *$ & & & & \\
\hline $\begin{array}{l}\text { Present } \\
\text { Emotion }\end{array}$ & $.51 *$ & $.20^{*}$ & & & \\
\hline Reliving & $.36 * *$ & .15 & $.64 * *$ & & \\
\hline $\begin{array}{l}\text { Central } \\
\text { Details }\end{array}$ & $.61 * *$ & $.28 * *$ & $.42 * *$ & $.35 *$ & \\
\hline $\begin{array}{l}\text { Peripheral } \\
\text { Details }\end{array}$ & $.55 *$ & $.21 \%$ & $.46 * *$ & $.39 *$ & $.60 \%$ \\
\hline
\end{tabular}

* $P<0.05, * * 0<0.01$, Two-tailed 
As for the type of traumatic incidents, HPEG subjects mone often reported death of a family member than LPEG subjects (frequencies being 5 and 2 , respectively). Similarly, HPEG subjects more frequently reported illness or injury than LPEG subjects (frequencies being 3 and 1 , respectively. On the other hand, LPEG subjects more often remembered death of an acquaintance, and being in an accident than HPEG subjects ffrequencies being 3 and 2 versus 0 and 0 , respectively). VAS scores and other relevant data of HPEG and LPEG are summarized in Table 4.5 .3 and discussed below.

The mean scores on the past emotion VAS were 52.8 and 95.8 for LPEG and HPEG, respectively. The difference between these mean past emotion scores was highly significant $[t(44)=-11.13, p<.01$, one-tailed $]$. The time elapsed since the traumatic situation was comparable for both groups $\left(m=28.7\right.$ and $m=27.2$ months for LPEG and $H_{P E G}$ respectively; $t(44)=0.29, p>.05)$. The difference between LPEG and HPEG concerning present emotion scores reached borderline significance $[t(44)=-1.78, p=0.08$, twotailed]. Therefore, differences between LPEG and HPEG with regard to central and peripheral detail information were analyzed by means of ANCOVA with present emotion as covariate. The results indicated, that HPEG subjects remembered significantly more central details than LPEG subjects $[F(1,43)=5.06, p<.05]$. With respect to peripheral details, there was no significant difference between both groups $\left[F(1,43)=0.34, p>{ }_{\text {.05 }}\right.$ ]. Although more subjects in the HPEG than in the LPEG reported remembering an outstanding detail (14 vs 8 for HPEG and LPEG, respectively), this difference attained only borderline significance $\left[X^{2}(1)=3.14, p=.08\right.$ ]. In the HPEG, 11 subjects classified this outstanding detail as central and 3 subjects categorised it as peripheral. In the LPEG, the outstanding detail was classified as central by 4 subjects and as peripheral by 3 subjects. One subject in the LPEG did not classify the outstanding detail.

Tabla 4.5.3. High Past Emotion Group (HPEG) versus Low Past Emotion Group (LPEG).

\begin{tabular}{lllll}
\hline Variable & $\begin{array}{l}\text { High past } \\
\text { emotion } \\
(\mathrm{n}=23)\end{array}$ & $\begin{array}{l}\text { Low past } \\
\text { emotion } \\
(\mathrm{n}=23)\end{array}$ & $\begin{array}{l}\text { Statistic } \\
\text { DF }\end{array}$ & P-value \\
\hline Months since event $^{\mathrm{a}}$ & $27.2(17.8)$ & $28.7(16.6)$ & $\mathrm{t}(44)$ & $\mathrm{ns}$ \\
Past emotion $^{\mathrm{a}}$ & $95.8(3.3)$ & $52.8(18.2)$ & $\mathrm{t}(44)$ & $<.01$ \\
Present amotion $^{\mathrm{a}}$ & $55.7(26.3)$ & $41.8(26.5)$ & $\mathrm{t}(44)$ & $<.1$ \\
Amount of central details $^{\mathrm{a}}$ & $67.0(24.7)$ & $43.7(27.4)$ & $\mathrm{F}(43)$ & $<.05$ \\
Amount of peripheral details $^{\mathrm{a}}$ & $54.6(31.8)$ & $42.4(26.7)$ & $\mathrm{F}(43)$ & $\mathrm{ns}$ \\
Outstanding detail $^{\mathrm{b}}$ & 14 & 8 & $\mathrm{X}^{2}(1)$ & $<.1$ \\
No outstanding detail $^{\mathrm{b}}$ & 9 & 15 & & \\
\hline
\end{tabular}

"Mean values. Standard deviations are in parentheses; "Number of subjects. 


\section{Discussion}

A large proportion of the subjects reparted vivid memories of quite emotional life events involving deaths, relational difficulties including divorce, or situations perceived as threatening. Emotion at the time of experiencing the trauma was rated higher than emotion at the time of recall, and subjects reported remembering moire central than peripherall detail information. As for the influence of emotion on detail memory, the results somewhat unexpectedly showed that the correlations of past emotion with memory for the amount of central and peripheral details were lower than the correlations of present emotion with both detail categories. Note that the correlations reported by Chistianson and Loftus (1990) showed a different pattern. In their study, both past and present emotion correlated moderately and significantly with the amount of central detallinformation remembered. Christianson and Loftus also found that the association between past emotion and central detail memory was stronger than that of present emotion and memory for central details. Additionally, the correlations between both original and present emotion with memory for peripheral details were low and not significant.

'There are several explanations for the discrepancies between Christianson and Loftus' (1990; experiment 1) results and the current findings. First, discrepancies may be related to different ways in which emotion was assessed. Christianson and Loftus asked their sample about the valence of their emotional feeling at the time of the event: subjects were asked to what extent their feelings were pleasant or unpleasant. In the current study, subjects were asked about the strength of their emotions at the time. Note that Bradley, Greenwald, Petry, and Lang (1992) view the concepts of valence and arousal as two orthogonal dimensions that define emotional behaviour. Furthermore, in their laboratory study, these researchers found evidence suggesting that the main predictor of future memory performance is the intensity, rather than the valence of the emotion.

Second, it may well be that the number of years that passed since the traumatic event plays a confounding role in reports of traumatic memories. The time that elapsed since the traumatic events may have been longer in the subjects of the current study than in the sample studied by Christianson and Loftus. Unfortunately, Christianson and Loftus (11990; experiment 11 provide no data on the age of the traumatic memorias. However, the results of experiment 2 of their study suggest that the memories in the current sample were slightly older than those studied by Christianson and Loftus.

In order to control for possible time effects, the analyses of the association between intensity of past emotion and central versus peripheral memory were restricted to those subjects who reported that the traumatic event occurred less than five years ago. In addition, the influence of present emotion on detail memory was controlled for. These analyses showed that there was a significant difference in the amount of central detail information reported: high past emotion subjects remembered more central details than low past emotion subjects. With respect to peripheral detail information, no significant differences between both groups emerged. Though high past emotion subjects more often reported remembering one outstanding detail than low past emotion subjects, this 
difference reached only borderline significance. In sum, the results support the general notion from the experimental literature (e.g., Christianson \& Loftus, 1991) that after emotional stress, people tend to remember central details of a traumatic event relatively well. However, the current data do not confirm the idea that memory for the peripheral detall information is impaired, i.e. is prone to amnesia.

The current study is retrospective, and focuses on what people think they remember from the most traumatic event they experienced in their life. No conclusions can be drawin about the accuracy of those memories. However, the notion that memory, as a belief system, is the result of reconstructive processes rather than a reflection of a "now print" mechanism that indiscriminately stores information as it originally occurred (Bohannon, 1988, Christianson, 1989; Neisser \& Harsch, 1992; Winograd \& Killinger, 1983) was supported in two ways by the current data. First, the correlations between present emotion and vividness, reliving, and the amount of centrall and peripheral detail information remembered were larger than the correlations of any of those variables with past amotion. One way of interpreting these results is that emotion experienced at the time of retrieving a traumatic event influences what is remembered to a greater extent than the strength of the original emotion. However, there is some evidence that reports of past emotion do not accurately reflect the emotion that was originally experienced during the event (Neisser \& Harsch, 19921. Second, the majority of subjects in the current sample that recalled one outstanding detail classified this detail as central. This casts doubts on the assumption of the "now print' hypothesis that traumatic information is stored indiscriminately. Yet, it should be noted that this kind of retrospective research is not free of the peril of circularity: that is to say, details may have been judged as 'central' by the subjects, for no other reason than that they were remembered.

To conclude, with respect to the memory of central detail information the results of the current study are in line with the results of laboratory studies that show that emotion promotes the memorization of central rather than peripheral information of an aversive event IChristianson, 1992; Christianson \& Loftus, 1991). It would be of interest to see whether these findings can be extrapolated to clinical populations, e.g., PTSD patients. Possibly, the reexperiencing symptoms in PTSD reflect the memorization of central detail information. 


\section{Main Results and their Implications for studying the Attentional Narrowing Hypothesis}

\subsection{Overview of the Main Findings}

The main purpose of the empirical studies in chapter 4 was testing the attentional narrowing hypothesis of emotional memory. Recall that this hypothesis holds that an increase in physiolagical arousal results in attentional focusing. Put differently, attention would be directed to the central aspects of an emotional event, at the cost of attention for peripheral aspects of that event. Consequently, memory for central information would be enhanced, whereas memory for peripheral information would be impaired. Table 5.1. (p. 92) summarizes the results of the studies in chapter 4 . This table includes only those variables that are pertinent to the attentional narrowing hypothesis, that is, emotion, attention, and memory.

As can be seen in this table, with two clear exceptions, the majority of studies found memory patterns that are at least partially consistent with the attentional narrowing hypothesis. By and large, these results are in line with earlier studies testing this account of emotional memory formation le.g., Burke et al., 1992; Christianson \& Loftus, 1990; 1991). Bielow, the findings will be discussed along the lines of the specific issues and questions that were outlined in section 3.2 .

\subsubsection{Physiological arousal, visual attention and memory}

It was stressed in section 3.2.1 that none of the previous experiments testing the attentional narrowing hypothesis (see table 2.1) concurrently measured arousal, attention, and central / peripheral memory. Therefore, the experiment in section 4.1 relied on measures of each of these three variables. Relative to a neutral slide, an emotional slide elicited more electrodermal activity, as well as eye-movement patterns indicative of attentional focusing on the centrall item of that slide. Unexpectedly, however, recall patterns were not consistent with attentional narrowing. 


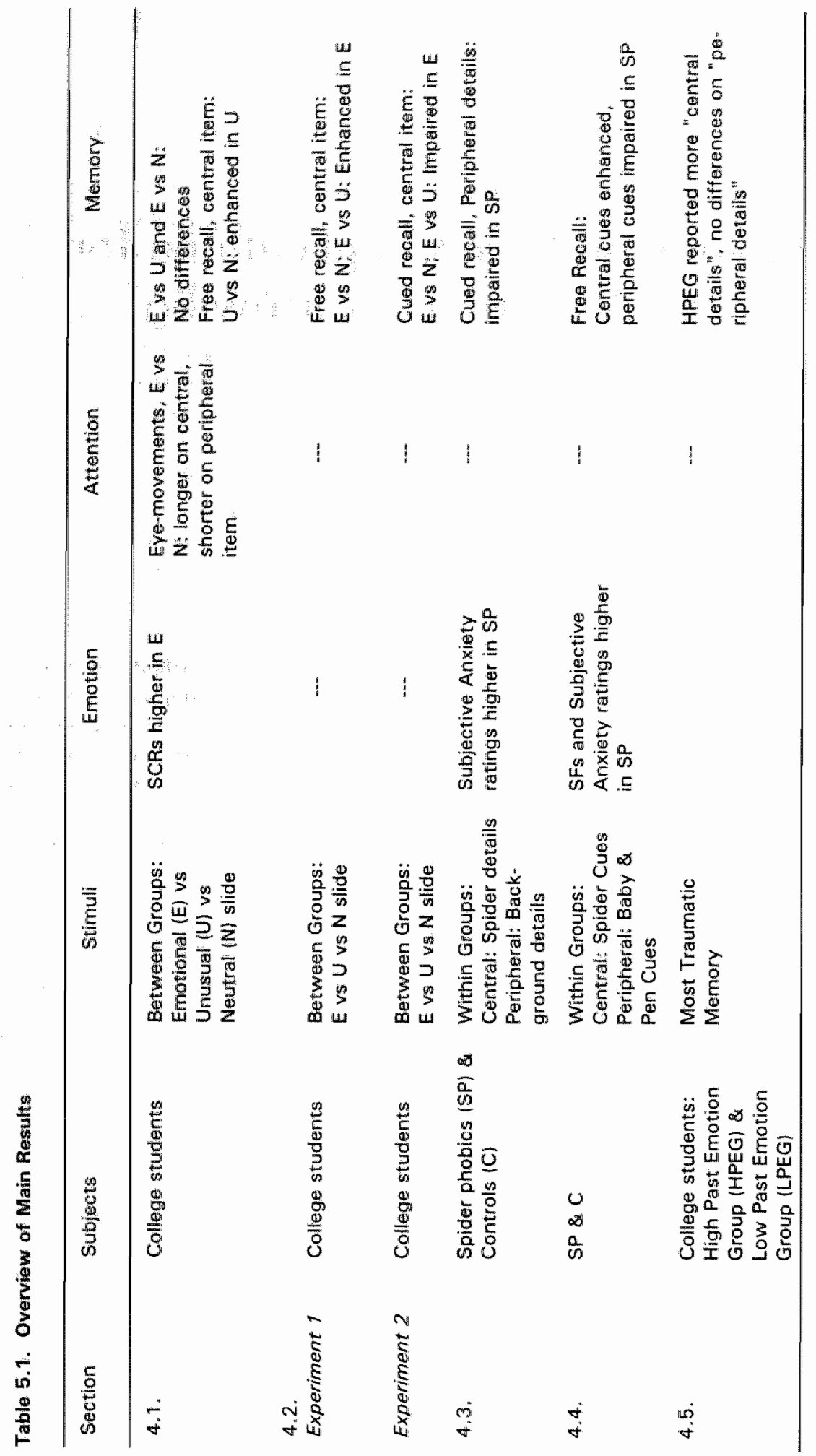


The attentional narrowing hypothesis implicates a direct and causal link between arousal, attention, and memory. Indeed, a correlational analysis showed that the time spent looking at the peripheral item was associated with recall of that item. In contrast, correlations between central fixation durations and central detail memory were weak and nonsignificant. Additionally, arousal did not contribute to the association between periphera! fixation durations and peripheral detail memory. Thus, the assumption of a straightforward link between arousal, visual attention, and detail memory was not confirmed in this study.

Two further experiments in chapter 4 also included indices of emotion. In experiment 4.3, subjective anxiety ratings were obtained. Experiment 4.4 measured subjective anxiety as well as spontaneous electrodermal activity. To explore the extent to which these variables were associated with memory, correlational analyses were carried out. Table 5.2 displays the correlations between the anxiety and memory diata of experiment 4.3 . The results of a similar analysis of the data of section 4.4 are given in table $5.3^{3}$.

These tables show that a number of associations between anxiety measures and memory attained statistical significance. In accordance with the attentional narrowing hypothesis, anxiety and peripheral detail memory were negatively correlated in experiment 4.3. Yet, contrary to predictions, a borderline significant negative correlation between subjective anxiety and central detail memory was found for the cued recall test. Pertheps this finding can be explained by the fact that central details in this experiment were not unequivocally central. This issue will be discussed later (see \$5.1.3). In experiment 4.4, various significant positive associations between emotionality and central item recall were found. In addition, subjective anxiety was negatively correlated with free recall of peripheral pens. Taken together, these results provide tentative support for the notion that emationality has a beneficial influence on central detail memory and hampers memory for peripheral information.

Table 5.2. Correlations between Anxïety and Recall in Experiment $4.3(\mathrm{n}=64)$.

\begin{tabular}{lccc}
\hline & Central details & Peripheral Detalls \\
Subjective Anxiety & -.02 & & Free Fecall \\
Subjective Anxiety & & Cued Recall & $-.35^{* *}$ \\
\hline
\end{tabular}

$r p=.05 ; * p<.01 ; * * p<.001$, one-tailed

\footnotetext{
In this experiment, spontaneous fluctuations were measured at baseline, as well as during an experimental phase. The attertional narrowing hypothesis predicts that physiological arousal during encoding results in differential recall. Therefore, the correlations in table 5.3 were calculated for number of SFs during the experi. mental phase.
} 
Table: 5.3. Correlations between Anxlety and Memory in Experiment 4.4 ( $n=46$ ).

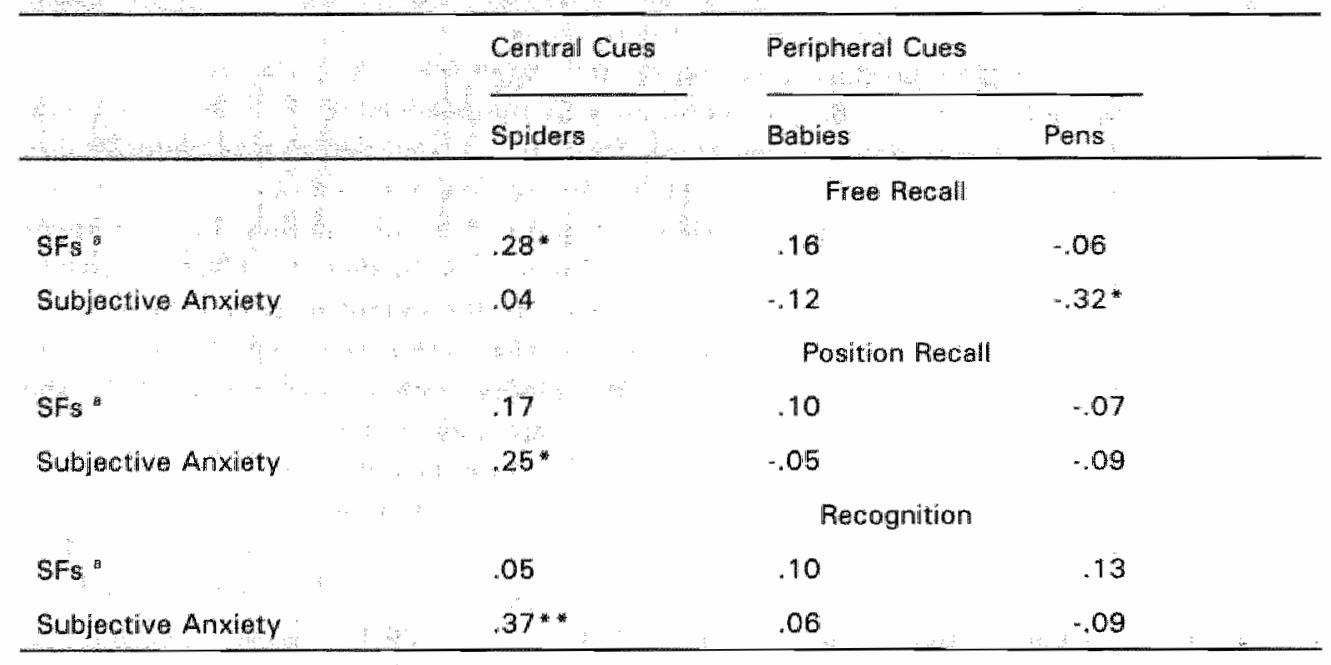

* $p<.05 ; " * p<.01$ one-tailed; ${ }^{a} \mathbb{N}=44$, due to 2 missing values

\subsubsection{Differences in stimu/us characteristics}

In section 3.2.2, it was noted that in earlier experiments on attentional narrowing le.g., Burke et al., 1992), relying on slides and normal subjects, stimulus materials differed by necessity. As a result, stimulus characteristics other than emotionality, such as salience, were not controlled for. The experimental studies in chapter 4 attempted to tackle this problem in two ways.

First, following Christianson and Loftus (1991), the experiments in sections 4.1 and 4.2 included an unusual control condition. It was found in section 4.1 that the eve-movement pattern in this unusisal control condition did not differ from that in the emotional condition. Furthermore, in two out of three experiments $(\$ 4.1 ; \$ 4.2$, experiment 2$)$, the emotional slide failed to elicit recall patterns consistent with attentional narrowing. Instead, there were some indications that the unusual slide elicited better recall for the central item than its neutral $(\$ 4.1 ; \$ 4.2$, experiment 2 ) or emotional $(\$ 4.2$, experiment 2) counterparts. It should be noted, though, that these studies differed from earlier experiments on attentional narrowing with respect to several technical aspects (i.e., slide durations, interstimulus intervals, identification instructions). Eliminating these differences (\$4.2, experiment 11), resulted in a recall pattern consistent with attentional narrowing. That is, a central detail of the emotional slide was more frequently recalled than the central detail of the unusual slide. The results of the second experiment in section 4.2 suggest that employing identification instructions, rather than relatively long slide presentation and interstimulus interval durations, was likely to be responsible for the failure to find recall patterns consistent with attentional narrowing in experiment 4.1 . Taken together, the effects of an unusual stimulus appear to be as follows. When a conventional design is 
used le.g., Christianson \& Loftus, 19911, central detail memory is more likely to be affected by emotionality than salience. However, when experimental parameters are changed to the effect that subjects become more involved, no such effects occuir. It might even be the case that under these circumstances, memory is enhanced by salience rather than emotionality.

A second method for circumventing a confound of emotionality with salience is presenting the same stimulus material to groups of subjects who differ in the way they evaluate these stimuli. This approach was followed in the experiments reported in sections 4.3 and 4.4. Specifically, spider phobics and non-spider fearful controls were exposed to threat relevant (central) and threat-irrelevant (peripheral) information. On the whole, the recall patterns in these experiments (see table 5.1) were consistent with the attentional narrowing hypothesis. That is, relative to controls, spider phobics displayed an enhanced memory for central information $(\$ 4.4)$ and an impaired memory for peripheral aspects $(\$ 4.3$ and $\$ 4,4)$.

\subsubsection{What is central, what is peripheral?}

In sections 2.4 .2 and 3.2 .3 , some problems with defining central and peripheral information were identified. The first problem pertains to discriminating central and peripheral aspects of a situation. Christianson (1992) argued that rather than being absolute and dichotomic categories, central and peripheral aspects should be viewed as two extremes of a continuum. In other wards, some information may not be as central as other information. But, then, exactly how central should a cue be in order to evoke attentional narrowing effects on memory? The central details employed in experiment 4.3 were quite diverse and pertained to all information that was temporally and spatially associated with spilders. However, many aspects were not threat-related per se le.g. , the jar containing a spïder). Thus, one explanation for the lack of difference in central detail memory between phobics and controls in experiment 4.3 is that these central details were not central enough. Of course; this explanation is post hoc. Therefore, experiment 4.4 employed central items that were strictly threat-related. In this experiment, phobics displayed an enhanced memory for central cues.

The second problem is whether the central/peripheral distinction should be made on conceptual (i.e., threat-relevance) or perceptual (i.e., spatial position) grounds. This issure was explored in experiment 4,4 , in which the spatial positions of conceptually relevant and irrelevant cues were manipulated. The results indicated that conceptual relevance, rather than centrality to the visual field, elicited recall patterns consistent with attentional narrowing. It should be noted, however, that this conclusion is based on the absence of reliable interaction effects of recall in phobics and controls with presentation format. It is possible that small sample sizes precluded detection of perceptual organization ffects. But, as things stand, it seems that central information is best defined as strictly threatrelated (i.e., emotion-eliciting) material. Whether this material is positioned in the centre of the visual field appears to be of less importance. 


\subsubsection{Ecological validity}

Section 3.2.4 discussed the question whether results from laboratory studies relying on normal subjects can be generalized to reallife traumatic situations: In light of this, the studies in chapter 4 attempted to approach real-mife events to a greater extent than is ustally the case in attentional narrowing experiments. Several strategies were followed.

First; in order to circumvent the problem that college students usually are relatively uninvolved bystanders (Yuille \& Tollestrup, 1992), the experiments in sections 4.1 and 4.2 attempted to increase involvement by giving extensive self-relevant instructions. Under these circumstances, however, recall patterns associated with attentional narrowing were not obtained. When subjects were given the instruction to merely look at the slides (i.e., were less involved), recall patterns consistent with attentional narrowing emerged. This issue will be further discussed in section 5.2.2.

The second strategy for approaching real-life situations to a greater extent than is usually the case in conventional laboratory studies was eliciting relatively high levels of emotion. This was accomplished in experiments 4.3 and 4.4 , in which spider phobics were confronted with phobia-related material. As was noted before, this strategy rendered recall patterns consistent with the attentional narrowing hypothesis.

Bearing the delicate issue of generalizability in mind, Christianson (1992) argued that the study of emotion and meimory should rely on multiple methods. That is, theorizing about mechanisms playing a role in emotional memory formation should be based on observations coming from laboratory as well as field studies. Section 4.5 describes a field study in which college students were asked about central and peripheral aspects of the most traumatic situation they ever experienced. Subjects reporting relatively high levels of emotionality at the time of the event indicated that they recalled more central aspects of their trauma than subjects who said that they experienced relatively low levels of emotionality. Whereas this observation is in line with the results of laboratory studies testing the attentional narrowing hypothesis, it should be emphasized that it may have suffered from retrospective report biases.

Taken together, attempts to increase the ecological validity of emotion and memory studies can be brought about by inducing relatively high levels of emotion. Because it is difficult to circumvent retrospective biases in field studies of emotional memory, confironting phobic subjects with their feared object under experimentally controlled conditions seems to be a promising method. Merely increasing involvement in normal subjects presented with slides does not seem to be a fruitful approach. All in all, this adds to the suspicion that earlier experiments on attentional narrowing (e.g., Christianson \& Loftus, 1991) depend to some extent on the fact that normal subjects are, indeed, uninwolved bystanders (see Yuille \& Tollestrup, 1992). 


\subsection{Implications for testing the Attentional Narrowing Hypothesis}

\subsubsection{Arousal}

The spider phobia studies described earlier found that self with detail memory. At first sight, this provides support for the attentional narrowing hypothesis of emotional memory. Note that previous studies of children's central and peripheral detail memory of highly stressful medical situations fGoodman et al, 1991; Howe et al., 1994) failed to find associations between stress ratings and detail memory. In this respect, the spider phobia studies were more successful than these earlier studies of real-life emotional events and detail memory. As yet, it is unclear how these contrasting findings can be interpreted. Possibly, the method for obtaining emotionality ratings was responsible: the spider phobia studies relied on self-rated anxiety, whereas adults judged the childrens' degree of stress in the earlier studlies.

Meanwhile, a closer look at the correlations between anxiety and memory in the spider phobia studies reveals an inconsistent pattern. That is, sometimes anxiety was associated with central detail memory but not with peripheral detail memory; sometimes this pattern was reversed. To complicate matters even further, in experiment 4.4 self-rated anxiety were more often related to memory measures than autonomous arousal as indexed by spontaneous electrodermal activity. This latter finding is unexpected for two reasons. First, Bradley and colleagues (1992) found that slides evoking relatively large electrodermal responses at encoding were more quickly identified in a subsequent recognition task. Although the authors did not report a correlational analysis, their findings may be interpreted as reflecting a positive connection between electrodermal activity and the accessibility of memory representations. Second the attentional narrowing hypothesis specifically assumes that the autonomous arousal component of emotion contributes to differential recall. Thus, it would be expected that physiological indices of autonomous arousal are more cllosely linked to memory than is self-reported emotion. Yet, in experiment 4.4 , only free recall of central items was associated with a physiological index of autonomous arousal.

The failure to obtain clear-cut links betwen electrodermal activity and memory raises several questions. To begin with, what does it mean when people display a relatively large number of spontaneous electrodermal fluctuations? Threatening situations from which escape is impossible are thought to mobilize a Behavioural inhibition System (BIS), which primarily influences electrodermal activity (Dawson. Schell \& Filion, 1990; Fowles, 1980). Thus; spontaneous fluctuations are a sensitive physiological index of anxiety fFowles, 1980). This does not mean, however, that electrodermal responses index all physiological processes that are relevant to emotional memory formation. Although electrodermal activity is part of the physiological response complex of the (sympatheticl autonomous nervous system, the different components of this response complex le.g., heart rate response, blood volume) show poor intercorrelations (Dawson et al., 1990). Moreover, sweat glands are innervated by sympathetic cholinergic fibres (Matsumoto, Walker, Walker \& Hughes, 1990). This innervation is an exception to the rule that autonomous sympathetic nerves typically secrete noradrenaline as their predominant chemical messenger. For this reason, Matsumoto and co-workers (1990) warn against generalizing from electrodermal measures to the workings of the autonomous nervous system as a whole. 
Recall that in discussing the Verkes-Dodson law (see \$2.3.1), Christianson quite legitimately wondered: "What kind of arousal is referred to in this function?" $11992, \mathrm{p}$. 295). It was argued in section 2.3 .1 that a general arousat concept should be abandoned. Instead, arousal should be regarded as a physiological component of emotion, varying across different emotional states (e,g, sexual arousal, anxiety-related arousal, etc; see Neiss, 1988). With this in mind, Christianson (1992) substituted general arousal with autonomous arousal in reformulating Easterbrook"s 1959 cue-utilization hypothesis (see \$2.3,2). However, in light of the discussion above; it now seems legitimate to ask: what kind of autonomous arousal is referred to in Christianson's reformulation? As yet, studies aimed at answering this question are scarce. The experiment by Cahill and colleagues (1994), identifying the $\beta$-adrenergic system as a possible candidate in the modulation of emotional memory, provides a promising starting point.

In the spider phobia studies described earlier, self-reports of anxiety were associated with memory and in that light, a further question may be asked. What do people mean when they say that they are anxious? One possibility is that anxiety ratings reflect a number of physiological responses. That is to say, anxious individuals may perceive various bodily responses that they subsequentily interpret as a single anxiety state. In this sense, self-reported anxiety may be a more adequate index of autonomous arousal than a single measure of any physiological response. At the same time, however, such interpretation may well be too simplistic. A common view hollds that emotion encompasses multiple components (e.g., Bradley, 1994; Lang, 1988; Neiss, 1988\%. More specifically, emation involves not only physiological, but also cognitive and behavioural responses. Thus, selfreported anxiety is most likely to be a composite measure, reflecting various response systems. In this light, it may be that spider phobics" fearful ruminations about spiders or urges to escape are as likely to have had an impact on their memory as autonomous arousal.

In summary, then, the specific role of autonomous arousal in emotional memory formation remains unclear. Research in this area could profit from pinpointing specific autonomous nervous systems involved in emotional memory. In addition, apart from physiological arousal, the role of other components of emotion (cognition, behaviour) in emotional memory formation should be taken into account.

\subsubsection{Attention, elaborative encoding, and memory}

Although the experiment described in section 4.1 found eye-movement patterns consistant with the attentional narrowing hypothesis, the expected memory patterns did not occur. In this experiment; subjects had received an extensive identification instruction. It was argued in section 4.2 that attentional narrowing effects on memory for perceptual details may have been overshadowed by elaborative processing induced by this identification instruction.

Why is elaborative processing or encoding important? Elaborative encoding refers to forming connections between a stimulus and its context or to finding meaningful connections between the stimulus and prior knowledge le.g., Graf, 1994; Schacter, 1996; Schwartz \& Reisberg, 1991). Simply put, elaborative encoding is thinking about the meaning of new information in rellation to what one already knows. Altematively, non- 
elaborative encoding is of a more perceptual nature and involves processing and interconnecting various physical features of a stimulus (Graf, 1994).

It has been argued 1e.g., Blaxton, 1989; Roediger, Wellon \& Challis, 1989; Roediger, 1990) that memory performance depends on a match between the processing type that is required during both encoding of a stimulus and the subsequent test of memory for that stimulus. This approach is known as the Transfer Appropriate Processing framework (TAP: see Roediger et al., 1989). This framework distinguishes two types of memory tests: conceptually-driven (e.gi, free recall) and data-driven (e.g., word-fraginent completion) tests. In a series of experiments, Blaxton (1989) showed that elaborative encoding (conceptual processing) resulted in enhanced performance on conceptually-driven tasks but not datadriven tasks. In contrast, encoding of physical characteristics (perceptual processing) resulted in enhanced performance on data-driven tasks, but not conceptually-driven tasks ${ }^{2}$. The TAP framework has received considerable criticism le.g., Moscovitch, GoshenGottstein \& Vriezen, 1994; Schacter, 1992/3. Nevertheless; it teaches the important lesson that memory performance is best characterized as an interaction between encoding and retrieval processes.

Bearing this in mind, the discrepancies between memory performance after 'mere viewing' $(\$ 4.2$, experiment 1$)$ and identification instructions $(\$ 4.2$ experiment 2$)$ might be explained as follows. A mere viewing instruction may encourage subjects to carefully inspect the physical properties of the presented slide (fi.e., predominantly engage in perceptual processingl. A subsequent cued recall task, in which part of the visual information is again presented, can be considered a data-driven test and this constellation may be appropriate for retrieving colour information. In contrast, identification instructions may cause subjects to engage in conceptual, elaborative processing. This type of processing may override the accurate encoding of physical stimulus properties. A subsequent datadriven cued recall test for colours may then result in relatively poor performance. A similar explanation has been forwarded (Fabiani \& Donchin, 1995) to account for the finding that engaging in elaborative encoding strategies fails to enhance memory for physically deviant words in an isolation paradigm (see $\$ 3.2 .2$ ).

In its original formulation, the cue-utilization hypothesis (Easterbrook, 1959) is silent about internal, cognitive processes. However, contemporary attentional narrowing accounts (Christianson, 1992; Heuer \& Reisberg, 1992) attempt to include cognition.

\footnotetext{
2 Note that the distinction between conceptual and data-driven tests differs firom the more frequantiv uasd dichotomy of explicit versus implicit memory testing (A.9., Graf \& Schacter, 1985). Explicit or direct memory teats incorporate an explicit ingtruction to retreve information about previous experience fe.g., frese nocall, recognition). Subsequent recall is accompanied by conscious awareness of the act of remembering lexplioit memory). Implicit or indirect memory tasks are tests in which no explicht instruction to remember is ghven 10.9. "word-completion, lexical decision). Enhanced performance on these tasks is interpreted as remembering without awareness (implicit memoryl. Presumably because physical characteristics are important in implicit memory, the impressiom has been created that all implicit testis are datandriven froediger att. al. 19891. However, Blaxton 11989 ) showed that some data-drivan tests involving axplicit instructions (cued recell) benefit from perceptual processing (see also, Schwartz \& Reisberg, 1991).
}

3 Moscovitz and colleagues (1994) argue that the TAP framework cannot fully account for dissociationis between explicit and implicit memory obserwed in patients suffering from organically based ammesias. In addition, they argue that focusing on processes does not leave room for connecting the TAP framework to specific memory structures in the brain. 
For example, Christianson (1992) proposes al post-stimulus elaboration mechanism superimposed on attentional narrowing. This author lChristianson, 1992; Christianson et all. 1991) argues that relative to neutral scenes, people think differently about emotional scenes and create a more personalized nairrative of these scenes. This 'different thinking' would occur in a late, conceptual stage of information processing. Christianson contrasts this late conceptual processing with premattentive, perceptual processing. This early stage of information processing would act automatically and independent of controlled and conscious thought (see also, Ohman, 1994). Due to pre-attentive processing, emotional significance would be quickly detected and subsequently, controlled and conscious resources would be allocated for further stimulus analysis (post-stimulus elaboration). All in all, post-stimulus elaboration in Christianson's terminalogy seems to reflect elaborative encoding or conceptual processing as described earlier in this section.

There is a fundamental difference between Christianson's interpretation of perceptual and conceptual processing and the view adopted here. In Christianson's formulation, perceptual processing is by definition automatic and unconsicious. In contrast, according to the TAP-framework, perceptual processing is not necessarilly unconscious and thus can be cletected with explicit, data-driven memory tests (Blaxton, 1989; Schwartz \& Reisberg. 19911. Within this framework, Christianson's main finding that emotion enhanced memory for the colour of central information (e.g., Christianson \& Loftus, 1991; Christianson et al. 1991 ; see also $\$ 4.2$, experiment 11 is interpreted as an adequate match between memory representations of perceptual information and the data-driven testing procedure (i.e., cued recall) employed in these experiments. The difference between the emotional and neutral conditions in colour memory may be explained by the modulating effects of arousal-related brain processes (e.g., Cahill et al., 1994; McGaugh, 1992) elicited by the emotional scene. These modulating effects would strengthen a perceptual memory representation of the central information in the emotional scene, rendering it more accessible given the appropriate percieptual cues.

Taken together, it is clear that the attentional narrowing hypothesis is limited in the sense that it does not take into account an interaction between encoding processes and the type of memory that is subsequently tested. The distinction between perceptual and conoeptual processing is interesting. Whether attentional narrowing effects occur most strongly when normal subjects viewing slides are engaged in perceptual encoding, as suggested here, could and should be tested empirically. It should be noted, though, that the findings of the spider phobia experiment in section 4.4 suggest that attentional narrowing effects may also be evident on conceptuallymdriven tasks. In this experiment, threatrelevance, rather than perceptual arganization, resulted in enhanced free recall. How the attentional narrowing hypothesis relates to information processing approaches of the emotional disorders will be discussed in the next section.

\subsection{Spider Phobic Memory: Attentional Narrowing or Cognitive Bias?}

In section 5.1.4, it was concluded that experiments in which phobics are confronted with their feared object provide a fruitful approach for studying the impact of relatively high levels of emotion on memory. It was argued earlier $(\$ 4.3$ and $\$ 4.4)$ that persons with a specific phobia are relatively normal people, apart from a circumscribed, but intense fear 
of some object or situation. Thus, it is assumed that studying the impact of phobic anxiety on memory might provide an experimental model for the impact of traumatic experiences on memory. The discussion below focuses on the question of to what extent phobic memory may be generalized to traumatic memory.

\subsubsection{Fear networks and information processing in phobics}

Over the past decade, a vast literature has accumulated on how anxiety disordered indi... viduals process threatening information le.g. Foa K Kozak, 1986; Wells \& Matthews, 1994; Williams et al., 1988; Williams; Mathews \& MacLeod, 1996/. A common starting point for theorizing is the view that in general, emotions are represented in memory as an associative network (Foa \& Kozak, 1986; Lang, 1988). Thus phobic individuals would have a "fear network" (Foa \& Kozak, 1986) that consists of information about phobic stimuli, anxiety responses (verbal, physiological, overt behaviour), and the meaning of stimulus and response elements. Compared to non-fearful persons, the fear network in phobics would be more coherent li.e., contain more associative links of relative high strength, Lang, 1988) or include more excessive response elements (Foa \& Kozalk, 1986). Whenever an incoming stimulus matches the fear network, it is activated and emotion production (e.g., physiological arousal, avoidance behaviour) follows.

It should be emphasized, that this view would predict the occurrence of a threat-congrum ent bias at all stages of information processing (Lavy, 1993). That is „ phobics would both selectively attend to threatening information and display an enhanced memory for that information. This is not, however, what the results of information processing studies in the anxiety disorders show. Although a threat-congruent attentional bias has been amply demonstrated (see for a recent review, Williams et al., 1996), evidence for a memory bias is contradictory Lavy, 1993; Wells \& Matthews, 19941. What may be the reason for these conflicting results in anxiety and memory studies?

During exposure therapy, Foa and Kozak (1986) observed a number of avoidant strategies in their patients, such as distraction, distorting fearful images, concentrating on nonfearful information and so forth. These clinical observations led these authors to propose that anxiety disordered patients may engage in such strategies to cognitively avoid the processing of threat-related information. This cognitive avoidance hypothesis has subsequently been offered as an explanation for fallures in finding memory biases in anxious patients (e.g., Dalgleish \& Watts, 1990).

Within an information processing model ${ }^{4}$ of the emotional disorders (Williarns et al., 1988), cognitive avoidance is viewed somewhat differently. This model proposes that anxiety disordered or high-trait anxious individuals are characterized by a tendency to allocate processing resources towards threat at the prenattentive, automatic stage. A hypothesized affective decision mechanism would regulate this directing of processing

\footnotetext{
4 The information processing model of emotional disorders proposed by Wulliams and co-workers 11988 ) is viewed as an alternatiwe to network theories (Wellis Mathews, 1994 ). Instead of emphasizing the ropresantation of information structures in memory, this model assumes that cognitive biases can independently occur at different stages of information processing. Perceptual processing at a pre-attentive, autometic stage is distinguished from elaboratiwe processing during a strategic stage.
} 
resources. However, upon entering the elaboration stage, further processing of threatening information is aborted. That is, a second affective decision mechanism, operating at a strategic level, would direct strategic processing resources away from threat information lelaborative cognitive avoidancel. Thus, fewer mnemonic cues would be stored in memory, resulting in a diminished retrievability of the threat information.

Taken together, both the network approach (Foa \& Kozak, 1986) and the information processing model (Wiliams et al, 1988 ) would predict an impaired memory for threatening information in phobic individuals, due to cognitive avoidance.

\subsubsection{What if cognitive avoidance is left out of consideration?}

It has been argued that cognitive avoidance is an subtle or unstable phenomenon (Cloitre \& Liebowitz, 1991; Wells \& Matthews, 1994). The findings in section 4.4 add to that suspicion: phobics showed relatively enhanced recall for phobic cues and this is inconsistent with the cognitive avoidance hypothesis. Thus, it was concluded in section 4.4 that the findings favoured an interpretation in terms of attentional narrowing and that studying spider phobic memory may provide a model for traumatic memory.

However, eritics might argue that both the network and information processing views do not assume that cognitive avoidance always plays a role, and that memory biases in anxious patients can never be obtained (see for example, Williams et al , 1988, p.183). These critics might further argue that the memory bias observed in experiment 4.4 is due to differences between phobics and non-fearful persons in information processing capacities or cognitive architecture, and that consequently, phobic anxiety provides a poor model for traumatic anxiety. The discussion below focuses on the question of to what extent the cognitive accounts of phobic anxiety preclude treating phobic memory as a model for traumatic memory, given that the cognitive avoidance hypothesis is left out of consideration.

First consider the information processing approach (Williams et al., 1988). For the anxiety disorders, this model assumes that there is some trait or disposition for the preattentive affective decision mechanistm to allocate processing resources to threat. $A$ further assumption is that the output of this mechanism would be influenced by high levels of state anxiety. Thus, high state anxiety would cause the affective decision mechanism to direct processing resources towards threatening information. Abandoning the cognitive avoidance assumption implies that strategic resources would also be allocated to the threatening information. Hence, more stimulus characteristics would be encoded in memory, rendering the threatening material more retrievable ${ }^{5}$. Note that the information processing model does not specify how a disposition for attending to threat is acquired ${ }^{6}$.

\footnotetext{
5ote that this type of elaboration differs from the definition of elaborative encoding described in section 5.2 .2 . In the latter definition. elaboration occurs when the input is processed in relation to the context of preaxisting knowledge, whereas Willams and co-workers 1988 l do not refer to this type of elaboration.

6) In addition, note: that this disposition is rather unspeciffied. Thus, in its original formulation (Williams et al, 1988\%. the information processing model does not account for the finding that spider phobics show an attantional bias towards spider stimuli, relative to general threat information le.g., Lawy, van den Hout \& 
Nor does the model specify how a high level of state anxiety is brought about: it merely states that a disposition to attend to threat is exacerbated under conditions of state anxiety. All in all, it seems safe to conclude that the information processing perspective allows for using the method of confronting spider phobics with their feared object as an experimental model for the impact of trauma on memory. In this way, an anxiety state acting on a disposition for attending to threat provides an analogue to emotion-induced attentional narrowing during trauma.

Considering the network model (Foa \& Kozak, 1986; Lang, 1988), however, paints a different picture. Recall that according to this approach, phobic lear of patients is represented differently in memory than fear structures in normals. If the cognitive avoidance concept is abandoned, the presence of a phobic fear network may enhance memory for phobic information. More specifically, the presence of an elaborative network of spider information would allow for elaborative encoding in the sense of connecting the incoming spider stimulus to this pre-existing knowledge in memory. Put differently, memory bias for spiders would be due to famillarity with spiders. Note that for testing attentional narrowing effects on memory, the role of physiological arousal is crucial. However, in fear network terminology, physiological response is part of fear network activation. Although physiological arousal may facilitate elaborative encoding (Bradley, 1994), it seems plaus* ible to assume that the presence of a physiological response is not the sole or even a sufficient requirement for enhanced memory for spider stimuli.

All in all, the network approach poses a problem for comparing phobic memory with traumatic memory. The difference would be that phobics may encode phobic stimuli in relation to elaborate pre-existing knowledge, whereas forming a memory representation of a first-time trauma most likely takes place in the absence of an existing elaborative memory structure for trauma. It remains to be empirically tested whether enhanced memory for phobic cues depends on physiological arousal or pre-existing knowledge. Perhaps an appropriate test would be to expose phobic individuals to their feared object while blocking physiological arousal (e.g., by a $\beta$ madrenergic antagonist). If an elaborated network of pre-existing knowledge is responsible for phobic memory bias, then enhanced memory would occur even in the absence of an arousal response. If however, physiological arousal is crucial, then memory enhancement is not likely to occur.

In summary, then, the question of to what extent phobic memory may be generalized to traumatic memory is yet unanswered. Attentional narrowing does account for the finding that spider phobics displayed enhanced memory for phobic cues in experiment 4.4 . However, if the assumption of cognitive avoidance is discarded, this memory bias may also be explained in terms of contemporary cognitive views of the anxiety disorders. An explanation in terms of an information processing framework (Williams at al., 1988), is not in conflict with testing the attentional narrowing hypothesis of emotional memory in a phobic sample. However, in terms of a fear network approach (Foa \& Kozak, 1986),

\footnotetext{
Qf... continued

Arntz, 1993. Note that a recent reformulation of the original model using a connectionist approach iWilliarns et al., 1996$)$ accounts for the specificity of the bias. Williams and co-workers (1996) propose that dute to previous experience with threat le.g., spidersi, premattentive information pathways are strengthened by neuromodulatory influences $10 . \mathrm{g}$. increased brain noradrenaline during anxietyl. However, thigi revised model focuses exclusively on pre-attentive processing and leaves the strategic stage of information pirocessing out of consideration. Therefore, the revised model is not further discussed.
} 
phobic memory may be enhanced due to connecting incoming phobic material to preexisting knowledge rather than an arousal response. This possibility should be ruled out empirically before it can be concluded that phobic memory provides an adequate analogue for traumatic memory.

\subsection{Concluding Remarks}

It appears that the study of emotion and memory would profit most from experiments in which relatively high levels of emotion are induced. Other than field studies, laboratory studies allow for circumventing retrospective biases. Taken together, confronting phobic subjects with their feared object under experimentally controlled conditions seems to be a promising method. This approach has several advantages over experiments in which normal subjects view either emotional or neutral slides. First, phobics and controls are presented with the same stimuli, thus excluding the possibility that memory is affected by differences in stimulus material per se. Second, relatively high levels of emotion are elicited in the laboratory, adding to ecological validity. However, the question of whether enhanced memory for phobic cues is brought about by elaborate fear networks or by attentional narrowing awaits further empirical testing.

In its current formulation, the attentional narrowing hypothesis is limited in that the exact physiological parameters responsible for differentiall recall are not specified. This issue should be addressed by future studies. In addition, cognitive variables in emotional memory formation (e.g., perceptual versus conceptual processing) deserve further exploration, as these variables have implications for attentional narrowing experiments relying on normal subjects. 


\section{Towards a Model of Partial Amnesia}

\subsection{Attentional Narrowing}

Attentional narrowing has been proposed as a more parsimonious and testable account for failures to recali aspects of a traumatic experience than special mechanism hypotheses such as repression and dissociation (Christianson, 1992; see also $\$ 3.1$ ). The main purpose of the present dissertation was to evaluate the merits of the attentional narrowing account: to what extent cian partial amnesia in PTSD be explained in terms of attentional narrowing?

Surely, the attentional narrowing hypothesis has potential to account for clinical observations that in some PTSD patients, good memory for some aspects (as indicated by reexperiencing symptoms) and bad memory for other aspects (i.e., partial amnesia) coexist. The finding that impaired recall is not restricted to perceptual stimulus characteristics (experiment 4.3 ) but also occurs for peripheral items as a whole lexperiment 4.4 , has particular relevance for modelling partial amnesia. It should be noted that earlier attentional narrowing experiments were carried out within the domain of forensic psychology. In other words, the prime interest of researchers such as Chistianson 119921 is to account for variations in exewitness memory. Within this context, memory for perceptual detail can be of great importance. For example, accurate eyewitness reports of the colour of a perpetrator's clothing or getaway car can be crucial for the conviction of that perpetrator. And, indeed, when it comes to the forensic phenomenon of weapon focus (see $\$ 2.2 .1$ ), attentional narrowing might provide the only plausible explanathor. Yet, from a clinical point of view, a failure to recall perceptual detail will be of less importance. Most likely, a diagnosis of partial amnesia will hinge on reports of an inability to recall whole fragments of a traumatic situation.

This draws attention to another point: partial amnesia is defined as allack of memory for important aspects of a trauma (APA, 1994). Likewise, in clinical literature partial amnesia is thought to reflect the forgetting of the most threatening aspects of a traumatic event (e.g., the moment that a rapist holds his knife to a victim's throat; Van der Hart, 1994). 
However, the attentional narrowing hypothesis predicts that amnesia occurs for unimpontant aspects of the trauma: arnnesia would pertain to those aspects of the situation that are irrelevant for immediate threat (see also $\$ 5.1 .3$ ). Thus, both the clinical literature and the attentional narrowing account hold that poor memory occurs for aspects of traumatic situations. The difference lies in the twpe of information that is poorly retained: threatrelevant information according to DSM-IV and threat-irrelevant information according to the attentional narrowing hypothesis. This would lead to the pessimistic conclusion that attentional narrowing cannot provide an adequate model for partial amnesia as depicted in DSM-IV. Two issues, however, make such a conclusion premature.

First, the exact nature of amnesia in PTSD is unclear "It remains to be empirically established whether lack of memory in PTSD patients reflects central, threatening, and important aspects rather than peripheral, non-threatening, and unimportant aspects. Clinical accounts claiming that amnesila mainly occurs for the most threatening aspects of a trauma are anecdotical (e.g., van der Hart, 1994) and systematic studies on the precise characteristics of partial amnesia are lacking (see \$1.2.3).

A second issue involves problems with defining both the notions of "importance" and "centrality". It was argued earlier (see \$1.2.3), that the concept of importance in partial amnesia depends on how particular aspects of an emotional event are interpreted. This parallels difficulties in determining the centrality of a particular aspect. Central aspects are best defined as essential for eliciting emotion (see $\$ 5.1 .3$ ) and again, this depends on how these aspects are evaluated. These considerations cast doubts an attempts to objectify a priori what information is particularly amnesia-prone. In case of spider phobics, it is clear what information is relevant or irrelevant to threat. In contrast, the diversity of traumatic experiences in PTSD patients will most likely rule out general statements about what qualifies as important or unimportant aspects of a trauma. As became apparent in the case of ms. G. $15 \% .1$, a perceptual detail that was unimportant within the context of a murder, gained substantial importance as her interpretation changed from a murder scenario into a rape scenario. Thus, whether a certain aspect is important / central or unimportant / peripheral hinges on the evaluation of the observer.

All in all, the attentional narrowing hypothesis can account for partial amnesia in that devoting little attention to a particular aspect has ramifications for subsequent recall of that aspect. However, impaired memory for peripheral aspects is difficult to reconcile with the clinical impression that amnesia would mainly affect central, threatening aspects. Whether this clinical impression can be validated by systematic empirical studies remains to be seen. Definitional problems, due to the subjective nature of notions such as "importance" or "centrality", may preclude firm conclusions as to what informational categories. are particularly amnesiamprone. Nevertheless, these definitional issues make it clear that subjective, cognitive variables (i.e., evalluation) should be considered in theorizing about the impact of attention deployment on memory. 


\subsection{Encoding}

Cognitive theories of PTSD share the premise that a traumatic experience violates existing knowledge and basic assumptions about the world (Brewin, Dalgleish \& Joseph, in press). For example, Foa and comorkers (Foa, Zinbarg \& Olasov-Rothbaum, 1992) proposed that the greater the degree of unpredictability and uncontrollability of a traumatic situation is, the greater the likelihood of developing PTSD symptomatology would be. Could this idea of a mismatch between an actual event and a cognitive set of expectations aid in accounting for the specific PTSD symptom of partial amnesia? In general, the memorability of an event is thought to increase when it is consistent with expectations and beliefs about that event (Kihlstrom; 1994). Yet; Kihlstrom (1994) argues that events that are highly incongruent with expectations are even more memorable, because they receive more elaborative encoding. Thus, at first sight the idea of a mismatch is incompatible with amnesia production.

Note, however, that elaborative encoding is an effortful enterprise. In a recent paper, Craick and colleagues (Craick, Govoni, Naveh-Benjamin \& Anderson, 1996) propose that episodic memory encoding is reflected by processes that involve both perceiving and comprehending external events. These authors further suggest that encoding operations are controlled: that is, they require conscious awareness and processing resources, varying with stimulus novelty, importance or compatibility with existing cognitive schemata. In light of this, it is fair to assume that conscious and strategic encoding of extremely incompatible (i.e., traumatici information draws heavily on processing resources. Schematic processing of incompatible material will require additional time and tradie-off effects are to be expected: time spent at processing one aspect cannot be used for encoding another aspect of the situation ${ }^{1}$. Especially those traumatic events that unfold within a split-second will not permit a full conceptual analysis of the situation.

Thus, attentional narrowing effects on traumatic memory are best understood as preferential encoding: that is, as an interaction between perceptual focusing and conscious attempts to relate highly incongruent information to pre-existing cognitive schemata. In contrast with earlier formulations (e.g., Christianson, 1992), this account does not suppose a causa/ role of autonomous arousal in attentional focusing. Arousal is viewed as a natural by-product of appraising the situation as extremely threatening. However, physio. logical processes involved in emotion (e.g., release of catecholamines in the amygdala) do play a role in strengthening memory traces (e.g." Cahill et al., 1994; Cahill \& McGaugh, 19961 . What kind of information would be stored in such a memory representation?

In the terminology of the transfer-appropriate processing framework (see 5.2 .2 ), the meaningful analysis of a traumatic situation involves conceptual processing, whereas the encoding of stimulus characteristics reflects perceptual processing. Roediger and col-

\footnotetext{
1 in this respect, earlier studies on visual attention are relevant. One study (Antes \& Kristjanson, 1993 ) found that when processing resources were drawn away by a listening task, owemfixations were restricted to highly informative regions of a wisual scane. Although these fixations were of longer durations, memory for the visual information showed no advantage. In addition. G.R. Loftus and Mackworth (1978) observed rellatively long eve-fixation durations on objects that wer unexpacted given the context. They suggested that these longer fixation durations reflected the time needed to add the incongruent information to a cognitiwe schema. Taken together, these findings lend support to the notion that schematic processing requires strategic resources and is time-consuming.
} 
leagues (1989) wiew these types of processing as two extremes on a continuum, rather than as a dichotomy. According to this view, the encoding of external information will usually involve both conceptual and perceptual processing, unless some environmental demand (6.g., an experimental instruction, Blaxton, 1989 / causes one processing mode to prevall over the other. Thus, most memory representations will consist of a mix of perceptual and conceptual information. It was suggested above, however, that in case of trauma, conceptual processing may fall short as a function of the limited nature of strategic prociessing resources. Following this line of reasoning, it is conceivable that some highly schema-incongruent information is not (fully) conceptually processed, yet receives attention during encoding. Then, the memory representation of this information will mainly consist of perceptual characteristics. Of course, if some information receives no attention whatsoever, it will not be represented in memory.

In summary, then, it is proposed that attentional narrowing is mediated by strategic and conscious efforts to understand the traumatic situation at hand. Autonomous arousal accompanies the evaluation of the traumatic event as threatening, and enhances storage of the information by strengthening memory traces. Due to limited strategic resources, some aspects would be stored at a predominantly perceptual level, whereas other aspects would be represented at both a conceptual and perceptual level. Finally, aspects that receive no attention at all, will not be stored in memory.

\subsection{Encoding and Retrieval Interactions}

It was argued in section 5.2.2, that memory performance should be vilewed as an interaction between encoding and retrieval processes. Prior to considering this interaction in light of traumatic memory, the characteristics of retrievall operations will be discussed.

Retrieval can take place in two modalities (Craick et al., 1996; Schacter, 1996). Strategic retrieval refers to deliberate and controlled search. This retrieval mode would be mainly involved in free recall tests (i.e.; answering the question "what happened?"). Recent evidence from neuroimaging studies (see for a discussion of this literature, Craick et al., 1996; Schacter, 1994, 1996) suggests that strategic retrieval is carried out by prefrontal areas in the right hemisphere. Alternatively, strategic elaborative encoding involves activation of areas in the lleft prefrontal cortex, suggesting a hemispheric encod. ing-retrieval asymmotry. Associative retrieval is thought to be a more automatic modality and occurs when a memory is triggered by an environmental cue. Thus, this retrieval mode would be activated by memory tests that provide a rich set of cues $\left(e_{n} g_{*}\right.$, recogni tion). Associative retrieval would involve brain structures in the medial-temporall (i.e., the hippocampus and adjacent cortical structures) and diencephalic (i.e., the thalamus and mammilary bodlies) regions.

Interestingly, this so-called hippocampal component (i.e., both the medial-temporal and the diencephalic regions) is also thought to be vital in the organization of explicit, episodic memory at a neurological level (Moscovitch et al., 1994; Squire, 1994) ${ }^{2}$. Moscovitch and

\footnotetext{
${ }^{2}$ In this respect, it is important to note that strategic retrieval is believed to interact with the hippocampal component (Craick et al., 1996). The strategic retrieval process would produce a mix of perceived and self-
} 
colleagues (1994) argue that the hippocampal component binds the different parts of a memory representation together. Various parts of the representation are stored in appropriate regions of the cortex, and the hippocampal component contains an index that points to these regions ${ }^{3}$. Thus, episodic remembering is like putting together pieces of a giant jigsaw puzzle, and traumatic episodic memory is no exception to that rulle (Schacter, 19961.

How, then, would encoding and retrieval processes interact in traumatio memory? Con* sider the following speculation. In the previous section; it was suggested that some aspects of a traumatic event are processed at a conceptual as well as a perceptuall level, whereas other aspects are mainly analyzed at a perceptual level. When some information is not (fully) understood, it is subsequently less likely to be accessed when strategic retrieval -involving conceptual processing - is invoked. Alternatively; appropriate cues, reinstating (part of) the perceptual characteristics of the trauma, may trigger associative retrieval and thus increase the probability that information that was not elaboratively encoded becomes available. According to this account, partial amnesia will be most apparent when a traumatized individual engages in controlled efforts to recount what happened during the trauma. Recollection involving associative retrieval will elicit a more complete traumatic memory. Note that information that was not attended to during encoding, can also not be reinstated by associative retrieval, simply because it is not represented in memory. Thus, partial amnesia may still occur during associative retrieval..

\subsection{Trying to forget}

It has been suggested that cognitive avoidance in PTSD patients may have a detrimental effect on their traumatic memory le.g., Brewin et al., in press; Koss. Figueredo, Bell, Tharan, \& Tromp, 1996; Wegner, Quillian \& Houston, 1996; Schacter, Koutstaal \& Norman, 1996). Note that cognitive avoidance in traumatized individuals is of a different nature than the type of cognitive avoidance discussed in section 5.3.2. This discussion focused on the idea that anxiety disordered patients would avoid the elaborative processing of incoming threatening material, with subsequent ramifications for recall. Thus, cognitive avoidance in this sense reflects avoidance of encoding. In PTSD patients, the traumatic experience is already encoded and represented in memory. These traumatic mem ories somehow obtain an intrusive character, leading to distress. Thus, in this sense, cognitive avoidance reflects avoidance of strategic retrieval. Whenever an intrusive memory or thought presents itself, a traumatized individual is likely to respond with conscious efforts not to think about their experience to avoid distress. These deliberate attempts to erase traumatic memories mav have the paradoxical effect that intrusions occur more

\footnotetext{
2 (., continued)

generated cues that are subsequently applied to the hippocampal component. This component, in turn, would reactivate representations that fit the "description" specified by this retrieval mode.

3 Eventually, the hippocampal component is no longer needed to provide an index for assiembiling an opilsodic memory, because direct conmections between the various cortical regions are gradually establishud. Hhis longterm process is referred to as consolidation, andits duration may vary between monthis or even decades (Schacter, 1996).
} 
often (Wegner et at, 1996).

How, then, would deliberate attempts to avoid traumatic memories affect the quality of those memorles? Wegner and colleagues (1996) reasaned as follows. Traumatic experiences are episodes extended in time, consisting of a sequence of scenes. Whenever a single scene comes to mind, it is suppressed. Suppressing many individual sicenes, then; may sever the links between them, undermining memory for the sequence of the events constituting the traimatic experience. There is some evidence that supports this notion. The results of an experimental study (Wegner et all, 1996) indicated that the accurate retrieval of the order of events in a non-traumatic film was disturbed after subjects had engaged in suppression of the film scenes. In addition, subjects who had suppressed were more likely to report that the film had a snapshot-like character. These results are in line with a fleld study by Koss and colleagues (1996). These authors found that compared to pleasant memories, rape memories were less likely to occur in a meaningful order. These rape mernories were also less likely to be talked or thought about. Taken together, suppression or non-rehearsal may have the specific effect of disturbing memory for the sequence of events.

Furthermore, deliberate attempts to suppress traumatic experiences may result in the forgetting of detalls or aspects of those experiences. For example, Koss and colleagues (1996) found that women who had been raped reported that they remembered this event less well than women who reported a pleasant experience. Rape memories were rated less clear, less detailed and so forth ${ }^{4}$. Experimental studies on intentional forgetting le.g.. Geiselman, Bjork \& Fishman, 1983; see Johnson, 1994, for a review) suggest that instructions to forget lower the probability that word stimuli are recalled. Bjork (1989) proposed that these experimental findings may be explained by a retrieval inhibition mechanism, due to an intention to forget in combination with the learning of new material. Thus, the avoidance of strategic retrieval in traumatized individuals may cause gradual forgetting of aspects of their experience. It has also been suggested that repeated efforts to avoid retrieval may obtain an automatic character (Brewin et al., in press). Thus, traumatized persons may be experts in intentional forgetting (Terr, 1994)

All in all, it seems that avoidance of strategic retrieval may add to the phenomenon of partial amnesia. Retrieval avoidance may have the specific effect of disturbing memory for the sequence of a traumatic event, or render details of this experience less accessible. Future studies may shed light on the precise workings of deliberate attempts to forget traumatic memories.

\footnotetext{
4. At first sight, these findings are in conflict with the findings reported in section 4.5 and the results of the study by Christianson and Loftus (1990). It should be noted that Koss and colleagues did not ask their subjects about the central / peripheral distinction. In addition, Koss and co-workers provide no information about the time that elapsed since the traumatic experience. It is thus unclear whether recency effects may are responsible for their finding that rape memories differ from memories of pleasant events.

5. Contrary to this idea, recent directed forgetting studies le.g., Cloitri, Cancienne, Brodsky, Dulit \& perry, 1996; MclNally, Metzger, Lasko \& Pitman, submitted) suggest that PTSD patients display an enhanced memorv for words thay were instructad to forget. However, these studies employed paradigm that does not separate encoding and retrieval operations ('see Johnson, 1994). Thus, the dea that PTSD patierits are skilled retriaval iryhibitors awaits further empirical tosting.
} 


\subsection{Why search for a Model for Partial Amnesia?}

The main purpase of the present dissertation was to evaluate the merits of attentional narrowing as a testable model of partial amnesia in PTSD. The account outlined above holds that processing of highly schema-incongruent information mediates attentional narrowing. As a consequence, some aspects may be elaboratively encoded, whereas other aspects may be merely processed at a perceptual level and are thus superficially encoded. The mode of retrieval subsequently determines memory performance. Finally, avoidance of retrieval may further add to the partial amnesia phenomenon. This account renders testable predictions that can be examined in future empirical studies.

It became apparent earlier $(51.2 .3)$ that the empirical evidence for the frequent occurrence of partiall amnesia is mixed. It was argued that one of the reasons for these mixed findings may well be that partial amnesia is a problematic symptom to measure. Clearly, the description of the symptom offered by DSM-IV (1994) should be reconsidered because it relies on vague notions such as "important aspects of the trauma" and 'beyond ordinary forgetfulness' (see $\$ 6.1$ ). The precise characteristics of partial amnesia should be clarified before firm conclusions can be drawn about the explanatory power of the account outlined in this chapter. Thus, a major challenge for future clinical studies on PTSD is to determine the exact nature of a failure to remember parts of a traumatic experience.

If it is not at all clear what partial amnesia is, why, then, is it important to provide an explanation? The answer to that question amounts to the following. In clinical literature, a common assumption is that some form of pathological forgetting of a traumatic event frequently occurs. A second common assumption is that pathological forgetting is caused by special mechanisms such as repression or dissociation. As became apparent in chapter 1 . it is questionable whether these ideas are justified. However, holding these assumptions has ramifications for therapy. For example, van der Hart (199.4) maintains that the most threatening aspects of a trauma slumbers in the unconscious as a 'dissociated pathogenic core", that causes symptoms. The author further argues that unless such a pathogenic core is recovered to consciousness, the traumatic symptoms will persist. Thus, holding the assumption that some threatening aspect of a trauma is unaccessible to consciousness, is likely to result in attempts to recover this aspect in therapy. Subsequently, therapists may engage in therapeutic techniques $\left\{\mathrm{e}_{\text {. }}\right.$.. hypnosis, guided imagery that at best. do not promote the accuracy af memory. The worst scenario is that these techniques may even cause false recollections to evolve (Yapko, 1994).

It should be emphasized that the assumption that some aspects of a traumatic event are processed at a perceptual level does not imply that these aspects reside in the uncon. scious as a 'pathogenic core'. Nor does this assumption fit the description provided by van der Kolk and Fisler (1995) that "some aspects of traumatic events appear to get fixed in the mind, unaltered by the passage of time or by the intervention of subsequent experience" (p. 508). These notions of van der Hart (1994) and van der Kolk and Fisler (1995) share the assumption that some aspects of a traumatic experience are stored in memory as an unconscious, exact copy of the actual event that could and therefore should be recovered. However, memory is a reconstructive, and not reproductive instance. Assuming that some aspects are perceptually processed implies that their memory representations may be activated by associative retrieval. However, note the emphasis on may. As Schacter (1996) put it: 
Wo mast not, Wowever, confuse these idieas whth the notion that all experiences are recorded somewhere in our brains, only awasthing the appropriate retheval cue to be brought into awareness. While controlled research hris demonstrated over and over that cues and reminders can lead to recall of experences that have seemingly disappeared, it does not necessarily follow that all experiences are preserwed and potentially tecallable. Sonetimes we forget because the right cues are not avaliable, but it is also likely that sometimes we forget because the relevant engrams have weakened or become blumed (p. 64 ).

In conclusion, similar to more mundane forms of episodic remembering, traumatic memory is by no means a perfect, reproductive instance. The omission of certain aspects in recall should not be taken as a sign of the activation of some pathological mechanism. Instead, these omissions may well be a natural consequence of the limited nature of information processing resources in combination with an imperfect match of encoding and retrieval strategies. 


\section{References}

Adller, A. (1945). Two different types of Post-Traumatic Neuroses. American Jowrnal of Psychiatry. $102,237-240$.

Albach, F. (1993). Freud's Verleidingstheorie: incest, Trauma, Hysterie. Middelburg: Stichting Petra.

Allen. J.G. (1993). Dissociative pracesses: Theoretical underpinnings of a working model for clinician and patient. Bulletin of the Menninger Clinic, 57, 287-308.

Andreasen, N.C. (1985). Pasttraumatic Stress Disorder. In: H.l. Kaplan \& B.J. Sadock (Eds.). Comprehensive Textbook of Psychiatry (Fourth Edition), (pp. 918-924). Baltimore: Williams \& Wilkins.

American Psychiatrici Association (1980). Diagnostic and Statistical Mamual of Mental Disorders, Third Edition. Washington: Author.

American Psychiatric Association 19871. Diagnostic and Statistical Manual of Mental Disorders, Third Edition-Revised. Washington: Author.

American Psychiatric Association (1994). Diagnostic and Statistical Manual of Mental Disorders, Fourth Edition. Washington: Author.

Antes, J.R.. \& Kristjanson, A.F. (1993). Effects of capacity demands on picture viewing. Perception and Psychophysics, 54. 808-813.

Anderson, K.J. (1990). Arousal and the inverted-U hypothesis: A critique of Neiss's "Reconceptualizing Arousal" Psychological Bulletin. 107, 96-100.

Archibald, H.C., \& Tuddenham, R.D. (1965). Persistent Stress Reaction after combat: A 20-year follow-up. Archives of General Psychiatry, 12,475-481.

Arntz, A., \& Lavy, E. (1993). Does stimulus elaboration potentiate exposure in vivo treatment?: Two forms of one-session treatment of spider phobia. Behawioural Psychotherapy, 2t, 1-12.

Başağlu, M., Paker, M., Paker, O., Özmen, E., Marks, I., lncesu, C., Sahin, D., \& Sarimurat (1994). Psychological effects of torture: A comparison of tortured with nontortured politicall activists in Turkey. American Journal of Psychiatry, 151, 76-81.

Bernstein, E., \& Putnam, F. (1986). Development, reliability, and validity of a dissociation scale. Journal of Nervous and Mental Disease $1744,727,735$.

Barnstein Carlson. E., \& Rosser-Hogan, R. (1993). Mental health status of Cambodian refugees ten vears after leaving their homes. American Journal of Orthopsychiatry, 63, 223-231.

Bernstein Carlson, E., \& Rosser-Hogan, R. (1994). Cross-cultural response to trauma: A study of traumatic experiences and Posttraumatic symptoms in Cambodian refugees. Journal of Traumatic Stress, 7. 43-58.

Bernstein Carlson, E., Putnam, F.W., Ross, C.A., Torem, M., Coons, P., Dill, D.L., Loewenstein, R.J., B Braun, B.G. (1993). Validity of the Dissociative Experiences Scale in screening for Multiple Personality Disorder: A multicenter study. American Joumal of Psychiatry, 150,1030 . 1036.

Blanchard, E.B., Hickling, E.J., Vollmer, A.J., Loos, W.R., Buckley, T.C., \& Jaccand, J. (1995). Shart-term follow-up of Post-Traumatic Stress Symptoms in motor vehicle accident victims. Behaviour Research and Therapy, 33, 369-377. 
Bjork, R.A. (1989). Retriewal inhibition as an adaptive mechanism in human memory. In: H.L. Roediger III and F. M.M. Craick (Eds.), Varieties of Memory and Consciousness: Essays in Honour of Endel Tulving lpp. 309.330). Hillsdale: Lawrence Erlbaum Associates.

Blaxton, T.A. (1989). Investigating dissociations among memory measures: Support for a TransferAppropriate Processing framework. Joumal of Experimental Psychology: Learning. Memory, and Cognition, 15, 657-668.

Bohannon, J.N. (1988). Flashbulb memories for the Space Shuttle disaster. Cognition, 29, 179 . 196.

Boon, S. Draijer, N. (1993). Multiple Persomality Disorder in the Netherlands: A clinical investigation of 71 cases. American Jaurnal of Psychiatry, 150, $489-494$.

Bornstein, R.F. (1993). Implicit perception, implicit memory and the recovery of unconscious material in psychotherapy. Journal of Nervous and Mental Disease, 181, 337-344.

Bower, G.H. (1990). Awareness, the unconsciousness, and repression: An experimental psychologist's perspective. In. J.L. Singer (Ed.), Repression and Dissociation: Implications for Personality, Theory, Psychopathology, and Health. Chicago: University of Chicago Press.

Bradley, M.M. (1994). Emotion and memory: A dimensional analysis. In: S.H.M. van Goozen, N.E. van de Poll, \& J.A. Sargeant (Eds.). Emotions: Essays on Emotion Theory (pp. 97-134). Hillsdale, NJ. Lawrence Erlbaum Associates.

Bradley, M.M., Greenwald, M.K., Petry, M.C., \& Lang, P.J. (1992). Remembering pictures: Pleasure and arousal in memory. Journal of Experimental Psychology: Leaining, Memory, and Cognition, $18,379-390$.

Braun, B.G. (1988). The BASK model of dissociation. Dissociation, 7, 4-23.

Brett, E.A., \& Ostroff, R. (1985). Imagery and Posttraumatic Stress Disorder: An overview. American Journal of Psychiatry, 142,417-424.

Brett, E.A., Spitzer, R.L., \& Williams, J.B.W. (1988). DSM-Ill-R criteria for Posttraumatic Stress Disorder. American Journal of Psychiatry, 145, 1232-1236.

Brewer, W.F. (1992). The theoretical and empirical status of the flashbulb memory hypothesis. In: E. Winograd \& U. Neisser (Eds.), Affect and Accuracy in Recall: Studies of "Flashbulb" Memories (pp. 274-305). Cambridge University Press.

Brewin, C.R., Dalgleish, T., \& Joseph, S. A dual representation theory of Posttraumatic Stress Disorder. Psychological Review, in press.

Briere, J., \& Conte, J. (1993). Self-reported amnesia for abuse in adults malested as children. Joumal of Traumatic Stress, 6, 21-31.

Brown, A., \& Kulik, J. (1977), Fleshbulb memories. Cognition, 5, 73-79.

Burke, A. Heuer, F., \& Reisberg, D. (1992). Remembering emotional events. Memory and Cognition, $20,277-290$.

Cahill, L. \& McGaugh, J.L. (1996). Modulation of memory storage. Current Opinion in Newrobiology, 6, 237-242.

Cahill, L.. Prins, B., Weber, M., \& McGaugh, J.L. (1994). B-Adrenergic activation and memory for emotional events. Nature, 371, 702-704.

Cardeña, E., \& Spiegel, D. (1993). Dissociative rections to the San Francisco Bay Area earthquake of 1989. American Joumal of Psychiatry, 150, 474-478.

Chueng. P. (1994). Posttraumatic Stress Disorder among Cambodian refugees in New Zealand. International Journal of Social Psychiatry, 40,17-26.

Christanson, S. A. (1984). The relationship between induced emotional arousal and amnesia. Scandinevian Journal of Psychology, 25, 147-160.

Cluristianson, S. $-\AA .(1986)$. Effects of positive emotional events on memory. Scandinavian Journal of Psychology, 27, 287-299.

Christianson, S. A. (1989). Flashbulb memories: Special, but not so speciall. Memory and Cognition, $17,435-443$. 
Christianson, S.-A. (1992). Emotional stress and eyewitness menory: A critical rewew. Psychological Bulletin, 112, 284-309.

Christianson, S. $\mathcal{A}$. \& Hübinette, B. $(1993)$. Hands up. A study of witnesises emotional reactions and memories associated with bank robberies. Applied Cognitive Psychology, $7,3651379$.

Christiansoin, S.-A., \& Loftus, E.F. (1987). Memory for traumatic events. Apphied Cognitive Psychalogy, 1, 225-239.

Christianson, S.A... \& Loftus, E.F. (1990). Some characteristics of people's traumatic memories. Bulletin of the Psychonomic Society. 28, 195-198.

Christianson, S.-A. \& Mjörndal, T. 11985). Adrenalin, emotional arousal and memory. Scandinavian Journal of Psychology, 26, 237 248 .

Christianson, S.-A. \& Loftus, E.F. (1991). Remembering emotional events: The fate of detailed information. Cognition and Emotion, 5, 81-108.

Christianson, S. $\AA$.., \& Nilsson, L.-G. (1984). Functional amnesia as induced by a psychological traurna. Memory and Cognition, 12, 142-155.

Christianson, S.-A., \& Nilsson, L.-G. (1989). Hysterical amnesia: A case of aversively motivated isolation of memory. In: T. Archer \& L. G. Nilsson (Eds.), Aversion. Avoidance and Anxiety: Perm spectives on Aversively Motivated Behavior (pp. 289-310). Hillsdale NJ: Eribaum.

Christianson, S.-A., Goodman, J., \& Loftus, E.F. (1992). Eyawitness memory for stressful events: Methadological quandaries and ethical dilemmas. In: S. $\mathbb{A}$. Christianson $($ Ed.). Handbook of Memory and Emotion: Theory, Research and Practice (pp. 217-241). Hillsdale: Erlbaum.

Christianson, S.-A., Loftus, E.F., Hoffman, H., \& Loftus, G.R. (1991). Eye fixations and memory for emotional events. Journal of Experimental Psychology: Learning. Memory and Cognition, 17. 693-701.

Christianson, S.-A., Nilsson, L.-G., Mjorndal, T., Perris, C., \& Tjellden, G. (1986). Psychologicall versus physiological determinants of emotional arousall and its relationship to laboratory induced amnesia. Scandinavian Journal of Psychology, 27, 300-310.

Classen, C., Koopman, C., \& Spiegel, D. (1993). Trauma and dissociation. Bulletin of the Menninger Clinic, 57, 178-194.

Cloitre, M., \& Liebowitz, M.R. (1991). Memory bias in Panic Disorder: An investigation of the cognitive avoidlance hypothesis. Cognitive Therapy and Research, 15, 371-386.

Cloitre, M., Cancienne, J., Brodsky, B., Dulit, R, \& Perry, S.W. (1996). Memary performance among women with parental abuse histories: Enhanced directed forgetting or directed remembering? Journal of Abnormal Psychology, 105, 204211.

Cohen, N.J., McCloskey, M., \& Wible, C.G. (1988). There is still no case for a flashbulb-mamory mechanism: Reply to Schmidt and Bohannon. doumal of Experimental Psychology: General, 117, 336.338.

Conway, M.A., Anderson, S.J., Larsen, S.F., Donnelly, C.M., McDaniel, M.A., McClelland, A.G.IA., Rawles, R.E., \& Logie, R.H. (1993). The formation of flashbulb memories. Mernory and Cognttion, $22,326-343$.

Craick, F.I.M., Govoni, R., Naveh-Benjamin, M. \& Anderson, N.D. (1996). The effects of dividied attention on emcoding and retrieval processes in human memory. Journal of Experimental Psycholagy: General, 125, 159-180.

Crombag, H.F.M., \& Merckelbach, H.L.G.J. (19961. Hervonden Herinneringen en andere Miswerstanden. Amsterdam / Antwerpen: Uitgeverij Contact.

Dallgliesh, T., \& Watts, F.N. (1990). Biases of attention and memory in disorders of anxiety and depression. Clinical Psychology Review, 10, 589-604.

Davidson, J.R.T., \& Foa, E.B. (1991). Diagnostic issues in Posturaumatic Stress Disorder: Considerations for the DSM-IV. Jaurnal of Abnormal Psychology, 100, 346 355.

Dawson, M.E., Schell, A.M. \& Filion, D.L. (1990). The electrodermal system. In: J.T. Cacioppo and L.G. Tassinary (Eds.I, Principles of Psychophysiology: Physical, Social, and Inferential Elements 
(pp. 295-324). Cambridge: Cambridge University Press.

Deffenbacher, K.A. (1983). The influence of arousal on reliability of testimony. lin: S.M.A. LioydBostock \& B.A. Clifford (Eds.), Evaluating Witness Evidence (pp. 235-251). Chichester: Witey.

Dettermah, D.K. (1975). The von Restorff effect and induced amnesia: Production by manipulation of sound intensity. Journal of Experimental Psychology: Human Learning and Memory, 1, 614628.

Derterman, D.K. (1976). The retrieval hypothesis as an explanation of induced retrograde amnesia. Quarterly Joumal of Experimental Psychology, 28, 623-632.

Detterman, D.K., \& Elis, N.R. (1972). Determinants of induced amnesia in short-term memory. Journal of Experimental Fisychologx, 95, 308-316.

Domb, Y., \& Beaman, K. (1991). Mr X-A case of amnesia. British Journal of Psychiatry, 158, 423425.

Easterbrook, J.A. (1959). The effect of emotion on cue utilization and the organization of behavior. Psychological Review, 66, 183-201.

Egeth (1994). Emotion and the eyewitness. In: P.M. Niedenthal \& S. Kitayama Eds.1. The Heart's Eve: Emotional Influences in Perception and Attention lpp. 245-267). San Diego: Academic Press.

Elliot, E.M., \& Briere, J. (1995). Posttraumatic stress associated with delayed recall of sexual abuse: A general population study. Journal of Traumatic Stress, $8,629-647$.

Ensink, B.J. (1992). Confusing Realities: A study on Child Sexual Abuse and Psychiatric Symptoms. Amsterdam: VU University Press.

Erdelyi, M.H. (1990). Repression, reconstruction, and defense: History and integration of the psychoanalytic and experimental frameworks. In: J.L. Singer (Ed.), Repression and Dissociation: Implications for Personality, Theory. Psychopathology, and Health. Chicago: University of Chicago Press.

Fabiani, M., \& Donchin, E. (1995). Encoding processes and memory organization: A model of the von restorff effect. Journal of Experimental Psychology: learning, Memory, and Cognition, 21. 224-240.

Feldman-Summers, S, \& Pope, K.S. (1994). The experience of "forgetting' childhood abuse: A national survey of psychologists. Journal of Consulting and Clinical PSychology, 62, 636-639.

Foa, E.B., \& Kozak, M.J. (1986). Emotional processing of fear; Exposure to corrective information. Psychological Bulletin, 99, 20-35.

Foa, E.B., Riggs, D.S. \& Gershuny, B.S. $(1995)$. Arousal, numbing and intrusion: Symptom structure of PTSD following assualt. American Jourmal of Psychiatry, 152, $116-120$.

Foa, E.B., Steketeo, G., \& Olasov Rothbaum, B. (1989). Behavioral/Cognitive conceptualizations of Post-Traumatic Stress Disorder. Behavior Therapy, 20, 155-176.

Foa, E.B., Zinbarg, R., \& Olasov Fothbaum, B. (1992). Uncontrollability and unpredictability in PostTraumatio Stress Disorder: An animal model. Psychological Bulletin, 112, 218-238.

Fowles, D. (1980). The thire arousal model: Implications of Gray's two-factor learning theory for heert rate, electrodermal activity, and psychopathy. Psychophysiology, 17, 87-104.

Frankel, F. (1990). Hypnotizability and dissociation. American Journal of Psyctiatry, 147, 823-829.

Freud, S. (1896/1952). Zur Atiologie der Hysterie. (Gesammelte Werke. Erster Band, Werke aus den Jahren 1892-1899\%. Frankfurt am Main: Fisher Verlag.

Fukunishi, I., Chishima, Y., \& Anze, M. (1994). Posttraumatic Stress Disorder and alexithymia in burn patients. Psychological Reports, 75, 1371-1376.

Garry, M., Loftus, E.F., \& Brown, S.B. (1994). Memory: A river runs through it. Conciousness and Cognition, 3, 438-451.

Geiselman, R.E., Bjork, R.A., \& Fishman, D.L. (1983). Disrupted retrieval in directed forgetting: A link with posthypnotic amnesia. Journal of Experimental Psychology: General, 112, 58-72.

Goodman, G.S., Hirschman, J.E., Hepps, D., \& Rudy, L. (1991). Children's memory for stressful 
events. Merrill-Palmer Quarterly, 37, 109-158.

Goodman, G.S. Quas, J.A., Batterman-Faunce, J.M., Fiddlesberger, M.M. \& Kuhn, J. (19941. Predictors of accurate and inaccurate memories of traumatic events experienced in childhood. Consciousness and Cognition, 3, 269-294.

Graf, P. (1994). Explicit and implicit memory: A decade of research. In: C. Umilta and $M$. Moscovitch (Eds.). Attention and Performance XV: Conscious and Nonconscious Information Processing (pp. 681-696). Cambridge, MA: The MIT Press.

Graf, P., \& Schacter, D.L. (1985). Implicit and explicit memory for new associations in nomal and amnesic subjects. Journal of Experimental Psychology: Learning. Memory, and Cognition. 11. 501.518 .

Green, B.L. (1993). Disasters and Posttraumatic Stress Disorder. In: J.R.T. Davidson, \& E.B. Foa (Eds.), Posttraumatic Stress Disorder: DSM-N and Beyond (pp. 75-97), Washington: APA.

Green, B.L., Lindy, J.D., \& Grace, M.C. (1985). Posttraumatic Stress Disorder: Towardis DSM-IV. Journal of Nervous and Mental Disease, 173, 406411.

Grinker, R.R., \& Spiegell, J.P. (1945). Men under Stress. Philadelphia: Blakiston

Hacking, I. (1995). Rewriting the Soul: Multiple Personality and the Sciencess of Memory. Princeton. NJ: Princeton University Press.

Hart, O. van der (1994). Totale amnesie voor traumatische herinneringen: Een reatctie op Merckelbach en Wessel. De Psycholoog. 29, 240-245.

Hart, O. van der, \& Horst, R. (1989). The dissociation theory of Pierre Janet. Journal of Traumatic Stress, 2, 397-412.

Haney, M.R., \& Herman, J.L. (1994). Amnesia, partial amnesia, and delayed recall among adult survivors of childhood trauma. Consciousness and Cognition, 3, 295-306.

Helsing. Professor van (1897/1992). Communication to Dr. Seward. In: B. Stoker (Ed.). Dracuka (p. 146). London: Penguin Books.

Herman, J.L. (1992). Trauma and Recovery. Basic Books.

Herman; J.L., \& Schatzow, E. (1987). Recovery and verification of memories of childhood sexual trauma. Psychoanalytic Psychology, 4, 1-14.

Heuer, $F_{n} \&$ Reisberg, D. (1990). Vivid memories of emotional events: The accuracy of remembered minutiae. Memory and Cagnition, 18, 496-506.

Heuer, F. \& Reisberg, D. (1992). Emotion, arousal, and memory for detail, In: S.-A. Christianson (Ed.), Handbook of Memory and Emotion. Theory, Research and Practice (pp. 151-180). Hillsdale: Erlbaum.

Holmes, D. (1990). The evidence for repression: An examination of sixty vears of research. In: JL. Singer (Ed.), Repression and Dissociation. Chicago: University of Chicago Press.

Hornstein, G.A. (1992). The return of the repressed: Psychology's problematic relations with psychoanalysis, 1909-1960. American Psychologist, 47, 254-263.

Horowitz, M.J. (1979). Psychologicall response to serious life events. In: V. Hamilton \& D.M. Warburton (Eds.). Human Stress and Cognition: An Information Processing Approach (pp. 235. 2631. Chichester: J. Wiley \& Sons.

Horowitz, M.J. (1986). Stress-response symdromes: A review of Posttraumatic and Adjustrnent Disorders. Hospital and Community Psychiatry, 37, 241-249.

Horowitz, M.J., Reidbord, S.P. (1992). Memory, emotion, and response to trauma. In: S. A. Christianson (Ed.), Handboak of Memory and Emotion: Theory, Research and Practice (pp. 343. 357). Hillsdale: Erlbaum.

Horowitz, M.J.. Wilner, N., \& Alvarez, W. 11979). Impact of Event Scale: A measure of subjective stress. Psychosomatic Medicine, 41, 209-218.

Horowitz, M.J., Wilner, N., Kaltreider, N., \& Alvarez, W. 11980). Signs and swmptoms of Posttraumatic Stress Disorder. Archives of General Psychiatry, 37, 85-92.

Howe, M.L., Courage, M.L., \& Peterson, C. (1994). How can I remember when "f" wasn"t there: 
Long-term retention of traumatic experiences and emergence of the cognitive self. Consciousiness and Cognition, $3,327 \times 355$.

Hunt, R. (1995). The subtlety of distinctiveness: What von Restorff really did. Psychonomic Bulletin and Review, 2, 105-112.

Isrälls, H. 11993). Het geval Freud: 1, Scheppingswerhalen. Amsterdam: Bert Bakkeir.

Johnsion, M.K. 119941. Processes of succesful intentional forgetting. Psychological Bulletion, 116, $274-292$.

Jong, P.J. de, Visser, S, \& Merckelbach, H. (1996). Startle and spider phobial Unilateral probes and the prediction of treatment effects. Journal of Psychophysiology, 10, 150-160.

Kanzer, M. (1939). Amnesia: A statistical study. Amenican Journal of Psychiatry, 96, 711-716.

Keane, T.M. (1993). Symptomatology of Vietnam Veterans with Posttraumatic Stress Disorder. In: In: J.R.T. Davidson, \& E.B. Foa (Eds.), Posttraumatic Stress Disorder: DSM-IV and Beyond (pp. 99-711). Washington: APA.

Kemp, A., Rawlings, E.I. \& Green, B.L. (1991). Post-Traumatic Stress Disorder (PTSD) in battered women: A shelter sample. Joumal of Traumatic Stress, 4, 137-148.

Kihistrom, J.F. (1994). Hypnosis, delayed recall, and the principles of memory. International vournal of Clinical and Experimental Hypnosis, 42, 337-345.

Kihlstrom, J.F., Glisky, M.L., \& Angiulo, M.J. (1994). Dissociative tendencies and Dissociative Disorders. Nournal of Abnormal Psychology, 103, 117-124.

Kinlstrom, J.F., Tataryn, D.J., \& Hoyt, I.P. (1993). Dissociative Disorders. In: P.B. Sutker \& H.E. Adams (Eds.), Comprehensive Handbook of Psychopathology (second edition), (pp. 203-234). New York: Plenum Press.

Kilpatrick, D.G., \& Resnick "H.S. (1993). Posttraumatic Stress Disorder associated with exposure to criminal victimization in clinical and community populations. In: J.R.T. Davidson, \& E.B. Foa (Eds.), Postraumatic Stress Disorder: DSM-IV and Beyond (pp. 113-143). Washington: APA.

Kim-Goh, M., Suh, C., Blake, D.D., \& Hiley-Young, B. (1995). Psychological impact of the Los Angeles riots an Korean-American victims: Implications for treatment. American Journal of Orthopsychiatry, 65, 138-146.

Klorman, R., Weerts, Th. C., Hastings, J.E., Malamed, B., \& Lang, P.J. (1974). Psychometric description of some specific fear questionnaires. Behavior Therapy, 5, 401-409.

Kolk, B.A. van der, \& Fisler, R. (1995). Dissociation and the fragmentary nature of traumatic memories: Overview and exploratory study. Journal of Traumatic Stress, 8, 505-525.

Kolk, B.A. van der, \& Hart, O. van der $(1989)$. Pierre Janet and the breakdown of adaptation in psychological trauma: American Journal of Psychiatry, $146,1530-1540$.

Kolk, B.A. van der, \& Kedish, W. (1987). Amnesia, Dissociation, and the return of the repressed. In: B.A. van der Kolk (Ed.). Psychological Trauma (pp. 173.190). Washington: American Psychiatric Press.

Kolk, B.A. van dèr, Brown, P., \& Hart, O. van der (1989). Pierre Janet on Post-Traumatic Stress. Journal of Traumatic Stress, 4, 365-378.

Koopman, C., Classen, C., Cardeña, E., \& Spiegel, D. 11995), When disaster strikes, Acute Stress Disorder may follow. Joumal of Traumatic Stress, 8, 29-46.

Kopelman, M.D. (1987). Amnesia: Organic and psychogenic. British Joumal of Psychiatry, 150, $428-442$.

Kopelman, M.D., Christensen, H., Puffett, A., \& Stanhope, N. (1994). The great escape: A neuropsychological study of Psychogenic Amnesia. Neuropsychologia, 32, 675-691.

Koss, M.P., Figueredo, A.J., Bell, 1., Tharan, M., \& Tromp, S. (1996). Traumatic memory characteristics: A cross-validated mediational model of response to rape among employed women. Journal of Abnormal Psychology, 105, 421-432.

Kramer, T.H., Buckhout, R., \& Eugenio, P. (1990). Weapon focus, arousal and eyewitness memory. Law and Human Behawiour, 14, 167-184. 
Kuch, K., \& Cox, B.J. (1992). Symptoms of PTSD in 124 survivors of the Holocaust. American Lournal of Psychiatry, 149, 337-340.

Lang, P.J. (1988). Fear, anxiety, and panic: Context, cognition and visceral arousal. In: $S$. Rachman, \& J.D. Maser (Eds.), Panic. Psychological Perspectives (pp. 219-236). Hillsdall: Lawrence Erlbaum Associates.

Lang, P.J., Greenwald, M.K., Bradley, M.M., \& Harnm, A.0. 119931. Looking at pictures: Aftective. facial, visceral and behavioral reactions. Psychophysiology, 30, 261-273.

Lavy, E. (1993). Attentional Bias and anxiety: Conceprual issues and empirical data. Maastricht: Datawyse.

Lavy, E., Hout, M.A. van den, \& Arntz, A. (1993). Attentional bias and spider phobia: Conceptual and clinical issues. Behaviour Research and Therapy, 31, 17.24.

LeDoux, J.E. (1992). Emotion as memory: Anatomical systems underlying indelible neural traces. In: S. A. Christianson (Ed.). Handbook of Memory and Emotion: Theory, Reserch and Practice (pp. 269-288). Hillsdale: Erlbaum.

Lindsay, D.S., \& Read, J.D. (1994). Psychotherapy and memories of childhood sexual abuse: A cognitive perspective. Applied Cognitive Psychology, $8,281-338$.

Loftus, E.F. (1993). The reality of repressed memories. American Psychologist, 48, 518-537.

Loftus, E.F., \& Burns, T.E. (1982). Mental shock can produce retrograde amnesia. Memory and Cognition, $10,318-323$.

Loftus, E.F., \& Kaufman, L. (1992). Why do traumatic experiences somatimes produce good memory (flashbulbs) and sometimes no memory (repression)? In: E. Winograd \& U. Neisser (Eds.). Affect and Accuracy in Recall: Studies of 'Flashbulb' Memories (pp. 212-223). Cambridge University Press.

Loftus, E.F., Garry, M. \& Feldman, J. (1994). Forgetting sexual trauma: What does it mean when $38 \%$ forget? Journal of Consulting and Clinical Psychology, 62, 1177-1181.

Loftus, E.F, Loftus, G.R., \& Messo, J. (1987). Some facts about "weapon focus". Law and Human Behavior, 11, 55-62.

Loftus, E.F., Polonsky, S., \& Fullilove, M. T. (1994). Memories of childhood sexual abuse: Remembering and repressing. Psychology of Women Quarterly, 18,67-84.

Loftus, G.R. (1972). Eye fixations and recognition memory for pictures. Cognitive Psychology, 3 , 525-551.

Loftus, G.R., \& Mackworth, N.H. (1978). Cognitive determinants of fixation location during picture viewing. Journal of Experimental Psychologv: Human Perception and Performance, 4. 565-572.

Mass, A., Kohnken, G. (1989). Eyewitness identification: Simulating the "weapon effect". Law and Human Behavior, 13, 397-408.

Madikasira, S. \& O'Brien, K.F. (1987). Acute Posttraumatic Stress Disorder in victims of a natural disaster. Journal of Nervous and Mentel Disease, 175, 286-290.

Matsumoto, R., Walker, B.B., Walker, J.M., Hughes, H.C. 11990). Fundamentals of neuroscience. In: J.T. Cacioppo and L.G. Tassinary (Eds.), Principles of Psychophysiology: Physical, Social, and Inferential Elements (pp. 58-112). Cambridge: Cambridge University Press.

McCloskey, M. (1992). Special versus ordinary memory mechanisms in the ganesis of flashbulb memories. In: E. Winograd \& U. Neisser (Eds.). Affect and Accuracy in Recall: Studies of 'Flashbulb' Mernories (pp. 227-235). Cambridge University Press.

McCloskey, M. Wible, C.G., \& Cohen, N.J. (1988). is there a special flashbulbumemory mechan. ism? Journal of Experimental PSychology: General, 117. 171 181.

MicGaugh, J.L. (1992). Affect, neuromodulatory systems, and memory storage. In: S.-A. Christianson (Ed.). Handbook of Memory and Emotion. Theory, Research and Practice (pp. 245268). Hillsdale: Erlbaum.

McNally, R.J., Metzger, L.J., Lasko, N.B., \& Pitman, R.K. Directed forgetting of trauma cues in women with histories of childhood sexual abuse. Manuscript submitted for publication. 
Merckelbach, H, \& van den Hout M.A, (1993). Trauma, herinnering en amnesie: Een notitie over de experimentele analyse wan psychogene aminesie. Gedragstherapie, $26,3-19$.

Moscovitch, M., Goshen Gottstein, Y., \& Vriezen, E. (1994). Memory without conscious recollecthon: A tutorial review from a neuropsychological perspective. In: $\mathrm{C}$. Umiltà and $M$. Moscovitch (Eds.). Attention and Performance XV: Conscious and Nonconscious Information Processing lpp. 619-660). Cambridge, MA. The MIT Press.

Myers, C.S. (1919). The study of shell shock: Being a consideration of unsettled points needing investigation, Lancet, January 11, p. 51-54.

Neiss, R. (1988). Reconceptualizing arousal: Psychobiological states in motor performance. Psychological Buhetin, $103,345-366$.

Neiss, R. (1990). Ending arousalls reign of error: A reply to Anderson. Psychological Bulletin, 107, 101.105.

Neiser, U. B Harsch, N. (1992). Phantom flashbulbs: Falsa recallections of hearing the news about Challenger. In: E. Winograd \& U. Neisser (Eds.l, Affect and Accuracy in Recall: Studies of 'Flashbulb' Memories (pp. 9-31). Cambridge University Press.

Nemiah, J.C. (1989). Dissociative Disorders (Hysterical Neuroses, Dissociative Type). In: H.ll. Kaplan \& B.J. Sadock (Eds:), Comprehensive Textbook of Psychiatry (Fifth Edition), (pp. 10281044). Baltimore: Williams \& Wilkins.

North, C.S., Smith, E.M., \& Spitznagel, E.L. (1994). Posttraumatic Stress Disorder in survivors of a mass shooting. American Journal of Psyctiatry, 157, 82-88.

ohman. A. 11994). The psychophysiology of emotion: Evolutionary and nonconscious origins. In: G. d'Ydewalle, P. Bertelso, \& P. Eelen (Eds.), Current Advances in Psychological Science: An International Perspective (pp. 197-227). Hove: Erlbaum.

Ost. L.G. 11989\%. One-session treatment for specific phobias. Behaviour Research and Therapy, 27, $1-7$.

Pillemer, D.B. (1984). Flashbulb memories of the assassination attempt on President Reagan. Cognition, $16,63-80$.

Pope, H.G., \& Hudson, J.l. (1995). Can memories of childhood sexual abuse be repressed? Psychological Medicine, 25, 121.126.

Putnam, F.W. (1989). Pierre Janet and modern views of dissociation. Journal of Traumatic Stress, 2, 413-429.

Reisberg, D., \& Heuer, F. (1992). Emotion's multiple effects on memory. In: J.L. McGaugh, N.M. Weinberger, \& G. Lynch (Eds.), Brain and Memory: Modulation and Mediation of Neuroplasticity (pp. 84-92\%. New York: Oxford University Press.

Roediger III, H.L. (1990). Implicit memory: Retention without remembering. American Psychologist. $45,1043-1056$.

Roediger III, H.L., Weldon, M.S., \& Challis, B.H. (1989). Explaining dissociations between implicit and explicit measusues of retention: A processing account. in: H.L. Roediger III and F.I.M. Craick (Eds.). Varieties of Memory and Consciousness: Essays in Honour of Endel Tulving (pp. 3-41). Hillsdale: Lawience Erbaum Associates.

Roszell, D.K. "McFall, M.E., Malas, K.L. (1991). Frequency of symptoms and concurrent psychiatric disorder in Vietnam weterans with chronic PTSD. Hospital and Community Psychiatry, $293-$ 296.

Rubin, D.C., \& Kozin, M. (1984). Vivid memories. Cognition, 16, 81.95.

Sargent, W. \& Slater, E. (1940). Acute war neuroses. Lancet, 2, 1-2.

Sargent, W., \& Slater, E. (1941). Amnesic syndromes in war. Proceedings of the Royal Society af Medicine, 34, 757-76.4.

Schacter. D.L. 11986). Amnesia and crime: How much do we really know? American Psychologist; 41. 286-295.

Schacter, D.L. (1992). Understanding implicit memory: A cognitive neuroscience approach. Ameri- 
can Psychologist, 47, 559-569.

Schacter, D.L. 11994). Priming and multiple memory systems: Perceptual mechanisms of implicit memory. In: D.L. Schacter \& E. Tulwing (Eds.). Memory Systems 1994 (pp. 233-268). Cambridge, MA: The MIT press.

Schacter, D.L. (1996). Searching for Memory: The brain, the mind, and the past. New York: Basic Books.

Schacter, D.L., Koutstaal, W.n \& Norman, K.A. (1996). Can cognitive neuroscience illuminate the nature of traumatic childhood memories? Current Ophion in Neurobiology, 6, 207-214.

Schacter, D.L., Wang. P.L., Tulving, E., \& Freedman, M. (1982). Functional retrograde amnesia: A quantitative case study. Neuropsychologia, 20,523-532.

Schmidt, S.R., \& Bohannon, A.N. (1988). In defense of the flashburb-memory hypothesis: A comment on McCloskey, Wible, and Cohen (1988). Journal of Experimental Psychology. General. 117, 332-335.

Schwartz, B., \& Reisberg. D. (1991). Learning and Memory. New York: Nortan and Company.

Sivec, H.d., \& Lynn, S.J. (1995). Dissociative and neuropsychological symproms: The question of differential diagnosis. Clinical Psychology Review, 15, 297-316.

Solomon, S.D., \& Canino, G.J. (1990). Appropriateness of DSM-III-R criteria for Posttraumatic Stress Disorder. Comprehensive Psychiatry, 31, 227-237.

Spiegel, D. (1994). Dissociative Disorders. In: R.E. Hales, S.C. Yuclofsky, \& J.A. Talbott (Eds.), The American Psychiatric Press Textbook of Psychiatry, second edition, (pp. 633-652). Washingtan: APA.

Spiegel, D., \& Cardeña, E., (1991). Disintegrated experience: The Dissociative Disorders revised. Journal of Abnormal Psychalogy, 100, 366-378.

Squire, L.R. (1994). Declarative and nondeclarative memory: Multiple brain systems supporting learning and memory. In: D.L. Schacter \& E. Tulving (Eds.), Memory Systems 1994 (pp. 203. 2311. Cambridge, MA: The MIT press.

Steblay, N.M. (1992): A meta-analytic review of the weapon focus effect. Law and Human Behavior, 16, 413-424.

Sutker, P.B., Uddo, M., Brailey, K., Vasterling, J.J., \& Errera, P. (1994). Psychopathology in war. zone deplayed and nondeployed Operation Desert Storm Troops assigned Graves Registration duties. Journal of Abnormal Psychology, 103, 383-390.

Teigen, K.H. (1994). Yerkes-Dodson: A law for all seasons. Theory and Psychology, 4, 525-547.

Terr, L.C. (1991). Childhood traumas: An outline and overview. Americam Joumal of Psychiatry, $148,10-20$.

Terr, L.C. (1994). Unchained Memaries: True stories of Traumaric Memories, Last and Found Now York: Basic Books.

Tulving. E. (1969). Retrograde amnesia in free recall. Science, 164, 88-90.

Wagenaar, W.A., \& Groeneweg, J. (1990). The memory of concentration camp survivors. Applied Cognitive Psychology, 4, 77-87.

Wallace, W.P. (1965). Review of the historical, empirical, and theoretical status of the Von Restorff phenomenon. Psychological Bulletin, 63, 410 424.

Watts, F.N., \& Covle, K. (1992). Recall bias for stimulus and response anxiety words in spider phobics. Anxiety Research, 4, 315-323.

Watts, F.N., \& Coyle, K. (1993). Phobics show poor recall of anxiety words. British Journal of Medical Psychology, 66, 373-382.

Watts, F.N., \& Dalgleish. T. [1991\%. Memary for phobia-related words in spider phobics. Cognition and Emotion, 5, 313-329.

Watts, F.N., Trezise, L., \& Sharrock, R. 119867. Processing of phobic stimuli. British dournal of Clinical Psychology, 25, 253-259.

Weaver, C.A. (1993). Do you need a "flash" to form a flashbulb memory? Journal of Experimental 
Psychology: General, 122, 39-46.

Wegner, D.M. Quillan, F. \& Houston, C. E. 11996). Memories out of order: Thought suppression and the disturbance of sequence memory. Joumal of Personality and Social Psychology, 71, 680691.

Wells, A, \& Matthews, G. (1994). Attention and Emotion: A Clinical perspective. Hove: Lawrence Erlbaum Associates.

Wessel, 1., \& Merckelbach, H. 11994\%. Characteristics of traumatic memories in normal subjects. Behavioural and Cognitive Psychotherapy, 22, 315-324.

Wessel, 1, \& Merckelbach, H. (1996). The impact of anxilety on memory for details in spider phobics. Applied Cognitive Psychology, in press.

Wessel, I., Rijsoort, M. van, Merckelbach, H., \& Arntz, A. (1995). Verklaringsmadellen voor Psychogene Amnesie bil Post-Traumatische Stress: Stoornis: Een illustratie aan de hand van een gevalsbeschrijving, Directieve Therapie, $15,52.66$.

Whitfield, C.L. (1995). The forgotten difference: Ordinary memory versus traumatic memory. Consciousness and Cognition, 4, 88-94.

Wilkinson, C.B. (1983). Aftermath of a disaster: The collapse of the Hyatt Regency hatel skywalks. American Joumal of Psychiatry, 140, 1134-1139.

Williems, J.M.G., Mathews, A., \& Macleod, C. (1996). The emotional Stroop task and psychopathology. Psychological Bulletin, 120,3-24.

Williams, J.M.G., Watts, F.N., MacLeod, C., \& Mathews, A. 11988). Cognitive Psychology and Emotional Disorders. Chichester: Willey.

Williams, L.M. [1994a]. What does it mean to forget Child Sexual Abuse?: A reply to Loftus, Garry, and Feldman (1994). Joumal of Consulting and Clinical Psychology, 62, 1182-1186.

Willams, L.M. (1994b) Recall of childhood trauma: A prospective study of women's memories of Child Sexual Abuse. Journal of Consulting and Clinical Psychologv, 62, 1167-1176.

Wilson, J.P. (1995). The historical evolution of PTSD diagnostic criteria. In: G.S. Everly, Jr., \& J.M. Lating (Eds.), Psychotraumatology: Key Papers and Core Concepts in Post-Traumatic Stress, (pp. 9-26). New York: Plenum Press

Winograd, E., \& Killinger, W.A. (1983). Relating age at encoding in early childhood to adult recall: Development of flashbulb memories. Jounnal of Experimental Psychology General, 112, 413-422.

Wright, D.B. (1993). Recall of the Hillsborough disaster of time: Systematic biases af "flashbulb" memories. Applied Cognitive Psychalogy, 7, 129-138.

Yapleo, M.D. (1994). Suggestions of Abuse: True and False Memories of Childhood Sexual Trauma. Now York: Simon \& Schuster.

Yuille, J.C., \& Cutshall, J.L. 11986). A case study of eyewitness memory of a crime. Jaurnal of Applied Psychology, 2, 291-301.

Yuille, J.C., \& Tollestrup, P.A. 11992). A model of the diverse effects of emation on evewitness memory. In: S. A. Christianson (Ed.), Handbook of Memory and Emotion: Theory, Research and Pracrice (pp, 201-215). Hillsdale: Erlbaum.

Zuuren, $\mathbb{F}$. van $(1987)$. Personality differences within a diagnostic entity: Types of phobia in men and women. Personailty and Individual Differences, 8, 101-111. 


\section{Samenvatting}

Het meemaken van een traumatische gebeurtenis kan een Postraumatische Stress Stoornis (PTSS) tot gevolg hebben. Mensen die aan deze stoornis lijden worden frequent geplaagd door ongewenste gedachten aan en herbelevingen van hun trauma. Tegelijkertijd kan het zo zijn dat PTSS patiënten zich belangrijke delen van hun trauma niet weten te herinneren. Dit symptoom staat bekend als psychogene amnesie. In dit proefschrift staat de vraag centraal hoe dit fenomeen verklaard kan worden.

In hoofdstuk 1 wordt psychogene amnesie nader beschouwd. Kenmerkend voor het symptoom is dat het niet terug te voeren is op organische oorzaken (bijvoorbeeld hersenbeschadiging of alcoholmisbruik) of op normale vergeetachtigheid. Psychogene amnesie kan verschillende vormen aannemen. Zo is geheugenverlies voor alle gebeurtenissen uit het verleden de meest extreme vorm. Om het vergeten van delen van een traumatische gebeurtenis te onderscheiden van andere vormen van psychogene amnesie, wordit in dit proefschrift van partiëlie amnesie gesproken. De prevalentie en aard van partiële amnesie blijkem niet goed onderzocht. Bovendien is het symptoom moeilijk te meten door vage begrippen als belangrijke delen en abnormale vergeetachtigheid. In klinische literatuur wordt echter aangenomen dat (partiële) amnesie voor een trauma vaak voorkont en wordt een aantal verklaringen voor het fenomeen beschreven. Volgens deze verklaringen wordt ammesie bewerkstelligd door psychologische afweermechanismen als verdringing en dissociatie, die (delen van) traumatische herinneringen in een onbewuste vorm in het geheuglen zouden opslaan. Verdringing en dissociatie zijn echter problematische begrippen. Ze zijn silecht gedefinieerd, hebben een geringe verklarende waarde en zijn niet recht streeks te meten.

In hoofdstuk 2 wordt een averzicht gegeven van de literatuur met betrekking tot emotie en geheugen vanuit de niet-klinische hoek. Op het eerste gezicht is deze literatuur tegen. strijdig: er zijn aanwijzingen dat emotie, en in het bijzonder de fysiologische component van emotie (arousal), het geheugen zowel kan verbeteren als verslechteren. In tegenstelling tot de Yerkes-Dodson wet, biedt de zogenaamde aandachtsvernauwingshypothese aanknopingspunten voor een verklaring van deze tegenstrijdige bevindingen. Volgens deze hypothese zorgt de autonome arousal die onderdeel is van een emotionele reactie voor een vernauwing van de aandacht. De aandacht zou met name gericht worden op die informatie relevant is voor de emotionele gebeurtenis (centrale details), hetgeen ten koste gaat van de aandacht voor irrelevante informatie (perifere details). Bijgevolg zou het geheugen voor centrale informatie relatief goed zijn, en het geheugen voor perifere informatie relatief slecht. Deze aandachtsvernauwingshypothese zou een spaarzamere en beter to toetsen verklaring kunnen bieden woor geheugenfenomenen bij PTSS-patięnten dan verdririging en dissociatie. In hoofdstuk 3 wordt een aantal specifieke vragen en aandachtspunten 
besehreven die van belang zijn voor het toetsen van dit aandachtsvernauwingsmodel.

Hoofdstuk 4 beschrijtt een vijftal studies waarin de aandachtsvernauwingshypothese werd getoetst. In paragraaf 4.1 wordt een experiment beschreven waarin studenten dia's met een emotionele, een opvallende of een neutrale inhoud bekeken, terwijl hun huidgeleidingsreakties lals index voor autonome arousal) en oogbewegingen werden gemeten. De emotionele dia lokte een hogere arousal uit dan de opvallende en de neutrale dia. Vergeleken met de neutrale dia was het patroon van de oogbewegingen bij de emotionele dia in overeenstemming met het aandachtsvernauwingsmodel. Wat de oogbewegingen betreft was er echter geen verschil tussen de emotionele en de opvallende groep. Met betrekking tot het geheugen voor de centrale en perifere informatie in de dia"s verschilden de drie groepen nauwelijks van elkaar. Om de reden te achterhalen voor het uitblijven van geheugeneffekten in dit experiment, werden twee vervolgexperimenten uitgevoerd. Deze staan beschreven in paragraaf 4.2 . In het eerste experiment werd de methode van Christianson en Loftus (1991) op de voet gevolgd. De resultaten lieten zien dat de centrale informatie van de emotionele dia beter werd onthouden dan die van de opvallende en de neutrale dia. Er werd verondersteld dat het verschil in effekten op het geheugen tussen dit experiment en het eerdere experiment (4.1) zou kunnen liggen aan een verschil in aanbiedingstijden van de dia's. Daarom werden in een tweede experiment de aanbiedingstijden systematisch gevarieerd. Tegen de verwachting in hadden aanbiedingstijden weinig effekt. Geconcludeerd werd dat een verschil in instruktie verantwoordelijk was voor de tegenstrijdige resultaten.

In de experimenten beschreven in paragraaf 4.3 en 4.4 werd het geheugen van spinfobici en niet bange proefpersonen voor dreigende en niet dreigende informatie onderzocht. De resultaten van deze experimenten lieten zien dat spinfobici een beter geheugen hadden vooir spin-gerelateerde informatie $(4.4)$ en een slechter geheugen hadden voor nietbedreigende informatie $(4.3$ en 4.4$)$.

Paragraaf 4.5 tenslotte beschrijft een studie waarin studenten naar de karakteristieken van hun meest traumatische ervaring werd gevraagd. Studenten die relatief veel emotie hadden ervaren tijdens deze gebeurtenis rapporteerden meer centrale aspecten te hebben onthouden dan studenten die relatief weinig emotie hadden gevoeld.

Hoofdstuk 5 geeft een overzicht van de resultaten van de vilif studies. Geconcludeerd wordt dat de spinnenfobie methode het meest geschikt lijkt als model voor traumatisch geheugen om de volgende redemen. De resultaten van veldstudies kunnen vanwege hun retrospectieve karakter ten proai vallen aan vertekeningen. Experimenten waarin studenten naar dia"s kijken omzeilen dergelijke vertekeningen, maar de resultaten zijn moeilijk te generaliseren naar levensechte emotionele situaties. Pogingen om studenten door middel van een instruktie meer betrokken te maken bij het aangeboden materiaal 14.1 en 4.2 , experiment 2) lijken geen aangewezen methode omdat de aandachtsvernauwingseffekten op het geheugen door een dergelijke instruktie worden overschaduwd. Het blootstellen van fobici aan hun gevreesde object brengt zowel betrokkenheid als en relatief hoog nivo van emotionaliteit teweeg. Tevens bespreekt hoofdstuk 5 een aantal implicaties voor het toetsen van het aandachtsvernauwingsmodel. Ten eerste, omdat de samenhang tussen angstmaten en geheugen niet eenduidig werd gevonden, wordt gepleit voor het in kaart brengen van de specifieke fysiologische processen die het geheugen voor emotioneel materiaal moduleren. Naast fysiologische responsen zouden tevens de cognitieve en gedragsmatige componenten van emotie in ogenschouw moeten worden genomen. Een 
tweede implicatie is dat geheugenprestaties moeten worden bezien als een samenspel van de pracessen die een rol spelen bij het encoderen van emotioneel materiaal en de processen die plaatsvinden bij het ophalen van de herinneringen aan dat materiaal. Als laatste wordt in hoofdstuk 5 ingegaan op de validiteit van de spinnenfobie methode als model voor traumatisch geheugen. De netwerk theorie van angststoornissen verondersteld dat spinfobici uitgebreide kennis over spinnen in hun geheugen hebben. Een altematieve verklaring voor de bevindingen in de spinnenfobie studie in paragraaf 4.4 zou dus kunnen zijn dat spinfabici bedreigende informatie beter onthouden omdat ze deze informatie kunnen relateren aan deze al bestaande kennis. Toekomstig onderzoek zou deze alternatieve verklaring moeten uitsluiten.

In hoofdstuk 6 wordt besproken in hoeverre aandachtsvernauwing het symptoom van partiële amnesie bij de PTSS zou kunnen verklaren. In principe sluit de aandachtsvernauwingshypothese aan bij de klinische observatie dat sommige aspecten van een trauma goed en andere aspecten slecht worden onthouden. Een belangrijk verschil tussen deze hypothese en de definitie van partiële amnesie ligt echter in het type informatie dat slecht onthouden zou worden. Volgens de aandachtsvernauwingshypothese zou het gaan om niet-bedreigende, onbelangrijke informatie. Volgens de definitie van partiële amnesie zou juist bedreigende, belangrijke informatie vergeten worden. Het is echter prematuur om te concluderen dat aandachtsvernauwing geen adequate verklaring kan bieden voor partiële amnesie. Of partiële amnesie inderdaad alleem betrekking heeft op belangrijke aspecten dient nog onderzocht te worden. Bovendien zijn begrippen als "onbelangrijk" en "perifeer" subjektief: ze hangen af van de interpretatie van degene die de traumatische gebeurtenis meemaakt. Daarom wordt gepleit om de betekenis die aan aspecten van een situatie wordt gegeven te betrekken in een model voor partiële amnesie. Volgens dit model wordt aandachtsvernauwing gemedieerd door pogingen om informatie die strijdig is met bestaande kennis over de wereld te begrijpen (elaboratief encoderen). Omdat elaboratief encoderen een beroep doet op de informatieverwerkingscapaciteit zullen sommige aspecten van de situatie slechts oppervlakkig worden verwerkt: de geheugenrepresentatie zal dan met name de perceptuele kenmerken van die aspecten bevatten. Geheugenprestatie wordt beschouwd als een interactie tussen encodering en de processen die een rol spelen bij het ophalen van de opgeslagen informatie. Her strategische zoekproces zal met name resulteren in het ophalen van informatie die op een conceptueel nivo is opgeslagen; het associatieve ophaalproces verhoogt de kans dat informatie die op een perceptueel nivo is opgeslagen wordt herinnerd. Het zal duidelijk zijn dat informatie waaraan helemaal geen aandacht is besteed, niet is opgeslagen en derhalve niet opgehaald kan worden. Volgens dit model zall partiele amnesie mat name worden geobserveerd als het strategisch zoekproces geaktiveerd is (bijvoorbeeld het beantwoorden van de vraag "wat heeft $u$ meegemaakt?" $)$. Bewuste pogingen om strategische ophalproces te onderdrukken kunnen tevens bijdragen aan het minder toegankelijk worden van de traumatische herinnering. 


\section{Dankwoord}

Harald Merckelbach, promotor. Ik vraag me af of er begeleider's zijn die zich nóg bereikbaarder opstellen dan jij. Je maakte zondermeer tijd voor mijn vragen en twijfels: mijn stukjes kwamen altijd per ommegaande en voorzien van grondig commentaar retour. Hooggeleerde en -gewaerdeerde Haraid, ik heb veel van je geleerd en ik verheug me op onze verdere samenwerking.

Marcel van den Hout, promotor. Al als student merkte ik hoe aanstekelijk je enthousiasme voor creatief en enigszins wild anderzoek was. Ik zall dat sprookjesbos-experiment dan ook niet snel vergeten. Als voorzitter van de vakgroep DEP was je een inspirerend gastheer.

Hermien Elgersma en Mirjam van Rijsoort, (Para/Nymfen. Dank voor jullie warme vriendschap en niet aflatende steun tijdens de pieken en dalen van het AlO-schap. Ik vind het heel bijzonder dat jullie straks samen met mij op dat podium willen staan om de promotie tot een goed einde te brengen.

Alle collega's van de vakgroep DEP en het instituut EPP wil ik bedanken voor het verschaffen van een stimulerend onderzoeksklimaat. Naar een aantal van jullie gaat mijn bijzondere dank uit. Peter de Jong; ik kijk met plezier terug op al ons ge-brainstorm over onderzoek. Bovendien leerde je me fietsen tijclens dat congres op Corfu: veel dank. Birgit Mayer; je was een geweldig kamergenoat. Dat je je buro zo bereidwillig afstond gaf me zeker de gelegenheid om rustig te schrijven, maar het was wél een stuk minder gezellig. Erik Schouten; dank je voor alle tijd die je vrijmaakte om te fungeren als mijn statistisch super-ego. Arnoud Arntz; je gastvrijheid maakte mijn eerste spinnen-experiment mogelijk. Annie Raven; je organisatie van de spinnenprojekten was voortreffelijk. Dank ook voor het scoren van mijn data. Alle mede-AIO's - FRaAl OnderzoekerS - bedankt voor avondlange gesprekken over het AlO-bestaan.

Scriptie-schrijvende en/of onderzoeks-assisterende GGKers: Petra van der Kooy, MarioLouise van Nieuwenhoven, Stella van Rijsoort, bedankt voor jullie inzet. Het samen denken over en uitvoeren van onderzoek heeft mij veel pret bezorgd.

Marja Hortulanus, bedankt voor het verzorgen van de adminstratieve rompslomp rond mijn promotie. Bovendien zorgden jij en Joost ervoor dat de omslag van mijn proefschrift zo mooi geworden is: veel dank voor julie inspanningen. Ger van Wunnik, dank voor het helpen scoren van videobanden vol oogbewegingen; Jos Adam en Fred Paas, bedankt voor jullie hulp bij het hanteren van de NAC-oogbril.

Als laatste wil ik de mensen bedanken die me vanaf de zijlijn hebben aangemoedigd bij deze race naar de eindstreep. Pa en ma, jullie hebben mij de kans gegeven om te studeren en me gesteund in alles wat ik bereiken wilde. Peter-Paul Mersch, jij was de allereerste die mij liet ervaren dat onderzoek doen verschrikkelijk leuk is. Erik, jij stond altijd onvoorwaardelijk en vierkant achter me. Dank je wel, voor alles. 


\section{Publications}

Cox, B.J., Wessel, I., Swinson, R.P., \& Norton, G.R. (1994). Citation patterns in anxiety disordlers research in 14 journals: 1990-1991. American Journal of Psychiatry, 151, 933-936.

Cox, B.J., Wessel, I., Norton, G.R., Swinson, R.P., \& Direnfeld, D.M. (1995). Publication trends in anxiety disarders research: 1990-1992. Journal of Anxiety Disorders, 9, 531.538.

Hout, W. van, \& Wessel, I. (1990), Faalangst. Bespreking van: Advances in Test Anxiety Research (R. Schwarzer, H.M. van der Ploeg \& C.D. Spielberger, Edls.). De Psycholoog, 25, 551-552.

Jansen, A. \& Wessel, I. (1994). Bespreking van: Dissociative experiences, trauma and hypnosis: Research findings and clinical applications in eating disorders (J. Vanderlinden). Maariblad Geestelijke Volksgezondheid, 49, 896-898.

Merckelbach, H. \& Wessel, 1. (1994). Recovered Memories. De Psycholoog, 29, 85-90.

Merckelbach, H. \& Wessel, 1. (1994). Ontdekt of uitgevonden? Seksueel misbruik en herinnering dankzij therapie. Skepter, $7(1), 16-21$.

Merckelbach, H. \& Wessel, I. (1994). Rituelen: Goed en slecht onderzoek naar satanisch misbruik. Skepter, 7/3), 23-26.

Merckelbach. H. \& Wessel, 1. (1995). Hoe authentiek zi]n "Recovered Memories" ? Direk tieve Therapie, 15, 148-166.

Mersch, P.P., Hildebrand, M., Hout, W.J.P.J. van, Lavy, E.H., Wessel, 1. (1992). Somatic symptoms in social phobia: A treatment method based on Rational Emotive Therapy and paradoxical interventions. Journal of Behaviour Therapy and Experimental Psychiatry, 23, 199-211.

Wessel. 1. (1995). Dissociatie, trauma en geheugen. Bespreking van: Fifth Annual Canference of the International Society for the Study of Dissociation. De Psycholoog, 30, 338-339.

Wessel, 1., \& Dreessen, L. 11995). Over onmacht en machtsherstel. Bespreking van: Traume en herstel: De gevalgen van geweld -van mishandeling thuis tot politiek geweld. (J.L. Herman). De Psychaloog. 30, 34-35.

Wessel. 1., \& Merckelbach, H. (1994). Onderzoek in Oude Pekala (2). Maandblad Geestelijke Volksgezondheid, 49, 554-556.

Wessel, I. \& Merckelbach, H. (1994). Characteristics of traumatic memories in normal subjects. Behavioural and Cognitive Psychotherapy, 22, 315-324.

Wessel, 1. \& Merckelbach, H. (1995). Over totale amnesie en pseudoherinneringen: Antwoord aan Ensink en Van der Hart. De Psycholoog, 30, 102-105.

Wessell, 1., \& Merckelbach, H. (1995). De zoektocht naar verborgen trauma's. Biespreking van: Unchained memories: True stories of traumetic memories, lost and found (L. Terr) en Suggestions of abuse: True and false memories of childhood sexual trauma (M.D. Yapko). Amsterdernse Boekengids, $7,10-15$.

Wessell, I., \& Merckelbach, H. (in press). The impact of anxiety on memory for details in spider phobics. Applied Cognitive Psycholagy.

Wessel, 1., \& Merckelbach, H. (in press). Memory for threat-relevant and threat-irrelevant cues in spider phobics. Cognition and Emation. 
Nessel, I., Mersch, P.P.A. (1994). A cognitive-behavioural group treatment for test-anxious adolescents. Anxiety, Stress, and Coping, 7, 149-160.

Wessel, 1., Hildebrand, M. Mersch, P.P. 11991). Sociale fobie: Een speurtocht naar de beste behandeling. De Psycholioog, 26, 385-390.

Wessel, I., Kooy, P. van der, Merckelbach (submitted). Arousal, attention and memory: Circumstantial evidence for the attentional narrowing hypothesis.

Wossel, I., Rijsoort, M. van, Merckelbach, H., \& Arntz, A. (1994). Verklaringsmodellen voor psychogene amnesie bij Post Traumatische Stress Stoornis: Een illustratie aan de hand van een gevalsbeschrijuing. Direktieve Therapie, $15,52-66$. 


\section{Curriculum Vitae}

Ineke Wessel werd op 4 september 1964 in Amsterdam geboren. Na het behalen van het diploma VWO in 1982 startte zij met de opleiding tot verpleegkundige $A$ in Rotterdam. In 1986 rondde zij deze opleiding af en begon met de studie Gezondheidwetenschappen in Maastricht. In september 1992 behaalde zij het doctoraal diploma met als afstudeerrichting Geestelijke Gezondheidkunde. Un februari 1993 werd zij als Assistent in Opleiding aangesteld bij de vakgroep Differentiële en Experimentele Psychologie van de Universiteit Maastricht. Vanaf maart 1997 is zij als wetenschappelijk projektmedewerker (Postdoc) in dienst van de Nederlandse Organisatie voor Wetenschappelijk Onderzoek (NWO). In deze hoedanigheid is zij werkzaam bij de Commissie Psychologie van de Universiteit Maastricht en doet onderzoek. naar trauma en autobiografisch geheugen. 